The Wisdom of Balance:

Revealing Taoist Principles through Architecture

$b y$

Mandy Man Yi Tsang, B.A.S.

A thesis submitted to

The Faculty of Graduate Studies and Research

In partial fulfillment for the degree of

\title{
Master of Architecture
}

\author{
School of Architecture, Carleton University \\ Ottawa, Ontario \\ May, 2006 \\ (C) Copyright \\ 2006, Mandy ManYi Tsang
}




$\begin{array}{ll}\begin{array}{l}\text { Library and } \\ \text { Archives Canada }\end{array} & \begin{array}{l}\text { Bibliothèque et } \\ \text { Archives Canada }\end{array} \\ \begin{array}{l}\text { Published Heritage } \\ \text { Branch }\end{array} & \begin{array}{l}\text { Direction du } \\ \text { Patrimoine de l'édition }\end{array} \\ \begin{array}{l}\text { 395 Wellington Street } \\ \text { Ottawa ON K1A 0N4 } \\ \text { Canada }\end{array} & \begin{array}{l}\text { 395, rue Wellington } \\ \text { Ottawa ON K1A ON4 } \\ \text { Canada }\end{array}\end{array}$

Your file Votre référence ISBN: 978-0-494-16477-8 Our file Notre référence ISBN: 978-0-494-16477-8

NOTICE:

The author has granted a nonexclusive license allowing Library and Archives Canada to reproduce, publish, archive, preserve, conserve, communicate to the public by telecommunication or on the Internet, loan, distribute and sell theses worldwide, for commercial or noncommercial purposes, in microform, paper, electronic and/or any other formats.

The author retains copyright ownership and moral rights in this thesis. Neither the thesis nor substantial extracts from it may be printed or otherwise reproduced without the author's permission.
AVIS:

L'auteur a accordé une licence non exclusive permettant à la Bibliothèque et Archives Canada de reproduire, publier, archiver, sauvegarder, conserver, transmettre au public par télécommunication ou par l'Internet, prêter, distribuer et vendre des thèses partout dans le monde, à des fins commerciales ou autres, sur support microforme, papier, électronique et/ou autres formats.

L'auteur conserve la propriété du droit d'auteur et des droits moraux qui protège cette thèse. $\mathrm{Ni}$ la thèse ni des extraits substantiels de celle-ci ne doivent être imprimés ou autrement reproduits sans son autorisation.
In compliance with the Canadian

Privacy Act some supporting forms may have been removed from this thesis.

While these forms may be included in the document page count, their removal does not represent any loss of content from the thesis.
Conformément à la loi canadienne sur la protection de la vie privée, quelques formulaires secondaires ont été enlevés de cette thèse.

Bien que ces formulaires aient inclus dans la pagination, il n'y aura aucun contenu manquant.

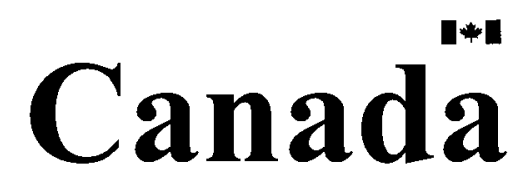




\section{Acknowledgements}

I would like to thank my thesis advisor, Professor Manuel Baez for his guidance and support in many ways throughout the process of this research.

I would also like to thank Professor Thomas Mical and Greg Andonian, for their valuable commands and criticism as well. Special thanks to my editor Jeffrey Malecki and my student colleagues, Tam Tran, Rick Hippolite and Janouque LeRiche. Lastly, I should thank my parents, for their understanding, care and loving support in all times. 


\section{Abstract}

This thesis proposes that the incorporation of Taoist wisdom into architectural design is a way to illuminate and clarify the essence of dwelling by emphasizing the balance between experiential satisfaction and physical integrity. It proposes that Taoist philosophy has a unique ability to reveal the intangible elements of architecture that involve both artistic, intuitive expression and technical discipline.

The first part of the thesis covers the origins of Taoism and its relevance to architecture, and it establishes a theoretical basis regarding the dualistic and balance nature of architectural activity (i.e. mass versus void in space and perception versus conception in our temporal experience). The subsequent sections will explore the philosophy of Taoism as it relates to light and the expressive creation of inspirational space. 


\section{Table of Contents}

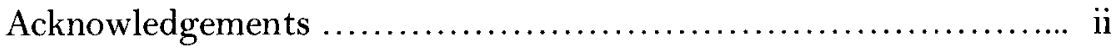

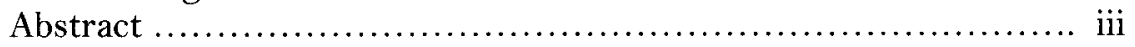

Table of Contents ............................................ iv

List of Illustrations ..............................................

Chapter One: Introduction .................................... 1

Chapter Two: Taoism and Architecture

2.1: The origin of Taoism ....................................... 5

2.2: The practice of 'Tao as the art of living ........................ 8

2.3: The interpretation of Taoism in architectural practice .......... 9

Chapter Three: The Tao of Dwelling

3.1: Heidegger and Lao-tzu ...................................... 32

3.2: What is it to Dwell? ........................................ 9

3.3: What is it to Build? ......................................... 38

3.4: Essence of Dwelling: Learning and Follow the Natural Unity ... 44

Chapter Four: Light and the Essence of Taoism ................ 46

4.1: Vastness ..................................................... 48

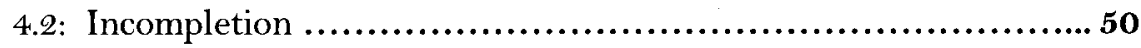

4.3: Formlessness ..................................................53

4.4: Oppositional Balance ......................................... 55

4.5: Boundary-less ............................................. 59

4.6: Scarcity .................................................. 64

4.7: Case Study: The Silent Light, Louis Kahn......................65

Chapter Five: The Design Proposal

5.1 Concept of the design proposal................................. 72

5.2 Site Selection: Porter Island, Ottawa......................... 72

5.3 Program Selection: The combination of Retirement .............75 Home and Daycare Center

5.4 Site Investigation: the six concepts as the exploratory tool in seeking the essence of the place $\ldots . \ldots \ldots \ldots \ldots \ldots \ldots \ldots \ldots \ldots \ldots \ldots \ldots . .16$

5.5 Design Issue: Various Perceptions of the Elderly and the Children ...................................................... 87

5.6 The Spatial Setting ....................................... 88

5.7 The Retirement Home: The Reconstruction of the Façade of the Existing Building ........................................96

5.8 The Daycare Center ........................................... 104

5.9 The New Extension Building: Indoor Garden, Library, Mediation space, new units ....................................... 108

5.10 Landscape Planning: Reflecting Pool ...................... 114

Conclusion ..................................................... 117

Appendix A: The Existing Building Floor Plan .................. 122

Works Cited ................................................... 123 


\title{
List of Illustrations
}

\author{
Chapter Two: Taoism and Architecture \\ Figure 1 Symbol of Yin Yang. Unkown. Book of Change. \\ 2 Church of the Light. Tadao Ando. Tadao Ando: Complete Works. 1989. \\ 3 The Annex of Naoshima Contemporary Art Museum. Tadao Ando. \\ Tadao Ando: Complete Works. 1995. \\ 4 Salk Institute. Louis Kahn. Louis I. Kahn : Light and Space 1965. \\ $5 \quad$ Salk Institute. Louis Kahn. Louis I. Kahn : Light and Space 1965. \\ 6 Falling Water. Frank Lloyd Wright. Eallingwater, A Frank Lloyd Wright Country \\ House, 1939. \\ 7 Naoshima Contemporary Art Museum. Tadao Ando. Tadao Ando: Complete Works. \\ 1992. \\ 8 Sunken garden at Chase Manhattan Plaza. Isamu Noguchi. Isamu Noguchi: Master \\ Sculptor. 1964. \\ 9 Entertainment Palace in Forbidden City. Unknown. Palace Architecture:Ancient \\ Chinese Architecture 1420. \\ 10 Falling Water: material detail. Frank Lloyd Wright. Fallingwater, A Frank Lloyd \\ Wright Country House. 1939. \\ 11 Chinese residential garden. Unknown. The Garden as Architecture: Form and Spirit in \\ the Gardens of Japan, China, and Korea. Qing dynasty. \\ 12 Church on the Water. Tadao Ando. Tadao Ando: Complete Works. 1988. \\ 13 Church of the Light. Tadao Ando. Tadao Ando: Complete Works. 1989. \\ 14. Chinese Pavilion. Unknown. The Garden as Architecture: Form and Spirit in the \\ Gardens of Japan. China, and Korea. Yuan dynasty.
}

\section{Chapter Four: Light and the Essence of Taoism}

15 Window in Rome. Unknown. Light Revealing Architecture. Unknown.

16 Koshino House. Tadao Ando. Tadae Ando: Complete Works. 1981.

17 Museum of Literature. Tadao Ando. Tadao Ando: Complete Works. 1991.

18 Seinajoki Library. Alvar Aalto. Nature and Space:Aalto and Le Corbusier. 1965

19 Church of the Light. Tadao Ando. Tadao Ando: Complete Works. 1989.

20 Chapel of Notre Dame-du-Haut. Le Corbusier. Nature and Space: Aalto and Le

Corbusier. 1955.

The Galli Tomb. Carlo Scarpa. Carlo Scarpa: The Complete Works. 1978.

Finca Guell, interior \& sectional drawing showing the structural system. Antonio Gaudi. Light Revealing Architecture. 1887.

Notre Dame du Haut. Le Corbusier. Nature and Space: Aalto and Le Corbusier. 1955. Afrum 1967, Installation Whitney Museum of American Art/

Raemar, 1969, Installation Whitney Museum of American Art. James Turrell. James Turrell: First Light, Church on the Water. Tadao Ando. Tadao Ando: Complete Works, 1988.

Fabrica (Benetton Communication Research Center). Tadao Ando. Tadao Ando: Complete Works. 1996.

Komyo Temple. Tadao Ando. Tadao Ando: Complete Works. 2000.

Kidosaki House. Tadao Ando. Tadao Ando: Complete Works. 1986.

The Annex of Naoshima Contemporary Art Museum. Tadao Ando. Tadao Ando: Complete Works. 1995.

Church of the Light. Tadao Ando. Tadao Ando: Complete Works. 1989.

Meditation Space. Tadao Ando. Tadao Ando: Complete Works. 1995.

Vietnam memorial. Maya Lin. Maya Lin. 1982.

Interior view of the Living room, Weiss House. Louis Kahn. Beginnings : Louis I. Kahn's Philosophy of Architecture 1950. 


\section{Chapter Five: The Design Proposal}

Conceptual sectional drawing, Weiss House. Louis Kahn. Beginnings : Louis I. Kahn's Philosophy of Architecture. 1950.

Detail sectional drawing, Weiss House. Louis Kahn. Beginnings : Louis I. Kahn's Philosophy of Architecture. 1950.

Explanatory drawing of possible arrangement of the sliding panels, south façade for the living room, Weiss House. Louis Kahn.Beginnings: Louis L.Kahn's Philosophy of Architecture. 1950.

Northeast façade, Philadelphia Psychiatric Hospital. Louis Kahn. Beginnings : Louis I. Kahn's Philosophy of Architecture. 1954.

Sectional drawing of the Northeast façade, Philadelphia Psychiatric Hospital. Louis Kahn. Beginnings: Louis L. Kahn's Philosophy of Architecture. 1954.

Keyhole Window: an Isometric diagram of the U.S. Consulate and Residence (unbuilt). Louis Kahn. Beginnings : Louis I. Kahn's Philosophy of Architecture. 1962.

Salk Institute's lecture halls (unbuilt). Louis Kahn. Beginnings : Louis I. Kahn's Philosophy of Architecture 1965.

Arial photo of Porter Island, Ottawa. Carleton University Library GIS Data.

Site Map, in relation to important landmarks, map edited by author.

Site Map, Zoning of the neighborhood, map edited by author.

The existing building on Porter Island, 'The Island Lodge Long Term Care Home', photo taken by author.

Senior exercise on Porter Island, photo taken by author.

Kids playing at the park in the neighborhood, photo taken by author.

Site Investigation of Porter Island, photos taken by author.

Observing the transformations of the site (viewing east towards the island),

photos taken by author.

View out from Porter Island, January to August, photos taken by author. Changes of Porter Island from January - August, photos taken by author.

Comparison of the lighting conditions through trees between winter and summer, photos taken by author.

Comparison of the lighting conditions of a day through water (view out from the island), photos taken by author.

Light and the reflection, the reciprocal image, photos taken by author.

Framing the vision (viewing west from the island), photos taken by author.

Sunset of Porter Island, Ottawa (viewing west from the island), photos taken by author.

The Site Plan drawing (1:500), drawing by author.

Site model (1:500), model by author.

The axonometric drawing (1:250), drawing by author.

Vignette, from the lounge of the senior home viewing across the playground of the daycare center, drawing by author.

Vignette, Children Classroom viewing out to the water Playground/ Reflecting Pool, drawing by author.

Vignette, Senior Assembly hall viewing out to the Reflecting Pool, drawing by author.

Vignette, The planting garden, drawing by author.

The Ground Floor Plan (1:250), drawing by author.

The $2^{\text {nd }}$ Floor Plan (1:250), drawing by author.

The Existing Building Condition, photos by author.

Living unit, louver extends from the unit out to the balcony, floor plan, drawing by author.

Living unit, showing different ways of adjusting the louver and shading different parts of the room, section, drawing by author.

Study sectional model of a single living unit with different possible ways of adjusting the louver when light penetrate into the space, model by author. 
Study sectional model of two units showing the relative relationship between the upper and lower units, model by author.

Study model, louver ceiling for the summer with non-reflective material, model by author.

Study model louver ceiling for the summer with reflective material, model by author. Study model, louver adjusted with different angle for the winter, with non-reflective material, model by author.

Study model, louver adjusted with different angle for the winter, with reflective material, model by author.

Section drawing, units and corridors (1:100), drawing by author.

Section drawing, communal lounge with the atrium space (1:100), drawing by author.

The renovated floor plan of the retirement home: $2^{\text {nd }}$ floor with living units, drawing by author.

The Ground Floor Plan of the Day Care Center, drawing by author. The cardboard model of the Child Playground, Arch Roof floating on light, model by author.

Arch roof of playground viewing the planting garden, section drawing (1:100), drawing by author.

Corridor space connects to retirement home, section drawing (1:100), drawing by author.

Classroom, Reading and the Activity space (1:100), drawing by author.

Section drawing, relationship between units, library and the indoor garden (1:100), drawing by author.

Indoor planting garden, floor plan (1:250), drawing by author.

Vignette of the Indoor Garden, drawing by author.

Library viewing the southern wall that separate from the planting garden, section drawing (1:100), drawing by author.

Library viewing north towards the residence's planting space, section drawing (1:100), drawing ay author.

South Wall (a luminous screen filtering light at different times of day), model by author. Living Unit, floor plan, drawing by author.

Living Unit, section, drawing by author. Meditation Space, floor plan, drawing by author.

The Reflecting Pool, Axonometric drawing (1:250), drawing by author. 


\section{Chapter One: Introduction}

Tou can look at any city and see that many of the buildings have no fiction. They are purely functional. They don't give people anything to think or dream about. They exist without inspiring people. The difference between a building and architecture is fiction. ${ }^{2}-$ Ando

The majority of residential projects prioritize economic concerns and functionality, often disregarding the important issues of how man should 'dwell' in urban centers. In a world governed by the technological perspective, architecture is increasingly having difficulties demonstrating its value and relevance to society and establishing a real identity as a legitimate discipline on its own. Consequently, the search for the essence of dwelling in architecture is fundamental to its survival as a discipline.

To dwell is to be able to dream within the circumstances of nature. Heidegger writes that 'letting-dwell' is a state of peace that permits such dreaming. ${ }^{2}$ The relationship between building and man is a dualism between the act of living and the accommodating of such dwelling. However, architecture today is built in an overly practical way where a specific sense of place has been lost, and many would argue that it has abandoned the kind of spaces capable of instilling a sense of dwelling or dreaming. Arguably, architecture should aim at experiential satisfaction as well as physical integrity. Architecture is a language that has the emotional power to explore the boundaries and implications of human uses of space.

1 Auping, Michael. Seven Interviews of Tadao Ande. (UK: Third Millennium Information Limited, 2002), 66.

2 Heidegger, Martin. "Building, Dwelling, Thinking." Rethinking Architecture: A Reader in Cultural

Theory. Ed. Neil Leach. (New York: Routledge, 1971), 114. 
The human condition is concerned with the desire to experience life situations as inspiring, and similarly, the purpose of a work of architecture is to promote and infuse such inspiration into daily life. Man finds meaning only when thought is given to the natural environment, since man does not exist in a vacuum, but within the dynamic order of nature. Therefore, architectural space should dictate relationships and associations with nature; it is the mediator that structures meanings between man and nature, and it reveals natural phenomena and the processes found in nature. The built world should raise an awareness of our surroundings as interconnected phenomena, which include people, plants, water, stones, and a myriad other things that are regulated by the diurnal cycle and the changing of seasons. In order to dwell in an inspiring way, the understanding of natural phenomena is essential since human sensation is deeply attuned to the natural environment; it is thus urgent that man should cultivate a profound phenomenological understanding of their environment in order to attain real sense of dwelling.

The Eastern philosophy of Taoism observes life in this manner and offers a balanced view of the changes in nature. The aim of Taoism is the search for a balance between humanity and nature, and the ultimate striving to be 'at one with nature.' Taoism sees life in a constant temporal flux. The essence of Taoism is not set against the processes of change but accepts the sense of the world through its changes in order to attain a perception that can reach a primordial harmony.

Lao-tzu, the founder of Taoism, believed that nature has a way of balancing itself and is governed by some unseen power that could be revealed: "The Tao is elusive and intangible, and yet within is image and form; it is dim and dark, and yet within is 
essence. This essence is very real, and therein lies faith. Thus I perceive the creation." ${ }^{3}$ According to Lao-tzu, Tao is the underlying law that orders the entire universe and makes the world function and brings all beings to life; however this law is often obscured for humans to comprehend because it is in a state of transforming and changing. Consequently, human's consciousness of the world is increasingly dependent on the objects around them but not to the inner subtleties and the underlying potency. In order for humans to perceive the natural environment, Lao-tzu believed that the intangible aspects of nature (such as light, shadow, sound, scent and movement) are the most vital because the essence of the creation lies in the intangible realm. "Molding clay into a vessel, we find the utility in its hollowness; therefore the being of things is profitable, the non-being of things is serviceable." ${ }^{4}$ Lao-tzu explained that the hollowness of the vessel is more important to be aware of because this void space is what utilized the vessel. He believed that the void or the intangibility allows the possibility for further development because a void is always capable of being filled by solid. Thus, Lao-tzu suggested that as humans engage in their life, they should be aware of the unseen contents.

From an architectural perspective, space should permit the intangible elements to be revealed and transformed by nature, and in this way, space would have the potential for fully transforming our perception of space. This research seeks the intangible and unseen content of architectonic form which offers a spiritual quality to architecture. The manifestation of spiritual inspiration and the harmony of dwelling can be achieved through Taoism's philosophical concepts revealed through the built world. These concepts are often vague, incomplete, and open to many interpretations depending on

\footnotetext{
${ }^{3}$ Lao-tzu. Tao-Te-Ching: A New Translation by Gia-Fu Eeng and Jane English. Trans. Gia-fu Feng and Jane English. (New York: Random House, Inc.), Chapter 21.

${ }^{4}$ Lao-tzu, Chapter 11.
} 
the context of the discussion. After all, Taoism does not directly instruct on architecture but teaches a way of living. Nonetheless, Taoism has everything to do with architecture as it questions what we know and take for granted about dwelling. Through an in depth investigation into Taoist philosophy, I have formulated six concepts that are relevant to architectural practice in the pursuit of the essence of dwelling and ultimately, balanced architecture. These ideas are Vastness, Incompletion, Formlessness, Oppositional Balance, Boundary-less and Scarcity. By revealing these concepts, one can establish a 'balanced architecture' which inspires the imagination and enriches lives on a daily basis by ensuring that the daily aspects of life, light and place are not forgotten in the search for enhanced functionality.

Additionally, the idea of a "balanced architecture" through Taoism will be further explored through the juxtaposition of the main architectural programs of a Retirement Home and a Daycare Center. A balanced architecture can be achieved by allowing children and the elderly to dwell in a harmonious and inspiring environment. Further issues concerned with the juxtaposition of these two programs will be discussed in the design proposal section.

The relevance of the concepts in architectural spaces can be significantly explored through the use of light. Light, as the source of life and a primary means of architectural expression, ties both practical and theoretical issues together while achieving a balanced dwelling. The true essence of dwelling is to make inhabitants feel inspired and creative, while remaining balanced within nature. 


\section{Chapter Two: Taoism and Architecture}

\subsection{The origin of Taoism}

Chinese civilization developed a highly ordered worldview that can be traced back thousands of years. Taoism began in 600 BCE by the philosopher Lao-tzu, who had been searching for a balance between man and the natural environment. The basic aim of his philosophy was the attainment of balance and harmony between yin and yang, the two great balancing oppositions that compose nature as a whole.

According to Taoism, the universe began with

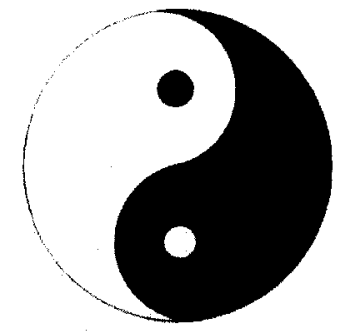

Figure 1: Symbol of Yin Yang the invisible vital force which governs all things in nature, and everything within nature possesses yin and yang qualities. Yin and yang literally mean 'dark side' and 'sunny side,' respectively. They symbolize the creative process through the interaction of a bipolar force. They are not entirely opposite to each other, but

rather dependent on each other. This can be explained better through the yin-yang symbol (Figure 1). It is a circle divided into light and dark hemispheres rotating around a central axis. It signifies a whole consisting of two opposite but interdependent natures. Within each nature is the seed of the other. The early Taoists generated this symbol to reflect how reality is organized. In ancient times, the Chinese believed that heaven is ruled by the yang force and earth is dominated by yin. In general, yin is equated with earth or creation, and its qualities are all the things that are passive such as darkness, shade, coldness, femininity and the void; yang is equated with the sky or heaven, and its qualities are all things that are active, such as light, the sun, heat, 
masculinity and mass. Yin and yang are the fundamental principles of all things; everything can be divided into mutually opposing and in terdependent elements, and together they form one unity.

The overall doctrine of Taoism can be explained through four main principles. The first principle, Oneness, sees the observer and the observed as part of the same system. The principle of Oneness conceives the two opposing forces as a totality. Taoism thus observes nature as being governed by the two complementary and basic forces of yin and yang. Taoism's second principle, that of Dynamic Balance, sees these two forces combined as one distinctive force in a perfect balance, as in the relationships between the sun and moon, heaven and earth, dark and light, chaos and order. These distinctions are understood as creating a balanced opposition that expresses itself through cycles, which are related to the third principle of Cyclical Growth. Taoism sees fundamental cycles everywhere in nature, such as summer and winter, light and dark. Since the distinctions are actually balanced and work together endlessly, Taoists believe that you can produce one thing from its opposite. This can be observed in a bamboo stick. "Yield and overcome; bend and be straight; empty and be full." The bamboo stick bend with the wind and it overcomes the wind by yielding to it. If it were stiff, it would break because it's so brittle. Since the bamboo stick bend and yield, it overcomes. Thus, weakness produces strength and strength produces weakness and this is the fourth principle of Harmonious Action.

Taoist philosophy is composed of the work of many philosophers from different periods, with Lao-tzu believed to be the founder of the doctrine. In the Tao Te Ching, Lao-tzu lays down the foundation of his thinking in eighty one chapters that are

\footnotetext{
${ }^{5}$ Lao-tzu. Tao-Te-Ching: A New Translation by Gia-Fu Feng and Jane English. Trans. Gia-fu Feng and Jane English. (New York: Random House, İnc.), Chapter 22.
} 
organized into two major sections known as the 'Tao Ching' and the 'Te Ching', dealing with the Tao and Virtue, respectively. 'Te' is translated as the virtue that always lies in Tao or the natural law that is the basis of all Taoism. The Tao Te Ching is an integral Taoist text and represents the ancient philosophical and speculative view of the Tao. In the book, Lao-tzu describes the world as created and supported by the Tao and encourages people to pursue simplicity and spiritual cultivation in order to recover a connection with this all-encompassing force.

The term Tao commonly refers to a road, path or the way, but in the Tao Te Ching, it is generally used to indicate the unseen and the underlying law of the universe that constantly changes the predictable rhythms and orderly patterns that structure and order the whole universe. It is a philosophical concept which describes the origins of all creation. In Taoist thought, everything is made of Ch"i, or energy. It is the energy that gives life, as it makes rivers flow and plants grow. The ancient Chinese regard this energy as the most original and fundamental raw material for the creation of things and all living creatures need this energy for survival and growth. In the Taoist view, Ch"i is the vital energy and the Tao is the underlying law that governs this energy. As a principle, Tao is always at a balanced state through an interaction between yin and yang. As well, the process of Tao is constantly involved in a cyclical change. The Taoist sees that nature has no absolute stillness, and they understand that life is a constant state of flux and change, rise and decay, as things alternate between day and night. Temporally, things change and are transformed. Within these changes, relative stability can be achieved when a harmony is reached between yin and yang. Tao is seen as one unending and continuing stream of action rather than a series of unconnected phenomena. 


\subsection{The practice of Tao as the art of living}

Taoism is more concerned with intuition rather than rational knowledge because Taoists think that reason alone does not make people wise. Thus, if one were to approach Taoism, reason and the intellect have to be left behind. According to Lao-tzu, if the Tao is named, then the Tao is not an eternal Tao. ${ }^{6}$ What this means is that if the Tao is described by words or explained rationally, then one does not truly understand and practice Tao because naming constrains one's thoughts and restricts the understanding of Tao into specific, predetermined meanings. Because the human intellect can never comprehend Tao, one can only perceive it when one has become as nameless and as free of conscious choices and evaluation as the Tao itself. Accordingly, to recognize Tao is to free oneself from previous experiences and knowledge, and allow unconscious intuition to take over.

According to Lao-tzu, human beings should cultivate inner perfection by realizing their original natures. They should not expect sudden enlightenment; rather, they should progress gradually and practice Tao in peace. The ultimate goal of this doctrine is to achieve immortality. Tao lies at the core of the practice, which is 'to sit quiet and perform no unnatural action'. The aim is to lead to the recovery of one's youthful vigor, a return to the state of infancy, and the attainment of immortality. Much of the essence of Tao is expressed as action through inaction. This does not mean to sit and do nothing, but to practice through minimal actions with no arbitrary efforts. In the book called "Taoist Experience", a Taoist practitioner describes his experience in his room:

\footnotetext{
${ }^{6}$ Lao-tzu. Tao-Te-Ching: A New Translation by Gia-Fu Feng and Jane English. Trans. Gia-fu Feng and Jane English. (New York: Random House, Inc.), Chapter 1.
} 
The room I live in has windows on all four sides. When wind arises I close them; as soon as the wind has died down I open them again. In front of my meditation seat a curtain is suspended; behind it a screen has been placed. When it is too light I draw the curtain to adjust the brightness inside. When it gets too dark I roll the curtain up again to let light in from outside. On the inside I calm my mind; on the outside I calm my eyes. Mind and eyes must be both completely at peace. If either light or darkness prevails, there are too many thoughts, too many desires. How could I ever calm myself inside and out?

From this, one can see the intimate relationship of Taoism with space. In this passage, the Taoist responds naturally to the rhythms of his surroundings. This experience has nothing to do with living in ornate buildings or merely being inactive, but interacting with and responding to the naturally harmonious rhythms of yin and yang. The Taoist always tries to keep himself in a balance between light and darkness, wind and stillness, mind and vision. To practice Tao is to respond modestly to all changes without resistance or arbitrary effort. The idea of this natural response is the essence of practicing Tao.

\subsection{The interpretation of Taoism in architectural practice}

By understanding Lao-tzu's observations and ideas regarding the orderly world view, many of his concepts become meaningful in the creation of dwelling spaces. In the Tao Te Ching, there are six major concepts that are relevant to contemporary architecture: Vastness, Incompletion, Formlessness, Oppositional Balance, Boundaryless and Scarcity.

\footnotetext{
${ }^{7}$ Kohn, Livia. The Taoist Experience: An Anthology. (New York: State University of New York Press, 1993) 83.
} 


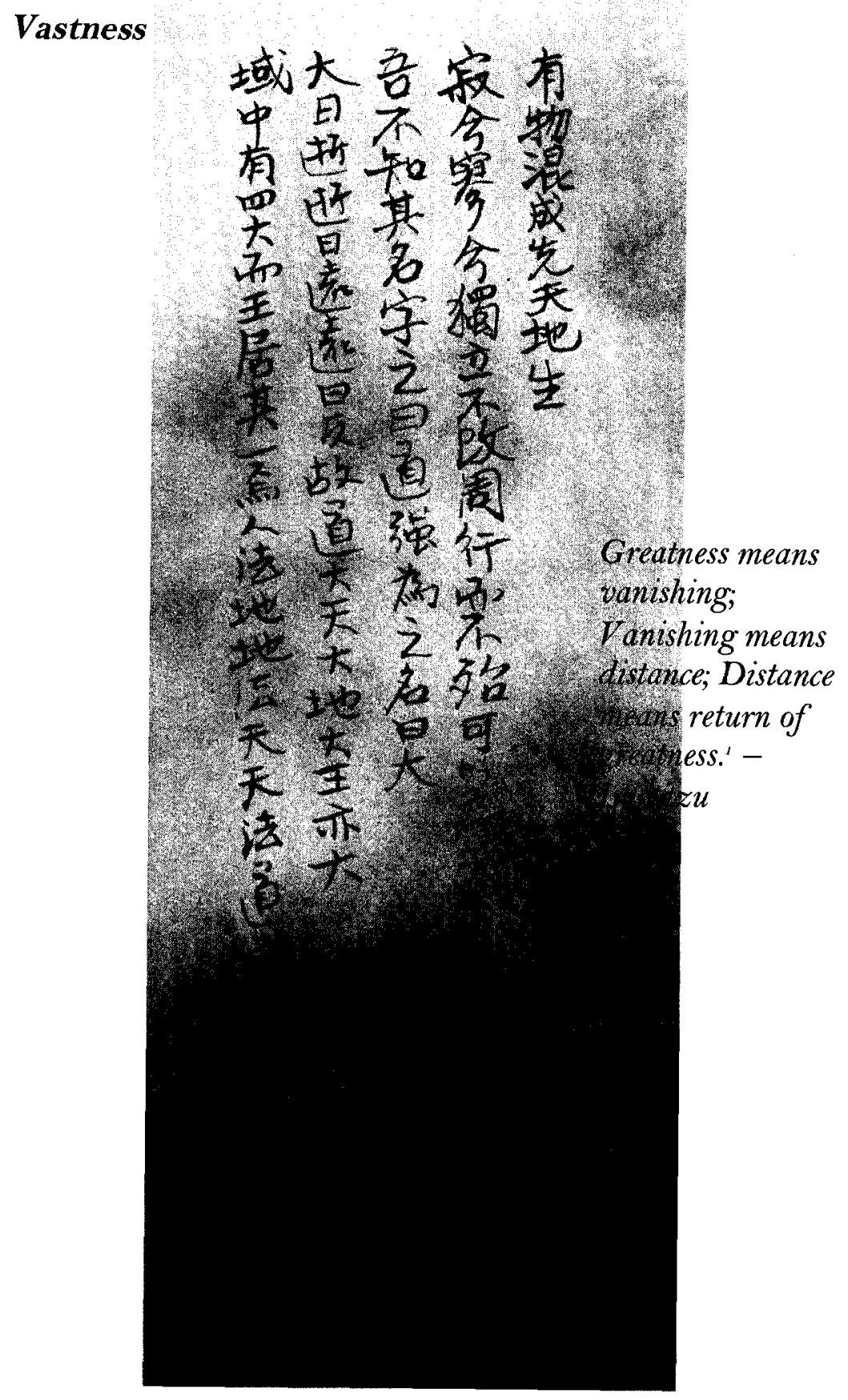

${ }^{1}$ Lao-tzu. Tao-Te-Ching. Vol. 307. (Shanghai: Commercial Press, 1929) Chapter 25. 
Greatness is referred to the Tao which is the underlying force that was mysteriously formed before the human existence. It was formed in chaos, which does not only move in one direction, but moves around everywhere forming the vastness of space. This immense space formed different degrees of distance, formlessness and shapelessness that one cannot see or touch but from them intuit the grandeur of space. Architecturally, the concept of Vastness does not necessarily mean the creation of a huge space, but to allow space to grow beyond its actual size and distance. According to Lao-tzu, gaining and losing are always in balance. For example, decreasing the size of the objects within a given space has the potential of creating an illusion of a greater space. As such, the creation of Vastness is the relative relationship between objects and the surrounding space.

Tadao Ando's "Church of the Light" (Figure 2) is a great example of a small space that achieves vastness through its play of light and shadows. Intense light penetrates the darkness of the rectangular box through a horizontal and a vertical cut in the altar wall. This cross pattern is intended to express the purity that exists in the relationship between individuals and nature. Light is rendered in an exceedingly abstract form, and consequently becomes more pure. In addition, the intense light penetrating the dark interior space creates an illusion of infinity beyond the room, thus contributing to the notion of a vast space beyond. This notion of Vastness is further strengthened because the light extends to the walls, ceiling and floor revealing the grandeur of the space within. Furthermore, the horizontal and vertical opening of light actually brings the human scale into perspective and accentuates its infinite vastness beyond the horizon. 
Ando's "The Annex (guest room) of Naoshima Contemporary Art Museum" (Figure 3) is another example of the architec tural achievement of Vastness. The opening of the roof allows the space to reach beyond its actual dimensions, and gives an impression of the space extending into the sky; at the same time the reflection in the water contains the image of the sky within the space. This idea of extension and containment allows the space to grow beyond itself and manifest a sense of vastness.

The concept of Vastness is significant to the creation of architectural space because it is concerned with spatial qualities and the relationship between the dwellers and their natural surroundings. The quality of Vastness implies a sense of infinity and it offers freedom for inhabitants to explore their emotional boundaries. The architectural examples above demonstrate possible ways that the quality of Vastness can be manifested through the use of natural materials like sunlight and water, and the effective and subtle use of openings. These openings or thresholds are meant to connect the natural surrounding with dwellers in daily life. Ultimately, through an awareness of Vastness, dwellers are able to better intuit the grandeur of nature. 


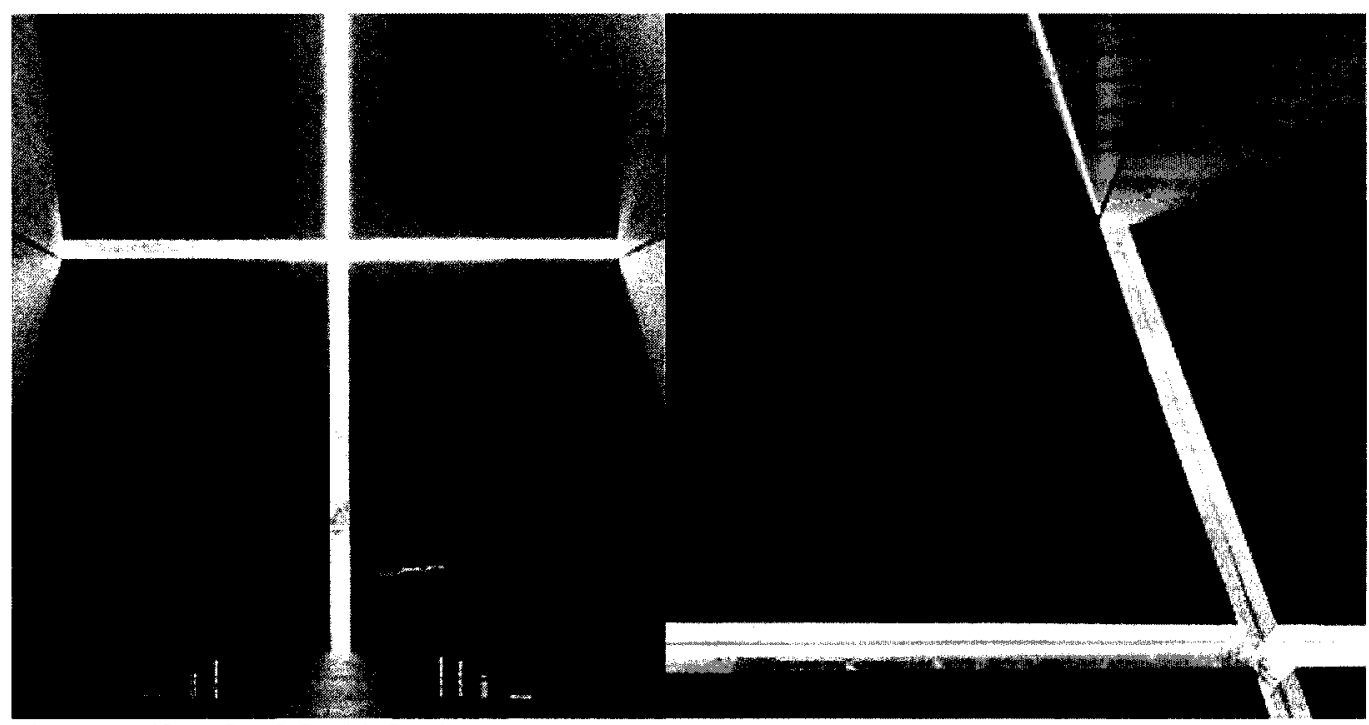

Figure 2: Church of the Light, Japan 1989

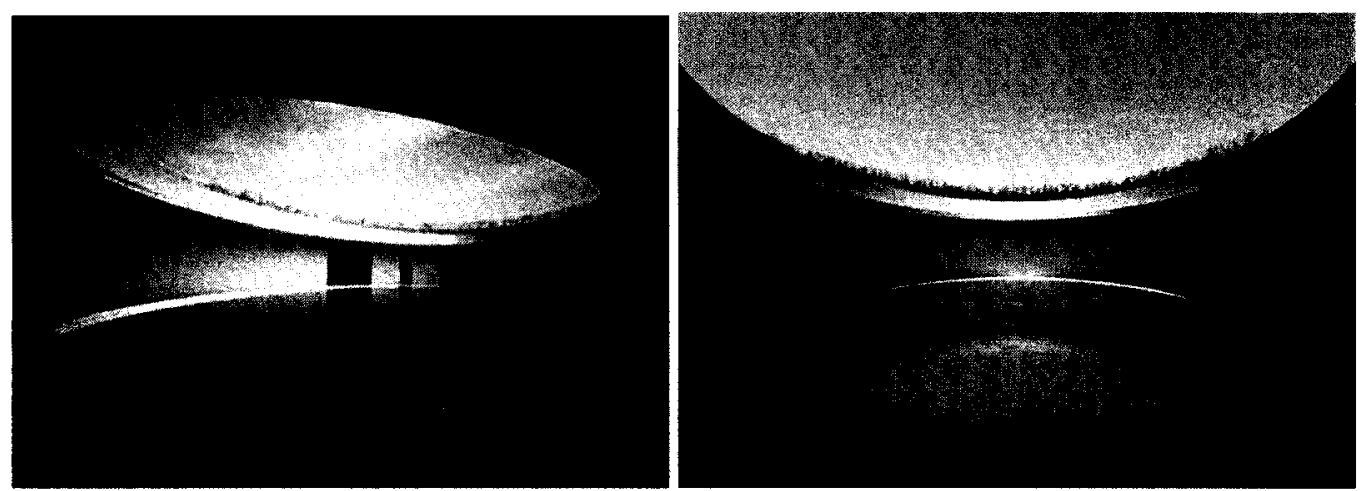

Figure 3: The Annex of Naoshima Contemporary Art Museum, Japan 1995 


\section{Incompletion}

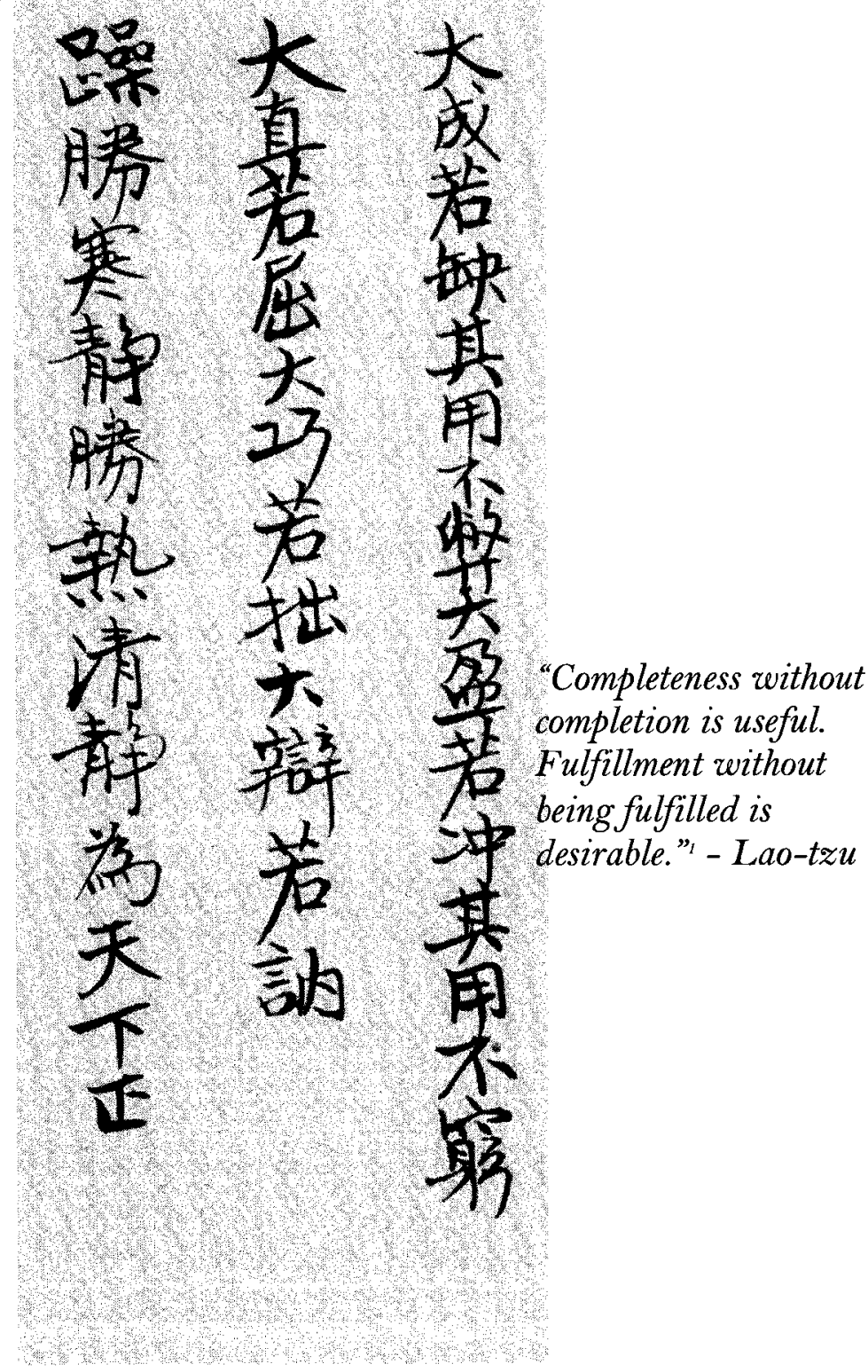

\footnotetext{
${ }^{1}$ Lao-tzu. Tao-Te-Ching. Vol. 307. (Shanghai: Commercial Press, 1929) Chapter 45.
} 
The idea of "completeness without completion" is favorable to Lao-tzu because it encompasses a more flexible and adaptable approach to the ever-changing world. Laotzu also believed that completion serves only one purpose for the immediate period, and is thus not valuable for future changes. The concept of incompletion can be applied to the creation of flexible architectural spaces. For example, adaptable spaces in a building can be designed to respond to seasonal changes of climate.

According to Lao-tzu, the environment is something beyond image. It is composed of infinite elements and integrated by hidden orders and laws. As such, the world can never be viewed in a totality but only as incomplete. According to his observations, nature is constantly shaping itself, and things are formed by the result of the interactions between things. For example, the light one sees has already been diffused and reflected many times before it comes into one's eyes; the color one sees is the result of the reflection of this already diffused light. Lao-tzu believed that the importance of the process of formation is to allow freedom for the infinite growth and to let things integrate and adapt to the changing world.

In architecture, a composition is comprised of multiple levels of form and content, such as light, color, line, shape, solid forms and so on. These elements are experienced compositely as interrelated contents in a composition. Similar to Lao-tzu's ideas on formation, the essential aspect of spatial perception is the possibility of its becoming something and allowing the infinite growth for completion. The formation of composition in architecture shares the same idea. In order to complete and fulfill a good composition, it has to contain an aspect of incompleteness or flexibility. For instance, the composition has to be completed by human experience and the perceiver or inhabitant's own particular journeys and viewpoints. The composition will reach its 
fullest development when a person completes its form through his or her imagination. Consequently, the composition will be unique because it will transform into many different permutations, each refracted by individual experiences.

For example, in his design for the Salk Institute, Louis Kahn devised a powerful composition that is spatially and symbolically incomplete. Two richly rhythmical buildings define a powerful axis that is open at each end and constitutes both a significant gesture and an infinite vision beyond the Pacific Ocean (Figures $4 \& 5$ ). The infinite vision and the openness between the earth and sky lead us into what Kahn refers to as "the sense of wonder". This sense of wonder is one's intuition, which is the most reliable and personal sense that an individual has. ${ }^{10}$ The life of knowing is very real, but it is personal. The idea of incompletion allows room for natural growth and allows architecture to shape our experience.

Frank Lloyd Wright's "Fallingwater" (Figure 6) is another architectural work that exemplifies the concept of incompletion. The perception of "Fallingwater" is constantly shifting because it is so thoroughly integrated with the seasonal systems that evolve and develop around the falls. The building plays on the way that the water cycle has an infinite pattern of evaporation, condensation, precipitation that completes the cycle of nature. Furthermore, the water cycle is connected in a continuous global chain; water never remains an isolated incident and never exclusively belongs to any specific time or place. Thus "Fallingwater," placed on an actual waterfall, becomes part of the experience of the water cycle. This act is also indicative of the fact that architecture is not an arbitrary act but is instead a process inseparable from nature. As one moves into the entrance area, one hears the water and feels its moisture. The transition from

${ }^{10}$ Tyng, Alexandra. Beginnings : Lowis I. Kahn's Philosophy of Architecture (New York: Wiley, 1984), 
outside to inside is thus a gradual change in atmosphere, and rather than a stark change of place. With the aim of adapting to the processes of growth and change, architecture should incorporate natural changes to be a fundamental aspect of its structure.
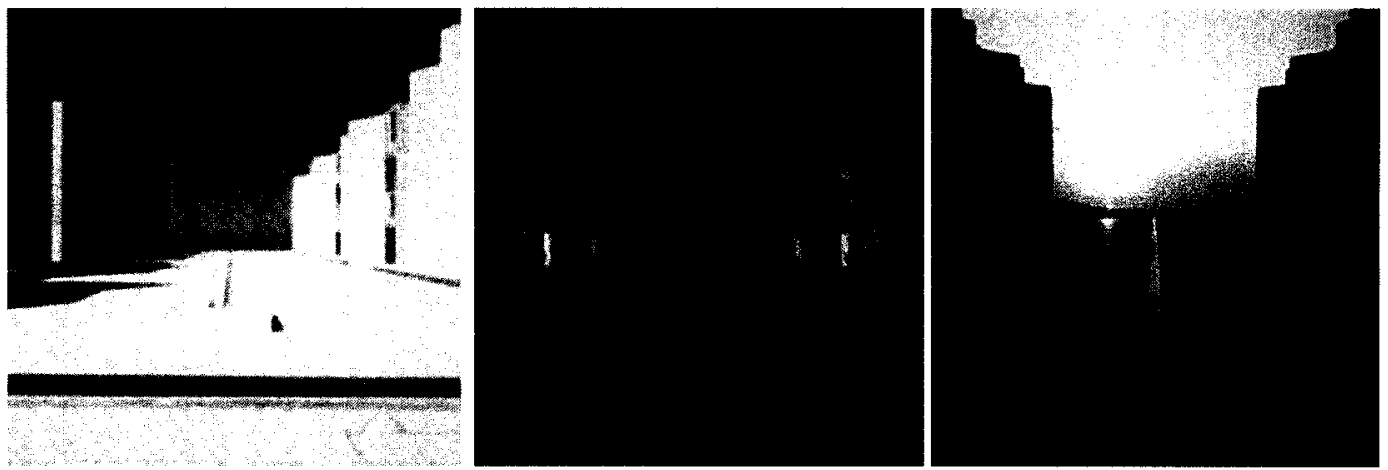

Figure 4: Salk Institute, La Jolla California 1965
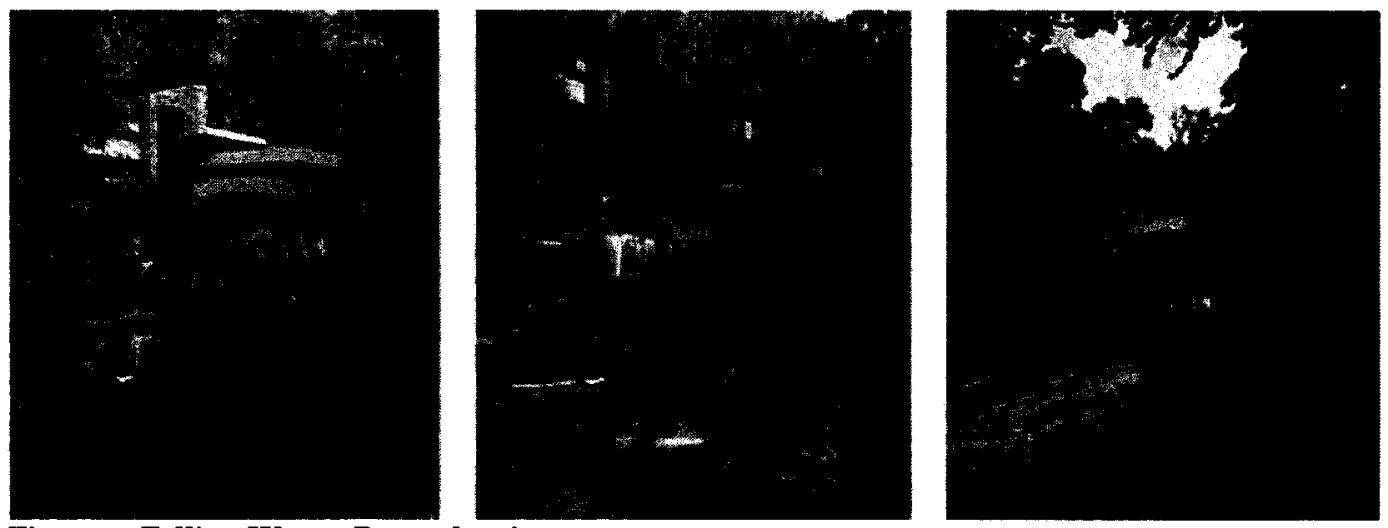

Figure 6: Falling Water, Pennsylvania 1939
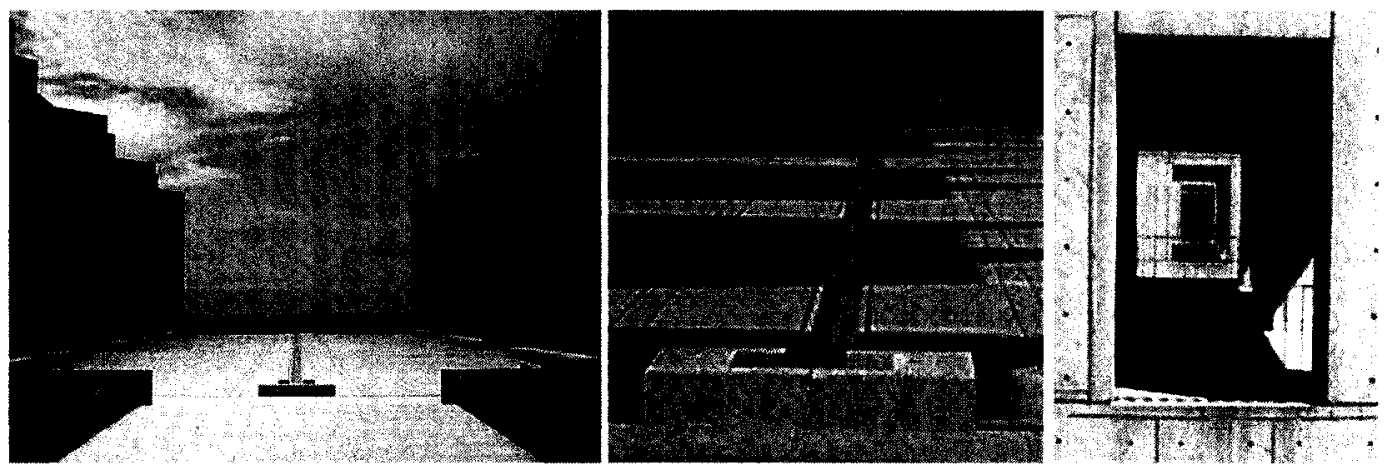

Figure 5: Salk Institute, La Jolla California 1965 


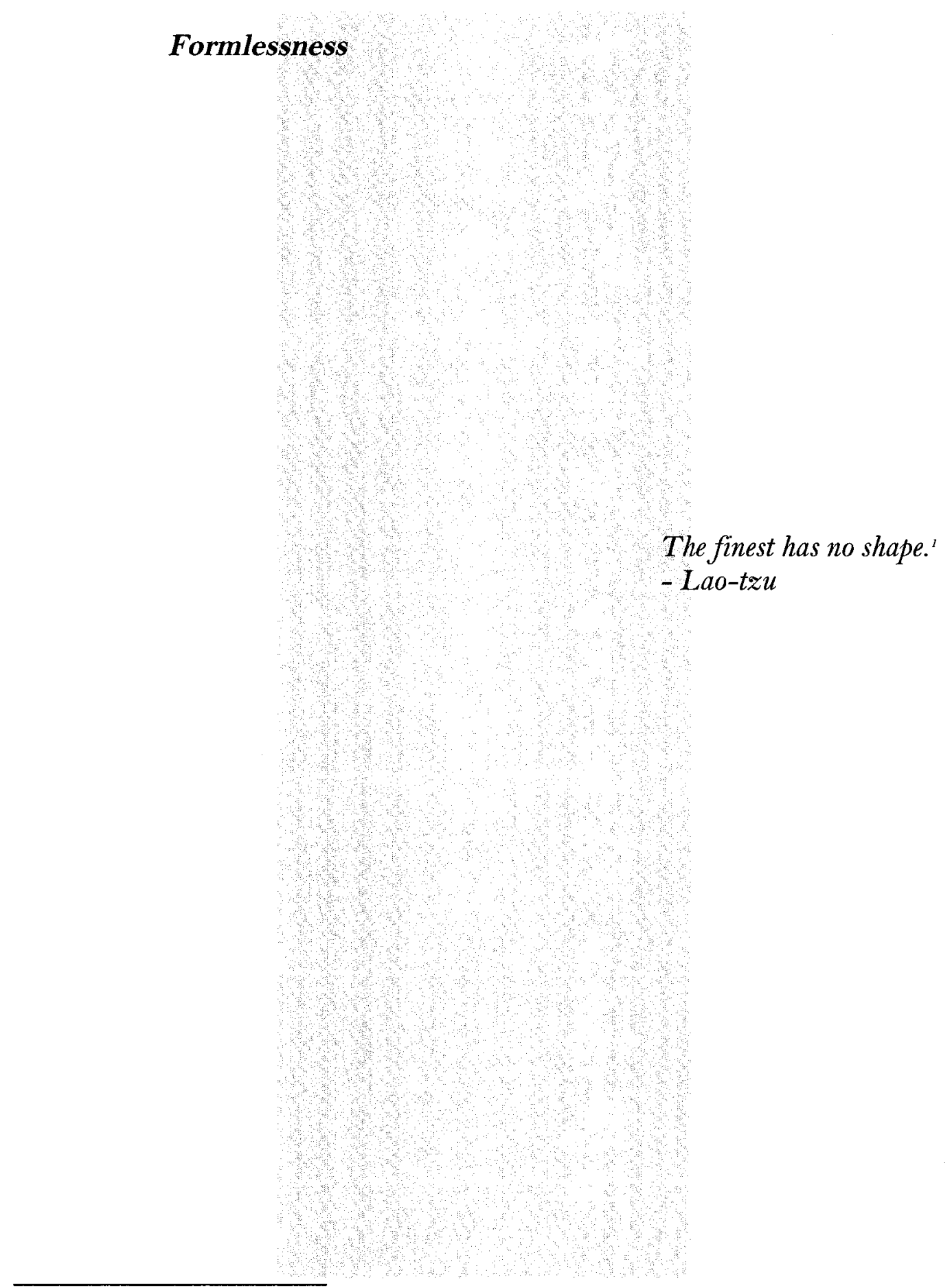

${ }^{1}$ Lao-tzu. Tao-Te-Ching. Vol. 307. (Shanghai: Commercial Press, 1929) Chapter 41. 
According to Lao-Tzu, the growing and living aspects of nature are composed of infinite elements erratically integrated through countless transformations. The formations of things are transformed according to the progression of time: a tree rises and decays, the weather and temperature changes throughout the different seasons, and day and night alternate. Living things never stay still; instead, they are constantly changing. The images that appear in our eyes have been transformed through many stages of change and formulated into images precisely at the moment that we perceive them. Since nature is conceived as a process of change, the finest has no final shape and instead it is constantly in the process of shaping and forming.

Architecturally, a lively space should similarly be responsive to changes over time because the qualities of the space will inevitably change. To enrich the quality of a space is not to still its essence, but to allow its essence to be transformed over time. For example, the changes of the sun's position and the consequently changing intensity of light will affect the way that spaces make people feel and also shape them into a variety of compositions by casting shadows at different times. Seasonal and climatic changes also stimulate the human senses, such as vision, touch, hearing and smell. All senses are influenced by the spaces that one occupies, and these spatial qualities are in turn influenced by their connectivity to nature. Thus, to create a harmonious atmosphere, the space must be integrated with the changes in the natural environment.

For Louis Kahn, architecture must continuously engage the real world as it exists in the present moment. He used materials as a means of reaching the eternal in order to stimulate new realizations, thereby enriching the world. Returning to the Salk Institute, Kahn captured the richness of the forms and materials between earth and sky. He designed a central courtyard, a place of silence, with a simple band of water running 
through it, which leads our vision into an infinite point. In fact, the plaza is seen as the façade to the sky. This open gesture relates the site to the Pacific Ocean and beyond, giving it a sense of formlessness. Kahn believed that it is the role of architecture to discover what he called 'the existence will' of a building and bring it into the world. He sees buildings as living beings that have a soul, and it is the architect's role to bring forth this inner essence.

Living is a passage of time, and living spaces should encourage dwellers to be aware of time and its transformative effects. The concept of Formlessness implies that spaces be constantly adaptable and flexible. An example of this is a space with an opening designed in relation to the morning sunlight from the east and the evening sunlight from the west, allowing sunlight to dictate designated spaces ideal for use throughout the day. In this type of formless space, every moment entails a different spatial quality due to the changing time, year and season, and the interaction of the site to this change. Hence, dwellers can embrace the unexpected surprises of their living space according to the countless transformations that nature offers. 


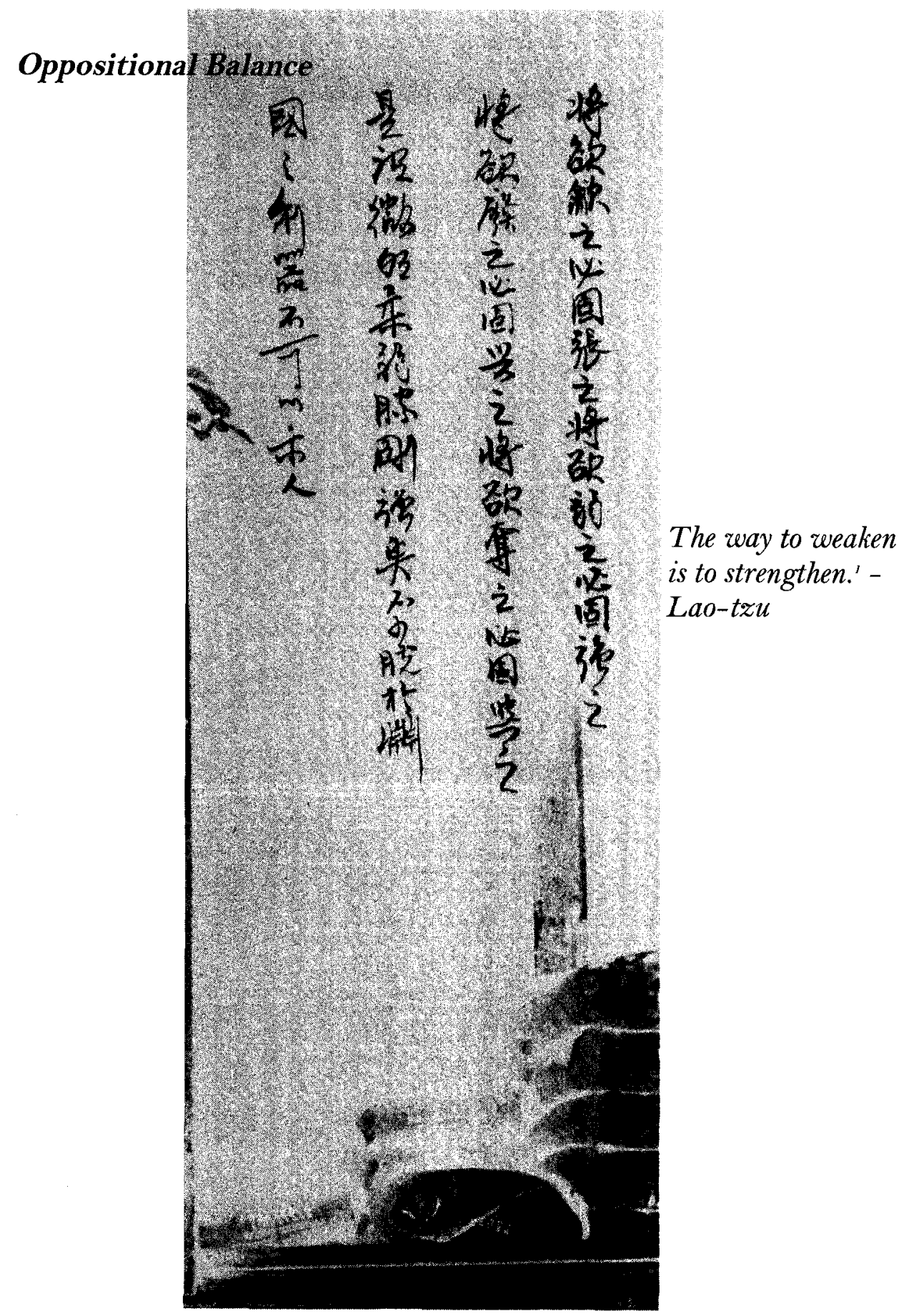

${ }^{1}$ Lao-tzu. Tao-'Te-Ching. Vol. 307. (Shanghai: Commercial Press, 1929) Chapter 36. 
Because of nature's countless transformations, Lao-tzu believed that it always has a way of balancing itself. He observed that things are created in distinction from each other, but are balanced and work together through endless cycles such as the seasons, day and night, life and death, attraction between the positive and negative poles of the magnetic field, the growth and decay of living things, etc.

He observed that in order to gain balance, one has to be suspended between the two extremes. He believed that every individual thing has its insufficient, negative and intangible content; a tree rises then it will decay, and it will rise again and decay once again. This process is a reversion, which means it is an act of re-turning. Reversion appears realistic when it relates to any conceivable pair of opposite states in nature. Lao-tzu explained this concept, as referred to earlier, through the observation of a bamboo stick: "Yield and overcome; bend and be straight; empty and be full."13 The bamboo stick bend with the wind and it overcomes the wind by yielding to it. Thus, the way to weaken is to strengthen. Taoists believe that you can produce one thing from its opposite, such as high and low rely heavily on each other. When a thing is described as high, it is because it is compared with low, and vice versa.

This concept of oppositional balance can be further explored through an examination of certain architectural spaces. In the design strategy for the "Naoshima Contemporary Art Museum" (Figure 7), Tadao Ando used the contrast between dark and light. For example, one enters one of the museum's halls through a dark space, and as one continues, limited openings gradually allow light in. One is able to better perceive light because of the darkness; because of the complete darkness, one feels the strong presence of the light. One can thus begin to feel the fundamental relationship

\footnotetext{
${ }^{18}$ Lao-tzu. Tao-Te-Ching: A New Translation by Gia-Fu Feng and Jane English. Trans. Gia-fu Feng and Jane English. (New York: Random House, Inc.), Chapter 22.
} 
between light and darkness and understand their mutual interdependence. In this case, the concept of oppositional balance has been effectively applied to the spatial qualities of a site.

In addition to spatial concerns, this concept can be applied to the boundary between the public and private realms, as exemplified in the work of Isamu Noguchi, the modern landscape sculptor, designer, and architect. Throughout his life he struggled to understand, alter and recreate his natural surroundings, believing that through sculpture and architecture, one could better understand the struggle with nature. His concept of space can be viewed as a dual conception that unifies the inner self with outer phenomena.

For example, "Sunken Garden" (Figure 8) is one of his works that exudes simplicity, but an enormous complexity is actually achieved. This mixed perception is created through the relationship between a series of large stones and the undulating surface of white granite cobbles in which the stones are set. Noguchi translates these material patterns into a permanent, ever-flowing and changing horizontal plane. The rhythmic movements and the subtle inter-relationships of the whole space give this most simple sculpture a calm intensity. As well, water generates a horizontal plane that complements each stone as an isolated piece of artwork. When the site is viewed as a whole, one can understand the dependency between two systems. In this specific example, the stones penetrating through the water plane complement the site's horizontality while the flat water plane emphasizes the significance of each individual stone. Furthermore, the opposition between the hardness of stone and softness of water harmonizes the art work as a balanced totality. 
Another example can be examined through the animated structure of traditional Chinese roof and columns (Figure 9), especially as they oppose each other in terms of heaviness and lightness. The bulky and heavy Chinese roof is elevated higher than necessary and its roof-corners are curled upward creating an illusion of a light roof structure. The structure is supported by light, narrow columns but is strengthened by strong colour contrast, and the roof is built heavily but lightened through the emphasis of curves. The idea achieved here is a holistic duality based on the combination of opposite pairs to form a visual balance.

Frank Lloyd Wright's selection of material for "Fallingwater" (Figure 10) also exemplifies the idea of duality. He used smooth concrete for the horizontal span and massive stone walls for the vertical compression. The two materials and the building method itself create a balanced opposition and work together to form a balanced composition. The stones are roughly squared, and their size, quality, and appearance result from their natural formation at a nearby quarry. The stones are laid in horizontal courses with the flatter ones projecting to form long irregular ledges which suggest natural formations rather than human technique. The concrete, on the other hand, is smooth and coloured ochre to contrast with the rough stone. The stones were carefully selected for their grain and shape; while the concrete was selected for its texture and colour. This dualism comes together as one material that embraces the house and interacts with the natural environment.

The idea of working with duality can apply to many aspects of architecture. To produce a smooth surface, we can always juxtapose it with a rough and textured surface. For instance, bright contrast can transform a surface quality, such as a strong and intense light fading and weakening a textured surface. Furthermore, the interplay 
between vertical and horizontal composition can change the sense of perception. For example, a vertical move alters the sense of breadth, while a horizontal move changes the sense of height. If we overlay the horizontal and vertical compositions, we get an enhanced sense of depth through this dual tension. When applied to living spaces, these concepts can help achieve a sense of balance and contribute to a harmonious sense of dwelling.

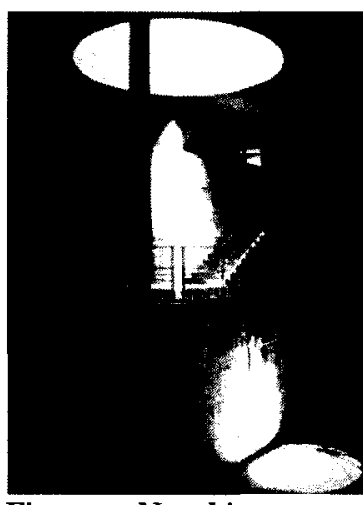

Figure 7: Naoshima Contemporary Art Museum, Japan 1992

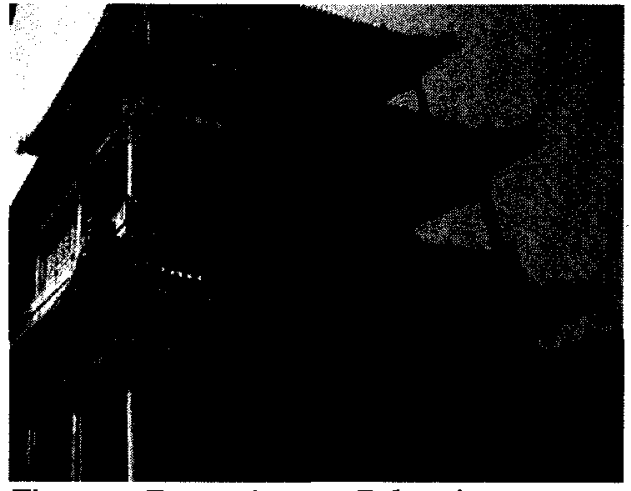

Figure 9: Entertainment Palace in Forbidden City, Beijing China 1420

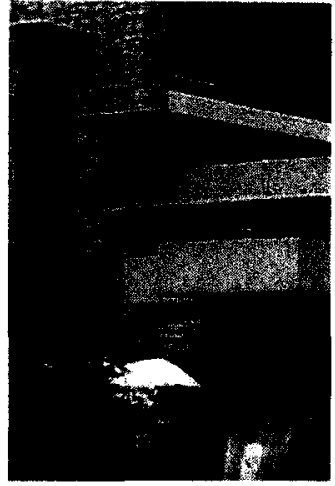

Figure 10: Fallingwater: material detail, Pennsylvania 1939

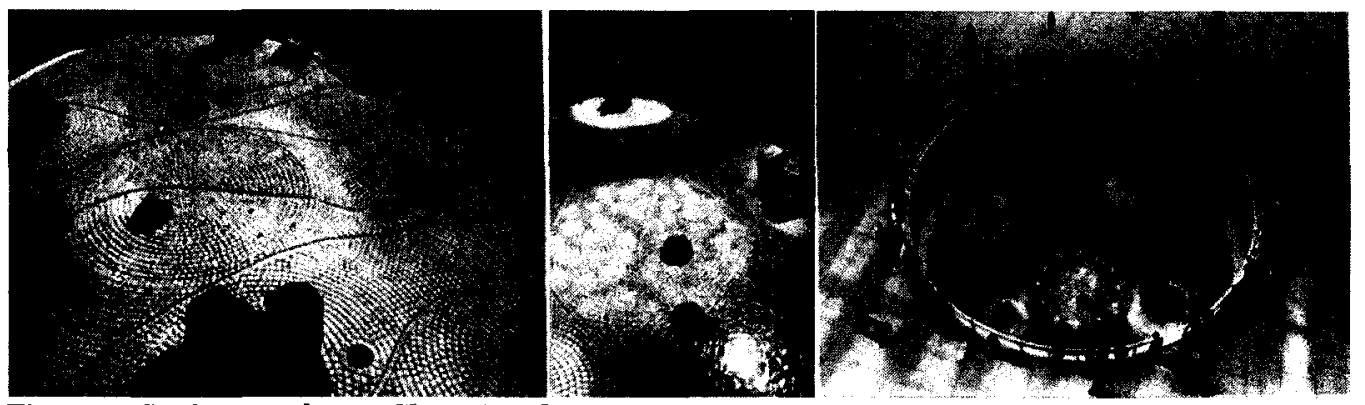

Figure 8: Sunken garden at Chase Manhattan Plaza, New York 1964 


\section{Boundary-less}

The greatest has no boundary. ${ }^{\prime}$ - Lao-tzu

${ }^{1}$ Lao-tzu. Tao-Te-Ching. Vol. 307. (Shanghai: Commercial Press, 1929) Chapter 41. 
Since nature is observed as a process of change, the material of the world is constantly in a state of being shaped and growing as it forms according to the vastness of space. Growth has no limit, so nature never is perceived as having boundaries. However, architecture is conditioned to have physical boundaries and thresholds that separate man from the external environment. In a way, we create such boundaries in order to avoid uneasiness and the fear of infinite space. Humans enjoy being enclosed and sheltered in their own spaces, as long as the enclosure does not encroach upon interpersonal space. If enclosure becomes a prison or a tiny space impinging upon personal comfort, then people will always opt for freedom and distance. Hence, the idea of achieving a balance between boundary and non-boundary in space should be an aim of architecture.

In order to achieve this balance, it is necessary to create flexible spaces. The layout of the ancient Chinese garden (Figure 11) serves as a great example of this concept. The garden has no center or focal point around which the whole composition is arranged; instead, there is a diffused balance of elements creating a more flexible composition. Thus, the layout has no climactic event or object, but rather a series of minor architectural events with the potential for connections among them and beyond. While the visitors walk around, the view of the garden changes, according to the traditional expression 'changing step, changing view'. These interdependent views construct many fantastic appearances throughout the ever-changing composition. The concept of this diffused layout illustrates a liberated approach toward enclosure without distinctive boundaries.

Similarly, in "Church on the Water" (Figure 12), Tadao Ando utilizes distance and brings it into the space. He creates openings in walls which frame and expose a 
nearby pond and the wilderness beyond. This space allows viewers to perceive the unobstructed images in the distance and achieve a greater sense of depth; the space thus engages the viewer's imagination, and the idea of being inside or outside becomes less defined. In the "Church of the Light" (Figure 13), Ando performs the same idea but in a more subtle way. He uses light and shadow to create depth and layers beyond to suggest there is greater space behind each layer.

The above architectural works exemplify how the concept of Boundary-less can be achieved through careful spatial organization and composition in regards to the awareness of the surrounding environment. This concept of boundary-less is crucial in the creation of our living spaces because it breaks the border between the interior and the exterior spaces, and hence it fastens dweller's relationship with their surroundings.

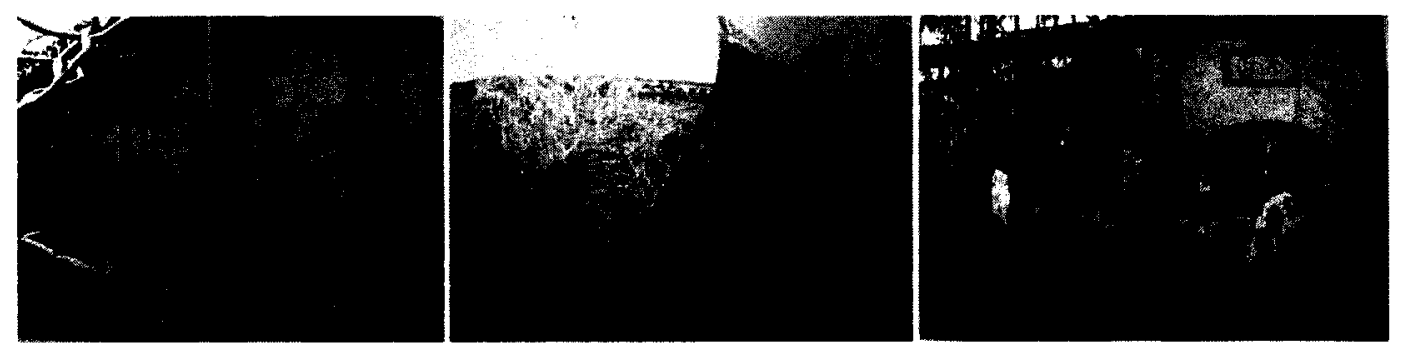

Figure 11: Chinese residential garden, Suzhou China, Qing dynasty
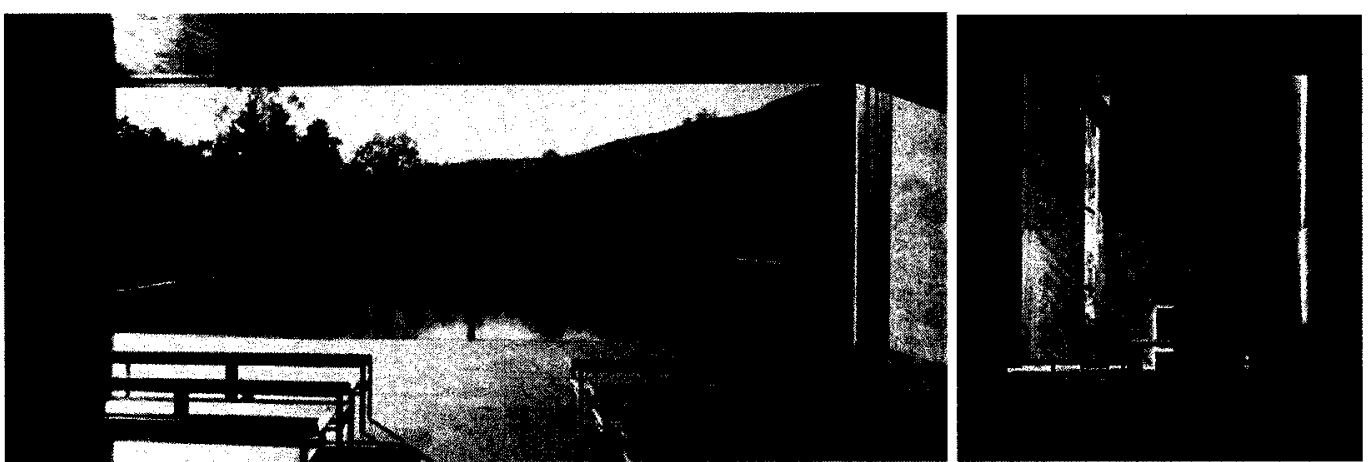

Figure 12: Church on the Water, Japan 1988

Figure 13: Church of the Light, Japan 1989 


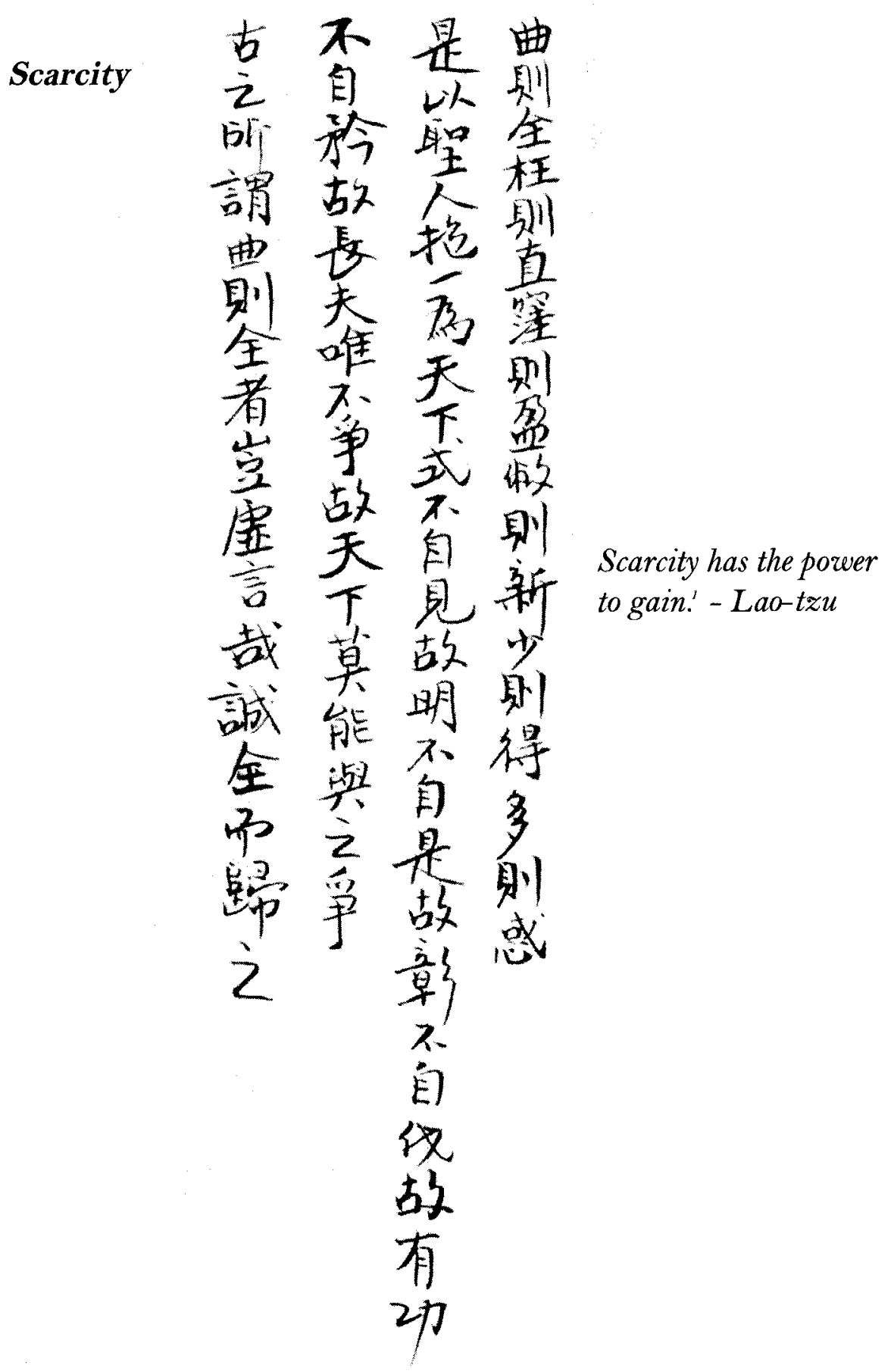

${ }^{1}$ Lao-tzu. Tao-Te-Ching. Vol. 307. (Shanghai: Commercial Press, 1929), Chapter 22. 
Lao-tzu advised that man should never compete with nature. He suggested that the way to live is to set one's mind free. He explained this idea through the depiction of the flow of water: "The highest good is like water. Water gives life to the ten thousand things and does not strive. It flows in places men reject and so is like the Tao."16 $\mathrm{He}$ explained that the way to set a mind free is just like the gesture of the water as it flows around obstacles and enters places without striving or competing. The way to live is to let one's mind act like the gesture of water and join the flow of the natural growth. The idea is to do less and let nature enrich the space, making it easier to see the interactions of the growth in the natural surroundings, thereby improving life.

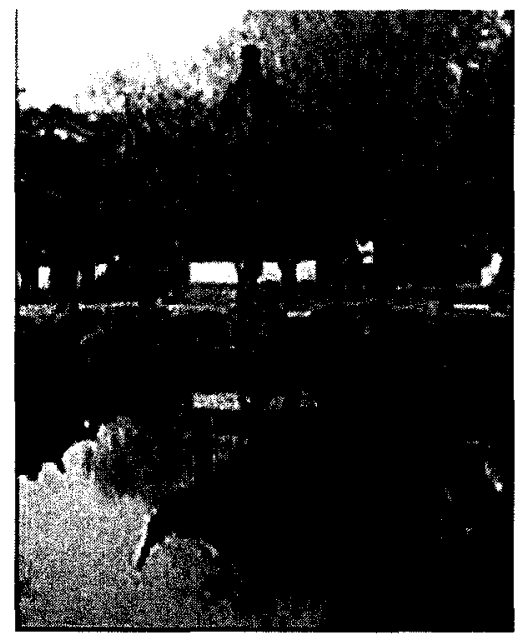

Figure 14: Chinese Pavilion, Suzhou China, Yuan dynasty
The traditional Chinese pavilion (Figure 14) is a harmoniously synthesized work of art which permits one to be mentally free. The pavilion is a freestanding tent which is open all around, and as such, it is vitally linked to nature and its landscape. The simplicity of this structure adapts to the vegetation and is usually placed alongside water. The play of flowing water emphasizes the pavilion's beauty by connecting it with nature. It thus becomes a place of relaxation and withdrawal into silence, which is a form of admiration and serves as an ideal state which allows the viewer to achieve the highest spiritual concentration in meditation.

The concept of Scarcity suggests that humans should ideally live without desire, and to live in such a way that allows natural transformations to enrich one's life. The

\footnotetext{
${ }^{16}$ Lao-tzu. Tao-Te-Ching: A New Translation by Gia-Fu Feng and Jane English. Trans. Gia-fu Feng and Jane English. (New York: Random House, Inc.), Chapter 8.
} 
Chinese pavilion, as discussed above, has shown that through a simple structural composition in a thoughtful and considerate relationship with its surroundings, a space can be transformed and modified into a natural and peaceful site.

To sum up the previous concepts in a single maxim, architectural space should be responsive to nature. Architecture is a vehicle that allows nature to manifest its properties. Nature offers countless transformations to the inhabiting space. These six Taoist concepts allow such transformations to be manifested in space, hence permitting man to dwell 'at one with nature'. 


\section{Chapter Three: the Tao of Dwelling}

\subsection{Heidegger and Lao-tzu}

The Tao that can be told is not the eternal Tao; the name that can be named is not the eternal name." ${ }^{\prime \prime}$ - Lao-tzu

We respond to the way only by remaining under way... The way of thinking cannot be traced from somewhere to somewhere like a well-worn rut, nor does it at all exist as such in any place. Only when we wall it are we on the move, on the way. This movement is what allows the way to come forward.$^{18}$ - Heidegger

Tao, the way, is Lao-tzu's poetic concept that captures the unity of man and nature that humans should cultivate in order to bring being into harmony. In the first chapter of the Tao-te-ching, he states that the concept of Tao cannot be expressed in words because the Tao is beyond logic and thus invisible to the intellect. He believed that if one tries to explain the Tao, only alienation will result. The significance of his concept of Tao is that he treated the Tao as a form of spiritual knowing that can only be verified by experience in life. This subjective understanding of the habitual manner of human beings on earth allows for a re-alignment with the Tao and hence, a life in harmony with nature.

This subjective understanding of life and nature is quite similar to the analysis of human existence by the German philosopher, Martin Heidegger (1889-1976). In his book, On the Way to Language, he claims that the way to understand human existence is to 'walk it' and experience it. He said that the way is not already there for one to follow but it comes into being as one travels along it. He further explains that the way does not lead or begin anywhere; one is always underway and remains so as long as one dwells on earth. Heidegger's thinking on the way and the way of Tao are similar in that

\footnotetext{
${ }^{17}$ Lao-tzu. Tao-Te-Ching. Vol. 307. (Shanghai: Commercial Press, 1929) Chapter 1.

${ }^{18}$ Heidegger, Martin. On the Way to Language, trans. Peter D. Hertz (New York: Harper and Row, 1977) p.126
} 
both conceive of the way as something subjective: the act of living has to be undertaken by oneself and be understood gradually as one lives. By juxtaposing Heidegger's and Lao-tzu's thought, one notices that they are comparable and that together, they can provide extensive insight into the essence of dwelling. Indeed, these insights are important to contemporary architecture in showing that the build environment can be more than mere shelter. Society must learn not to limit itself to the idea of a building as only a practical construction, but instead as a place for dwelling.

\subsection{What is it to Dwell?}

To dwell, to be set at peace, means to remain at peace within the free, the preserve, the free sphere that safeguards each thing in its nature. The fundamental character of dwelling is this sparing and preserving. ${ }^{\prime s}$ - Heidegger

In his essay "Building Dwelling Thinking," Heidegger attempts to uncover the original meaning and real nature behind the terms 'build' and 'dwell'. By characteristically tracing the roots of the terms, he explores the roles they play for human beings in the world. In the essay, he states that to dwell means to be at peace, and one can remain at this peace only when one is free from harm and danger. To understand what Heidegger means by peace and freedom from danger, one has to investigate his notions of sparing and preserving, which he believed are the key characteristics of dwelling.

\footnotetext{
${ }^{19}$ Heidegger, Martin. "Building, Dwelling, Thinking." Rethinking Architecture: A Reader in Cultural Theory. Ed. Neil Leach. (New York: Routledge, 1971), 102.
} 


\section{Sparing and Allowance}

The sparing itself consists not only in the fact that we do not harm the one whom we spare. Real sparing is something positive and takes place when we leave something beforehand in its own nature..$^{20}$ - Heidegger

Without allowance for filling, a valley will run dry; without allowance for growing, creation will stop functioning. ${ }^{21}-$ Lao-tะu

Heidegger's ideas of sparing and preserving describe ways that human beings can conduct themselves on this earth. Sparing is essentially the avoidance of harming nature. Usually, sparing has a negative connotation that one refrains from inflicting harm on it. However, he explains that sparing also implies the positive act of restoring a being to its full potentiality where humans are kept in reserve and that nature flourishes.

Lao-tzu believed that the avoidance of harming nature is to be aware of the allowance or the opportunity for growth. The way to avoid harming is to let growth take place. Lao-tzu described this concept through the observation of a valley. He claimed that it is an act of allowing that determines the chances of water filling the valley, and he believed that without this allowance, the valley would become dry. Through the observance of natural behavior, Lao-tzu claimed that the act of allowing or 'allowance' is fundamental for humans to be aware of because it allows for growth and the holistic functioning of life on the earth. Thus, as human beings are part of the world, they should take natural growth into account when they act in the world.

Both concepts of 'sparing' and 'allowance' encourage positive human behavior on earth. Lao-tzu regards growth as the basic function of nature and all things obtain their

\footnotetext{
${ }^{20}$ Heidegger, Martin. "Building, Dwelling, Thinking." Rethinking Architecture: A Reader in Cultural Theory. Ed. Neil Leach. (New York: Routledge, 1971), 102.

${ }^{21}$ Lao-tzu. Tao-Te-Ching. Vol. 307. (Shanghai: Commercial Press, 1929), Chapter 39.
} 
forms from the process of growth. The act of allowing permits humans to dwell naturally and peacefully within such growth. For Heidegger, the act of sparing permits man to dwell on one's own path, neither causing negative effects for others nor causing harm and destroying the environment. But he believed that as one dwells on one's own path, one is also dwelling on others' because all humans are considered part of the world. Both of the concepts of 'sparing' and 'allowance' are passive and active in nature. Since both concepts are considered, dwelling is interconnected with others (both to nature and other dwellers), nature and its growth thus are able to flourish in one's journey if one is able to refrain from harm or be passive by letting natural growth to take place.

\section{Care and Seeing}

To spare and preserve means: to take under our care, to look after the fourfold in its presencing. What we take under our care must be kept safe."2 - Heidegger

Always remain free from desires and you can see its wonder; always cherish desires and you can only observe its outcome..$^{2 y}$ - Lao-tzu

The idea of preserving means to protect and to maintain oneself from harm, but Heidegger explains that this can only be achieved when one cares. To care is to give attention to the surrounding environment and this care is what makes dwelling different from sheltering. Dwelling on earth is more than living in a safe and secure space, but to constantly be aware of the interaction of one's own existence and the surrounding environment. Heidegger's notion of 'care' provides extensive insight into the idea of dwelling; it is through care that we can know and understand these relationships and interactions. To 'care' allows the act of dwelling to accomplish a concrete relationship with things; the human relationship to things is crucial to

\footnotetext{
${ }^{22}$ Heidegger, Martin. "Building, Dwelling, Thinking." Rethinking Architecture:_A Reader in Cultural

Theory Ed. Neil Leach. (New York: Routledge, 1971), 103.

${ }^{23}$ Lao-tzu. Tao-Te-Ching. Vol. 307. (Shanghai: Commercial Press, 1929), Chapter 1.
} 
dwelling because things are considered as the entities that contain various properties which affect the ability of humans to dwell. In order not to accomplish the act of dwelling abstractly, giving attention or 'care' to things and the interaction of things is crucial. This is similar to Lao-tzu's idea of clarity. In the first chapter of the Tao-teching, he explains that the way to live is to be able to 'see its wonder' and not merely to 'observe its outcome'. Seeing the wonder of nature is a process that deeply considers natural growth and its transformations. Through this process, one becomes knowledgeable about the formation of things in nature and recognizes one's own existence from an understanding of the context of the place in which one lives. If one only observes the outcomes of nature, then one is limited to seeing the end results of how a thing looks, but not how a thing forms. This is important because knowing how a thing forms would permit one to find its essence but not its appearance. Both Laotzu's thoughts on 'the way to live' and Heidegger's idea of 'caring' share the same point that to live is to be able to clarify one's understanding of place through the recognition of 'wonders' and 'presencing'.

The idea of 'presencing' refers to the state of being present and aware of the full ramifications of space. The space that Heidegger refers to is called the 'Fourfold', and it contains the earth, the sky, the divinities (spirits), and the mortals (humans). The significance of these four parameters is that they are interconnected to each other. Thus, humans are part of the fourfold, and dwelling consists not only of protecting and caring for the environment, but of being cared for and protected by it. 


\section{The Fourfold and Tao}

In saving the earth, in receiving the sky, in awaiting the divinities, in initiating mortals, dwelling occurs as the fourfold preservation of the fourfold. ${ }^{2+}$ - Heidegger

Man follows the earth; Earth follows heaven; Heaven follows the Tao; Tao follows what is natural. ${ }^{95}$ - Lao-tzu

The fourfold is seen as one, and humans should thus dwell harmoniously within it by not interfering with the other three parameters. There are several key maxims that Heidegger outlines in order to maximize harmonious dwelling. For example, Heidegger writes, "saving the earth does not master the earth" ${ }^{66}$ In other words, humans should dwell on the earth in a way that does not conquer, control or harm the earth. He continues: "They receive the sky as sky" 27 The humans should let the natural law and order guide their daily journey, so they do not harm the natural order. "They await the divinities as divinities." 28 Here, Heidegger means that humans should cultivate their spiritual being, so they can have a closer relationship with one's entire existence. Another important Heideggarian phrase: "They initiate their own nature" 99 In other words, we should practice life as a process onto death, so we can begin the process of growth. Thus, to save, receive, await, and initiate are all part of way that humans should act in order to enhance the sense of dwelling. These manners convey a harmony with the parameters of the fourfold.

Heidegger's concept of the fourfold is similar to Lao-tzu's concept of the Tao, which also consists of four parameters: human, earth, heaven (sky) and the Tao (spirit).

\footnotetext{
${ }^{24}$ Heidegger, Martin. "Building, Dwelling, Thinking." Rethinking Architecture: A Reader in Cultural Theory. Ed. Neil Leach. (New York: Routledge, 1971), 103.

${ }^{25}$ Lao-tzu. Tao-Te-Ching. Vol. 307. (Shanghai: Commercial Press, 1929), Chapter 25.

${ }^{26}$ Heidegger, Martin. "Building, Dwelling, Thinking." Rethinking Architecture: A Reader in Cultural Theory. Ed. Neil Leach. (New York: Routledge, 1971), 103.

${ }^{97}$ Heidegger, 103.

${ }^{28}$ Heidegger, 103.

29 Heidegger, 103.
} 
In order to ideally situate themselves within the natural order, humans should be guided by and engage with the earth, which is in turn guided by heaven, which is in turn guided by the Tao. People should situate themselves within the four parameters so they do not interfere with one another. This guidance is similar to the way that Heidegger described how one should let the parameters guide oneself along in such a way as to not cause interference and disturbance.

Combining the two approaches, we find that dwelling is enabled when one both 'cares' and 'sees the natural wonders'. For Heidegger, 'care' is what makes dwelling different from sheltering because caring permits one to clarify one's own existence by recognizing and understanding one's surrounding environment, the fourfold, and hence one would be able to attain the feelings of safety and security while dwelling. For Laotzu, the true meaning of inhabiting nature is when one is able to see and be thoughtful about natural growth and transformation. Both of their concepts share the common thought that dwelling is about letting oneself clarify one's own existence and give meaning to the relationship between oneself and their spatial environment.

\subsection{What is it to Build?}

Before further clarifying this relationship, we should investigate the definition of what space is according to Heidegger and Lao-tzu.

\section{Space as Interval and Un-bounded}

A space is something that has been made room for, something that is cleared and free, namely within a boundary, Greek peras. A boundary is not that at which something stops but, as the Greeks recognized, the boundary is that from which something begins its presencing. ${ }^{\text {so }}$ Heidegger

\footnotetext{
${ }^{30}$ Heidegger, Martin. "Building, Dwelling, Thinking." Rethinking Architecture:A Reader in Cultural Theory. Ed. Neil Leach. (New York: Routledge, 1971), 105.
} 
Something mysteriously formed; Born before heaven and earth; In the silence and the void; Standing alone and unchanging; Ever present and in motion; Perhaps it is the mother of ten thousand things... Being great, it flows; It flowes far away; Having gone far, it returns." Lao-tzu

According to Heidegger, a space is an area within a boundary, which gives a sense of clarity to the space and the security that nothing is interfered with or obstructed. However, this boundary does not limit because it allows things in the fourfold to be present in the space; it is a constructive and productive limitation. In his conception of the fourfold, Heidegger states that things on earth grow, the path of the sun rotates, the spirit attains its presence, and humans develop; the boundary around a space, however, does not 'stop' things from progressing according to the fourfold, but lets these things present themselves within the boundaries of space.

To Lao-tzu, space itself is motionless, empty and is formed beyond human knowledge. Since things in nature are observed in a process of change, the boundary that holds these ever-changing things can have no fixed qualities. Thus, space is seen as formlessness and shapelessness. From both definitions of space, the common notion arises that space is not a boundary that has fixed dimensions but is rather an interval with ever-changing qualities.

\section{Extension and Vastness}

The space provided for in this mathematical manner may be called "space," the "one" space as such. But in this sense "the" space, "space," contains no spaces and no places. We never find in it any locations, that is, things of the kind the bridge is. As against that, however, in the spaces provided for by locations there is always space as interval, and in this interval in turn there is space as pure extension. ${ }^{s 2}$ - Heidegger

\footnotetext{
${ }^{31}$ Lao-tzu. Tao-Te-Ching: A New Translation by Gia-Fu Feng and Jane English. Trans. Gia-fu Feng and Jane English. (New York: Random House, Inc.), Chapter 25.

${ }^{32}$ Heidegger, Martin. "Building, Dwelling, Thinking." Rethinking Architecture: A Reader in Cultural Theory. Ed. Neil Leach. (New York: Routledge, 1971), 106.
} 
Greatness means vanishing; Vanishing means distance; Distance means return of greatness. $^{s 3}-$ Lao-tzu

Heidegger explains that the meaning of space is more than mathematical calculations and physical measurements, but is instead an interval that indicates the relationship between man and his position. The characteristic of this interval is that it gives an 'extensive' quality to space, which allows for measurements of distance, spans, directions, and more importantly, the possibility and flexibility of measuring space according to the relationship of one's position to other spaces. The measurement of the interval is beyond numbers and calculations, but it signifies the relationship of distance and the intimacy between man and the things within or between spaces.

Lao-tzu's description of space also conveys a sense of the beyond and a sense of the nearness measured by intervals. He believed that a space forms different degrees of distance and that this distance flows out of sight and returns back to where it starts. He sees the natural space as a 'flow' and the distance that this flow travels creates a boundary for the space. Since a flow has no limitation, the boundary of the space gives a vast quality because it does not obtain any forms or shapes but merely intervals and relationships between two positions.

From both of their understandings, we see that space essentially consists of context. The value of a space occurs when it can locate the context it provides and the relationships it creates with others. When considered as an interval, space forms connections with other spaces and draws out the intimacy between man and space.

${ }^{33}$ Lao-tzu. Tao-Te-Ching. Vol. 307. (Shanghai: Commercial Press, 1929), Chapter 25. 


\section{Thinking and Mind}

If all of us now think, from where we are right here, of the old bridge in Heidelberg, this thinking toward that location is not a mere experience inside the persons present here; rather, it belongs to the nature of our thinking of that bridge that in itself thinking gets through, persists through, the distance to that location..$^{\text {st }}$ - Heidegger

Without going outside, you may know the whole world. Without looking through the window, you may see the ways of heaven. The farther you go, the less you know. Thus the sage knows without traveling; He sees without looking; He works without doing. ${ }^{s 5}$ Lao-tzu

Man's relationship to space is not merely an experience of the present, but also contains past experiences which involve thought processes. Heidegger demonstrated this point by outlining the process of connecting one's experience to distant locations without the necessity of physical travel, but through thinking. Thought permits one to experience continuously beyond the spatial interval, from one location to another. $\mathrm{He}$ believed that the connection between two spaces involves human participation, and human participation involves thinking; thus, thinking forms a junction between one place to the other.

Heidegger's view is similar to Lao-tzu's on mind and space. According to Laotzu's description, knowledge of the sage is what connects him to the outer world. The intimacy between man and space is not necessarily defined by the experience of physical traveling in-between spaces, but it can be accomplished through the experience of thinking and knowing. The sage is able to accomplish without acting because his mind participates along with what he knows, thus he is able to communicate to the outer space without going outside. Lao-tzu believed that real living involves one's mind and an understanding of what nature presents and offers.

\footnotetext{
${ }^{34}$ Heidegger, Martin. "Building, Dwelling, Thinking." Rethinking Architecture:A Reader in Cultural Theory Ed. Neil Leach. (New York: Routledge, 1971), 108.

${ }_{35}$ Lao-tzu. Tao-Te-Ching: A New Translation by Gia-Fu Feng and Jane English. Trans. Gia-fu Feng and Jane English. (New York: Random House, Inc.), Chapter 47.
} 
For both Heidegger and Lao-tzu, the relationship between man and space involves thinking, but this conception is neither representational nor calculated, but subjective. In other words, human thinking is influenced by past experiences, which affect the perception of space, and hence affect the relationship to the world. But, most importantly, the understanding of space cannot be thought of in terms of calculated measurements, but understood as a spatial interval that allows individuals to flexibly inhabit a space beyond their physical location.

\section{Building as Letting Dwell and Acceptance}

The nature of building is letting dwell...only if we are capable of dwelling, only then can we build. ${ }^{s}$ - Heidegger

Accept and you become whole; once whole, the world is as your home..$^{37}$ Lao-tzu

According to Heidegger, the built environment is crucial in dwelling because it supports and reflects a person's way of situating in the world. Building is a grouping together of spaces to enhance the sense of dwelling. From the previous section, we learned that dwelling is letting oneself clarify one's own existence and emphasizing the existential relationship one has to space; thus, building as a way to ground this sense of dwelling has to accomplish this act of letting oneself and the world be. This letting permits the built environment to attain the presence of oneself within nature.

On the other hand, Lao-tzu did not mention anything specifically about building, but his idea on the manner of living is quite close to Heidegger's idea of 'letting dwell'. Lao-tzu believed that the way to concretize the sense of living is to become part of

\footnotetext{
${ }^{36}$ Heidegger, Martin. "Building, Dwelling, Thinking." Rethinking Architecture: A Reader in Cultural Theory Ed. Neil Leach. (New York: Routledge, 1971), 108.

${ }^{37}$ Lao-tzu. Tao-Te-Ching:A New Translation by Gia-Fu Feng and Jane English. Trans. Gia-fu Feng and Jane English. (New York: Random House, Inc.), Chapter 22.
} 
nature by accepting what nature presents. The real sense of living is for one to feel like home, and this can be achieved only when one is able to accomplish the act of acceptance.

The aim of a building is to enhance the particular human experience and the built environment has to become sensitive to these experiences. The way to manifest this idea is to let oneself find the intangible aspects of the build environment, so it permits oneself to see, understand and to think within one's living.

\section{Bringing Forth and Finding the Intangible}

For building brings the fourfold hither into a thing, the bridge, and brings forth the thing as a location, out into what is already there, room for which is only now made by this location. ${ }^{s s}$ - Heidegger

Moulding clay into a vessel, we find the utility in its hollowness; Cutting doors and windows for a house, we find the utility in its empty space. Therefore the being of things is profitable; the non-being of things is serviceable. $.^{39}-$ Lao-tzu

For Heidegger, letting dwell is to allow things to be revealed, and also to 'bring forth' their being. Heidegger believed that they are concealed, such as the growth of plants on earth, and the hidden laws that guide the path of the sun. These are the characteristics of the fourfold that affect the interconnected relationships between humans and their position in space. The process of creating a space must thus focus on the context of the things concealed in the fourfold, and thus Heidegger believed that the idea of 'bringing forth' is crucial in the process of making spaces as places.

In contrast with Heidegger, Lao-tzu did not give any specific suggestions on how the process of creation can proceed, but he did raise the importance of engaging with the intangibles of space. The basic idea of Lao-tzu's thinking is that once tangible fulfillment is reached, the possibilities for growth and change are limited; one should

\footnotetext{
${ }^{38}$ Heidegger, Martin. "Building, Dwelling, Thinking." Rethinking Architecture: A Reader in Cultural Theory Ed. Neil Leach. (New York: Routledge, 1971), 110.

s9 Lao-tzu. Tao-Te-Ching. Vol. 307. (Shanghai: Commercial Press, 1929), Chapter 11.
} 
thus always consider the intangibilities, which leads to the potential for further development. He pointed out that the Void, conventionally regarded as negative, is a vital part of the whole because it is always capable of being filled by a solid. If a house is without doors and windows, the empty space of the house will not be utilized.

Thus, the process of creating space should address this behavior of letting the intangibles appear within what is present in the natural environment. For instance, a building design could focus on the interplay between natural sunlight and its shadows; hence the quality of a space would be transformed along with the natural rhythms of the sun's path. The value of a space lies in this act of bringing forth because a space is created within the natural environment, and the things within it are governed and influenced by the hidden natural order. Humans are thus encouraged to heed the silence of the hidden truths by seeking the intangibles and bringing them out from their 'concealedness' in order to provide the widest range of opportunities for individuals to dwell and think.

\subsection{Essence of Dwelling: Learning and Following the Natural Unity}

The real dwelling plight lies in this that mortals ever search anew for the nature of dwelling that they must ever learn to dwell..$^{\text {to }}$ Heidegger

Harmonize with its light, Sympathize with its dustiness. This is the way of natural unity." $-L a o-t z u$

Heidegger summarized his essay, "Building Dwelling Thinking", by stating that real dwelling for humans is about learning and adapting to the natural environment because humans are part of the world. The way to give clarity to one's own existence is for one

\footnotetext{
${ }^{40}$ Heidegger, Martin. "Building, Dwelling, Thinking." Rethinking Architecture: A Reader in Cultural

Theory. Ed. Neil Leach. (New York: Routledge, 1971), 109

${ }^{41}$ Lao-tzu. Tao-Te-Ching. Vol. 307. (Shanghai: Commercial Press, 1929) Chapter 56.
} 
to learn to dwell through 'caring' for and attuning to nature, especially to the things that are concealed. As Heidegger suggested, the way for one to learn is when one does not interfere with the fourfold by not conquering the earth, cultivating the spiritual being and by practicing life as a process. The way of learning also changes over time for different people. Thus, humans must learn to dwell by adapting to their own specific place and time, and with thinking that helps one to understand and clarify one's identity in a particular place of the world.

According to Lao-tzu, the way to learn is to follow and engage with the natural law and order in order to attain unity with nature. The way to attain such unity is not merely to 'harmonize', but one should 'sympathize' or actively engage with feelings and understandings of the natural order. As mentioned earlier, the real sense of living is to 'see the natural wonders' which involves knowing the transformations of nature and responding to them with one's mind.

What lies in common in both of their concepts is that the essence of dwelling is primarily subjective and has to be cultivated and understood by oneself. Dwelling must allow communication between the outer world and the inner self. It is a learning process of exploration, discovery, understanding and interpretation of natural materials, forms, orders and phenomena. The accommodation of this dwelling can be incorporated into design and architecture; indeed, buildings should engage with the forces and phenomena of nature, reveal its order, and make this order part of the dwellers' own. 


\section{Chapter Four: Light and the Essence of Taoism}

Use the light that is within you to regain your natural clearness of sight ${ }^{22}$ Lao-Tzu

According to Lao-tzu, the way to live is to attain unity with nature by following and engaging with the natural order. By following he means letting one's habitual experiences be led by natural rhythms, and by engagement, he means letting one's mind understand and connect with that order. Thus, the true sense of living occurs when one is able to cultivate one's mind within the natural environment through exploring and understanding its wonders. Taoists believe that this natural order is governed by the two basic and distinctive forces of Yin and Yang. They combine to create the fundamental principle governing all things whereby everything can be divided into mutually opposing and independent elements, and together they form one unity.

This concept can be exemplified by observing the rhythms of the sun's path. The sun orbits around the earth and continuously divides it into day and night. During the day, the sun gives off light that provides energy to all living things on earth; at night, the living things are at rest in darkness. Although day and night are in opposition, they are in fact dependent on each other because they are followed by and give meaning to each other; they are distinct, but seen as one entity. Since the rhythm is continuous and consistent, it generates order and patterns that structure the earth into predictable seasons, weather patterns, and conditions of light. Consequently, since these rhythms and patterns are cyclical, Taoists believe that human lives are similarly part of this cycle. Life is thus not defined as much by beginnings or ends, but as part of

\footnotetext{
${ }^{42}$ Lao-tzu, Tao Te Ching, quoted in Hastings. Encyclopedia of Religion. (New York: Charles Scribner's Sons. 1908-26, vol.8) 51.
} 
the endless cycle of death and rebirth of all life. The entire natural world is governed by this movement, such that trees decay in the winter and bloom again in spring. Thus, all life on earth is seen as part of the process of growth according to the temporal cycle.

To truly experience the process of growth, one has to see it within the context of sunlight because all growth requires the light of the sun. It is also the fundamental source for the habitual experiences that permit one to learn, explore and understand the world. For instance, people who live on the east side of a building experience early sunrises, while people who live on the west side typically experience late mornings. Thus, one's sense of time and space are affected by the way that one experiences light, and this strongly influences the way that one understands and perceives the surroundings.

According to Lao-tzu, ideal living should allow one's mind and sight to merge, see the truth and attain a real sense of life. He believed that human beings should cultivate inner perfection and realize their original natures. The way to cultivate inner perfection cannot be isolated from the experience of light because one's mind is subconsciously influenced by sight. Moreover, sight cannot be isolated from sunlight. Through vision and sensation, one learns about and understands the surrounding space. Observing and responding to changes in light is thus in fact a way of manifesting the essence of living through learning, by exploring and understanding natural growth. Through the following philosophical concepts of Taoism, one may further understand how light can merge mind and sight and manifest the essence of dwelling. 


\subsection{Vastness}

Greatness means vanishing; Vanishing means distance; Distance means return of greatness. ${ }^{* 3}-$ Lao-tzu

According to Lao-tzu, the spaces that contain the quality of vastness do not necessarily obtain their value from any significant form or shape, but from the measureless spatial intervals that define one's relationship to space. Vastness implies infinity, which offers a sense of freedom to experience life. Furthermore, one can achieve this liberty only when one connects their inner self with the outer environment.

One way to bring such a quality into a space is to permit sunlight to enter and let its transformations shape a space according to the infinite changes in lighting conditions. Light travels, bounces, is filtered, absorbed, and reflected from all things; these properties greatly affect the quality of a space, and hence the experience or awareness of this space. Consequently, the question of how to bring sunlight into a space such that it offers a sense of liberty and freedom becomes a crucial issue.

Light allows sight and sensation, which helps to orient and clarify a location within nature because different places have their own patterns (i.e. speckled, smooth), types of light (i.e. intense, filtered, weak), and colours. Through light, one is able to communicate with one's sight and mind. Looking back at the previous example of Tadao Ando's “The Annex of Naoshima Contemporary Art Museum" (Figure 3), the way he framed the opening of the roof allows the image of the sky and its light to interact with the inhabitants' minds. Through the frame, the ever-changing light turns the sky into a changing image that stimulates one's mind. By observing the transformations, one is able to locate one's position in relation to the vastness of the sky.

${ }^{43}$ Lao-tzu. Tao-Te-Ching. Vol. 307. (Shanghai: Commercial Press, 1929), Chapter 25. 
The actual perspective of the observer is able to go beyond the simple distance between the ground and the roof; indeed, the distance becomes an interval that measures the relationship between man's position in the museum and the vastness of the sky. This massive opening permits one's mind to extend beyond the physical dimensions of the space and experience the quality of vastness by stimulating the mind through light and vision.

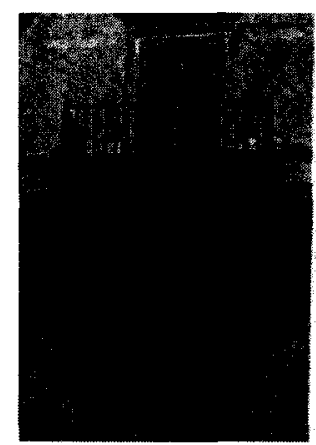

Figure 15: Window in Rome, Italy

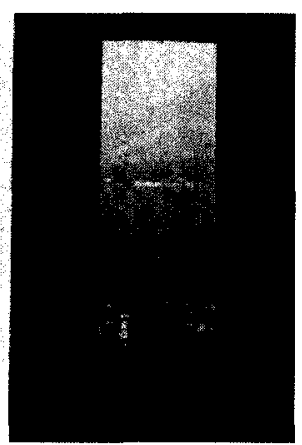

is designed as a tall, rectangular shape that is a human-scaled opening allowing

sunlight and unblocked views into the unit (Figure 15). When one stands in front of the window, one is well-situated to comprehend the vastness of the space beyond. More importantly, more than an enhanced view, it also reveals an expressive and cultural attitude towards light that extends beyond the practical need for illumination. This tall casement window responds to both climatic and social rituals as it opens fully for ventilation and allows one to go out on the balcony and participate in the life of the street below. The exterior shutters are louvered to block some sunlight and heat, while still allowing for ventilation. The bottom sections of the shutters flip up to increase ventilation and allow one to see the street. The solid wood shutters on the interior provide a third line of defense against light, heat, and sound, and the resulting dark interior also conveys a psychological sense of coolness. This window allows the dweller 
to experience light through a personal, sensational response and thus allows light to reveal the spatial qualities of the unit at a specific space and time.

Man's awareness of his existence within a space is revealed through the presence of light, and more precisely, through the perception of light in a space. When a space is capable of creating a dialogue between one's mind and the expansive outer environment, then the vastness of the space is revealed, and one acquires a greater sense of freedom.

\subsection{Incompletion}

Completeness without completion is useful. Fulfillment without being fulfilled is desirable. ${ }^{H}$ - Lao-tzu

Lao-tzu believed that the concept of Incompletion is fundamental to human experience because it opens up possibility for natural growth to become part of the process of living. Hence, for a space to accommodate one's living it has to take consideration into natural change as part of the design, such as accepting that sunlight warms up a space during the day, and then using that heat later to respond to the cold climate. By allowing the temporal rhythms of the sunlight and its heat to become part of the design considerations, a space becomes adaptable and responsive to natural growth, while also being in a state of incompletion.

For example, adaptable spaces can be designed through the use of light in order to transform uncomfortable conditions within a space. This "Koshino House" (Figure 16), Tadao Ando designed a few slots in a wall that allow sunlight to penetrate into the building. Even the entrance of small beams of light into a building on a cold winter day can add a sense of warmth, liveliness and sparkle to the interior. As another example is Ando's "Museum of Literature" (Figure 17), suggests that the way light and water

\footnotetext{
4. Lao-tzu. Tao-Te-Ching. Vol. 307. (Shanghai: Commercial Press, 1929) Chapter 45.
} 
interact when light hits a moving surface of water may create a sense of cooling in hot climates. His design strategy was thus to integrate water and light into the design in order to lessen the glare of direct sunlight, while also providing a visually cool yet light-filled setting.

Light not only conveys visual messages within architectural spaces, but also produces a physiological reaction because of its heat. The use of light in a building affects feelings of comfort in relation to the thermal variables within different climates. There are thermal realities associated with light and buildings, such as heat loss and heat gain between the temperature outside and inside. A building should provide both comfort and delight while responding to these thermal realities.

The design of Alvar Aalto's "Seinajoki Library" (Figure 18) uses light in a way that celebrates the climatic conditions of Finland. The library has a large area of glazing that admits light into the main book stack and south facing reading area. Windows are placed at the top of a high wall with a curved ceiling. This area effectively shields people in the library from losing their body heat to the cold, since the glazing is kept at a distance from the occupants. Also, a sunshade redirects sunlight in the summer when the sun is high, while still allowing some of the light to reach the interior by being bounced from the outside of one slat to the inside of the one above. In the winter time, sunlight from very low angles is admitted into the building to play on the columns that support the outer section of the ceiling and reading counter. The entire curved perimeter section of the library works as one great light fixture that controls the admission of light into the library without imposing too great a thermal load on the building, either for winter heating or summer cooling. 
Light not only provides illumination, but can do so in a way that enriches one's experience of heat. Its conditions change constantly from day to night and winter and summer; by incorporating light into a design, a space can allow these changes to become part of the inhabitants' living experience. It can be used as thermal energy to warm up a space when it is cold and also as a visual cooling effect when it is hot. The responsive design scheme would permit light to complete one's habitual experiences by balancing and being responsive to the ever-changing climate, hence providing comfort to the living environment.
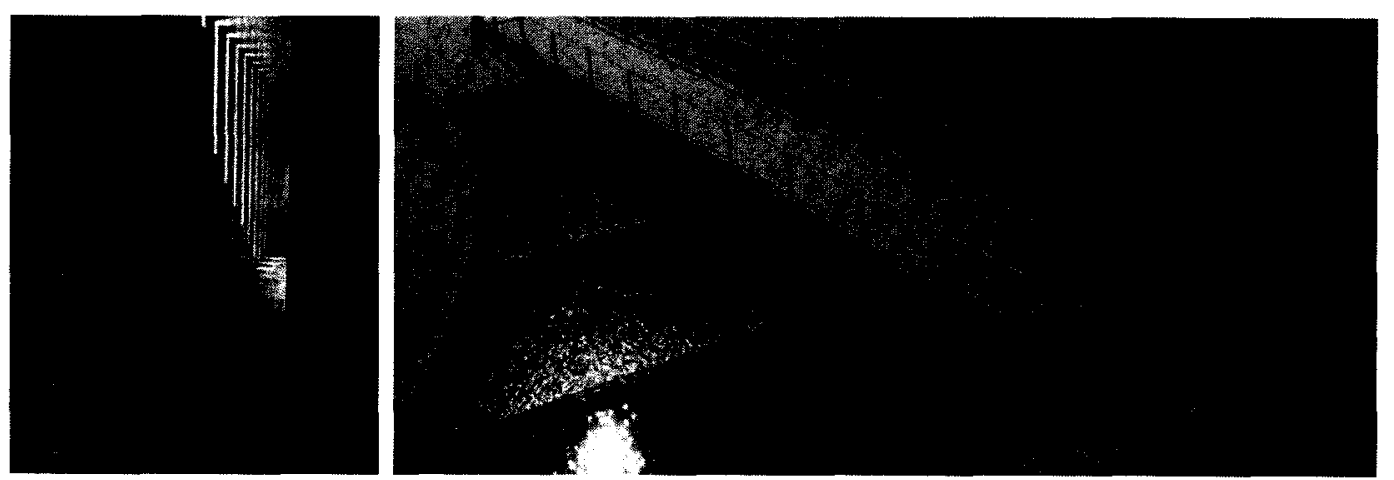

Figure 16: Koshino House, Figure 17: Museum of Literature, Japan 1991 Japan 1981
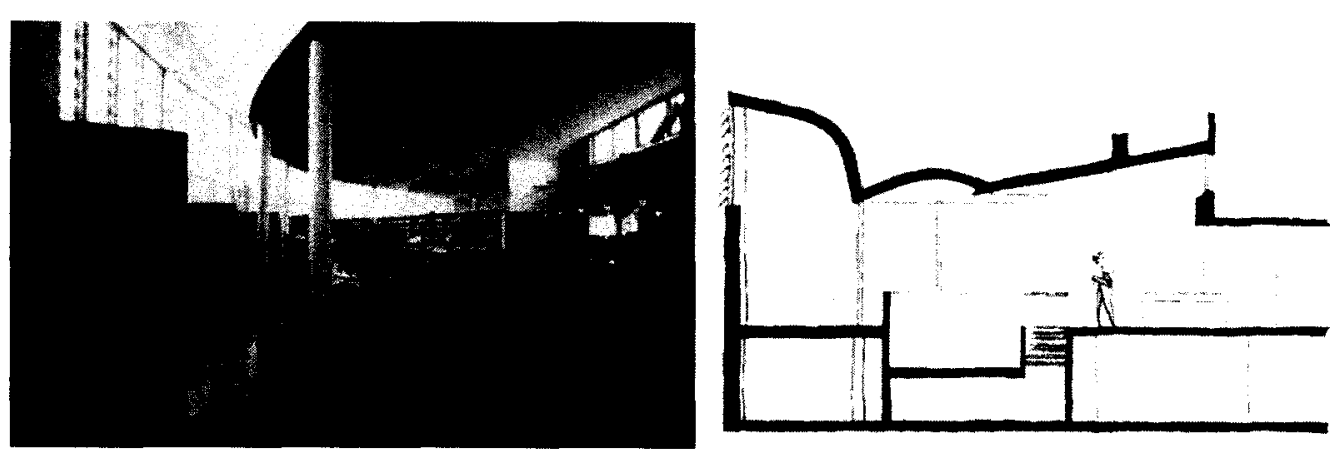

Figure 18: Seinajoki library, interior and sectional drawing, Finland 1965 


\subsection{Formlessness}

The finest has no shape $e^{15}-$ Lao-tzu

Our eyes are constructed to enable us to see forms in light ${ }^{t 6}-$ Le Corbusier

The concept of Formlessness not only implies the adaptable and flexible qualities of living spaces, but when applied to light, it can mean the creation of unexpected surprises for the dwellers of a space. We perceive spaces by their form and forms are perceptible by light. The relationship between light and form is thus inseparable; and indeed, light can enrich forms at the same time as it can decompose them.

Tadao Ando's "Church of the Light" exemplifies that idea that light can enrich forms (Figure 19). The church is simply designed as a bare concrete box with a wall cutting through it at a 15 degree angle which is oriented in a specific relation to the sun and the sunlight emphasizes the form of the room through the very thin cruciform cutout, referred to earlier, in the wall. The beams of light that penetrate through the cross change in relation to the changes of the sun, and the form of the space is shaped by the variability of light. This reciprocal relationship between the light source and the form also informs our tactile experience. This work exemplifies the fact that one's perception of a space can be heightened by clarifying the relationship between the light and the shape of a building.

On the other hand, light seemingly decomposes forms when form and light are juxtaposed and interact in other specific ways. For instance, strong patterns of light and shadow can decompose our perception of form. In Le Corbusier's "Chapel of Notre Dame-du-Haut" (Figure 20), the interior is very dim because there are only small

${ }^{45}$ Lao-tzu. Tao-Te-Ching. Vol. 307. (Shanghai: Commercial Press, 1929) Chapter 41.

${ }^{46}$ Le Corbusier. Towards a New Architecture. Trans. Frederick Etchells. (New York: Dover Publications, INC., 1986) 8. 
openings that allow daylight into the church. These openings are either deeply baffled or adorned with coloured glasses that filter the light as it passes through the south wall. The contrast between the daylight and the dim interior is great enough that the edges of the splayed openings and the tones from light to dark are blurred so as to conceal the exact form. When one enters the church, the space appears dark and the surfaces are vaguely illuminated by bits of coloured light which only allow one to perceive varying shades of gray. The materiality of the forms is denied by the way that light and shadows play over them. The light has thus diffused the edges and decomposed the form. Light decomposes forms, blurs man's vision and disturbs the way one perceives spaces; on the other hand, light enriches forms and clarifies vision. This playfulness of light enriches the qualities of living spaces as it can sometimes give a quality of fuzziness and sometimes clarity. Architecture needs to further address the way that one perceives light, and hence evoke emotions by incorporating the unexpected surprises and wonders that nature has to offer. It needs to flexibly apply light into a design in order to address the different needs of a space. 

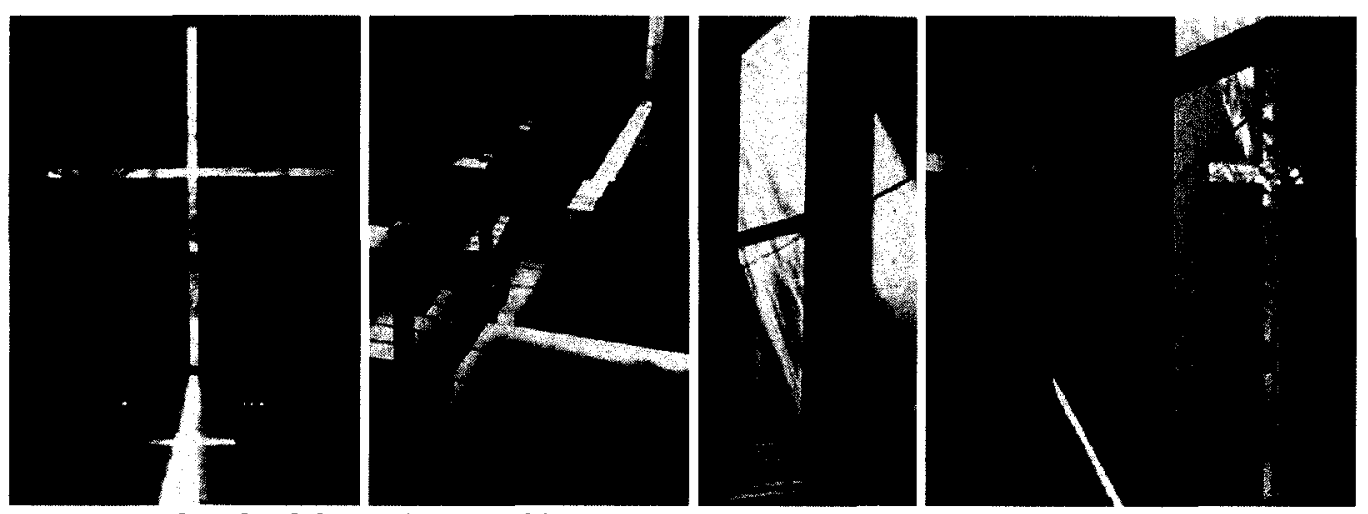

Figure 19: Church of the Light, Ibaraki Japan

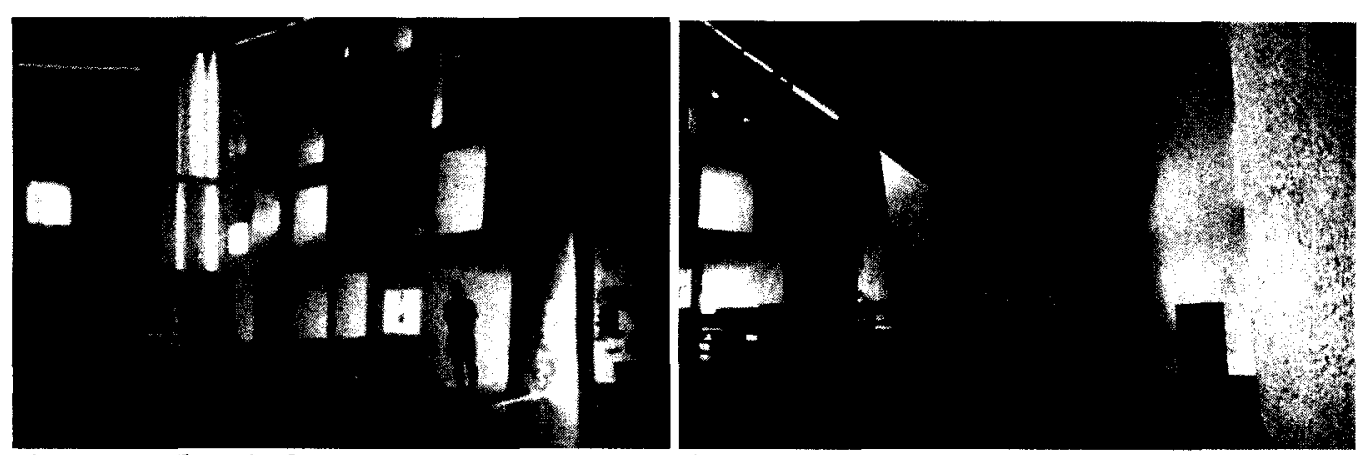

Figure 20: Chapel of Notre Dame-du-Haut, Ronchamp France 1955

\subsection{Oppositional Balance}

The way to acquire positive is to contain negative. ${ }^{*}$ - Lao-tzu

To Lao-tzu, all things on earth are created in opposite pairs: "When the people of the earth all know beauty as beauty, there arises the recognition of ugliness; when the people of the earth all know the good as good, there arises the recognition of evil." $48 \mathrm{He}$ pointed out that if one wants to recognize one thing, one has to compare with its opposite; and only through comparison can one gain the recognition of the things

\footnotetext{
${ }^{47}$ Lao-tzu. Tao-Te-Ching. Vol. 907. (Shanghai: Commercial Press, 1929) Chapter 28.

${ }^{18}$ Lao-tzu. Tao-Te-Ching: A New Translation by Gia-Fu Feng and Jane English. Trans. Gia-fu Feng and Jane English. (New York: Random House, Inc.), Chapter 2.
} 
unseen. To the Taoist, the act of living must permit such recognitions to be revealed in the everyday experience in order to permit one to achieve a balanced way of life.

In reality, the everyday experience of light allows one to participate in the balanced system of nature. Light offers many dual qualities for living, such as the interaction between light and materials which can both emphasize and mute the inherent properties of materials. Materials are crucial to understanding light in architecture because they can be greatly enhanced as light is absorbed by, reflected from and refracted through various materials. Indeed, the essential structure of a work of architecture is revealed by different qualities of light and how these qualities are presented through the treatment of materials.

For example, in the "Galli Tomb" (Figure 21), Carlo Scarpa used stone and light as the only materials in his design. He portrays the meaning of human existence on earth between life and death through the use of light and the textures of the stone. The tomb is a simple rectangular volume of stone, roughly sculpted with a T-shaped opening at the center; a narrow vertical band runs smoothly down from the top as it meets the T-shaped opening. The opening is closed by a slab of white granite, and flowers grow out from the opening towards the light. Scarpa's choice of white granite and the use of the contrast between the rough and smooth textures of the stone, helps to intensify the mystery of the entire form. Light is revealed differently on the smooth surface, where it appears brighter than on the rough areas, as if the tomb had been corroded by time. When different intensities of light reflect off the textures, the work seems composed of many different forms. This interplay is subtle and not immediately noticeable because of the essential simplicity. However, as different light illuminates the work, the forms and significance of the composition emerges. 
Aside from emphasizing materiality, light also helps to reveal and conceal structural systems in relation to the purpose and function of spaces. In Antonio Gaudi's "Library of Finca Guell" (Figure 22), light reveals the structural order of the space as it is released eloquently into the library. In the main reading room, windows are set between the arches at the ends of a parabolic vault. As daylight enters in between these arches, they block and allow light to enter according to their shape and position; hence, the structural module provides a varied rhythm of light and dark. The relationship between this structure and light gives clarity to the space and offers a cheerful reading environment to the occupants.

Light certainly reveals structure, but sometimes structure is hidden purposefully. In the "Chapel of Notre Dame du Haut" (Figure 23), Le Corbusier treated light as one of his architectural materials in the construction of the structure and the space. The roof sags in the middle which suggests weight, yet along the top of the thick masonry walls that one assumes are built in order to support the roof, there is a slit between the wall and the ceiling, which allows light to enter. The surprising passage of light contradicts one's expectation of the structure. In fact, the roof rests on columns of reinforced concrete located inside the thick rubble walls. Le Corbusier treated light as the inspiration for structural innovation, and his interplay between patterns of light and rhythms in the structure obscures the understanding of the space, thus inspiring the occupants' imagination.

Light thus offers dual qualities for everyday experience. It can interact with materials to enrich the spatial qualities of a structure, and it can also reveal and conceal the architectural structure to enhance visual perception and extend spatial boundaries. 

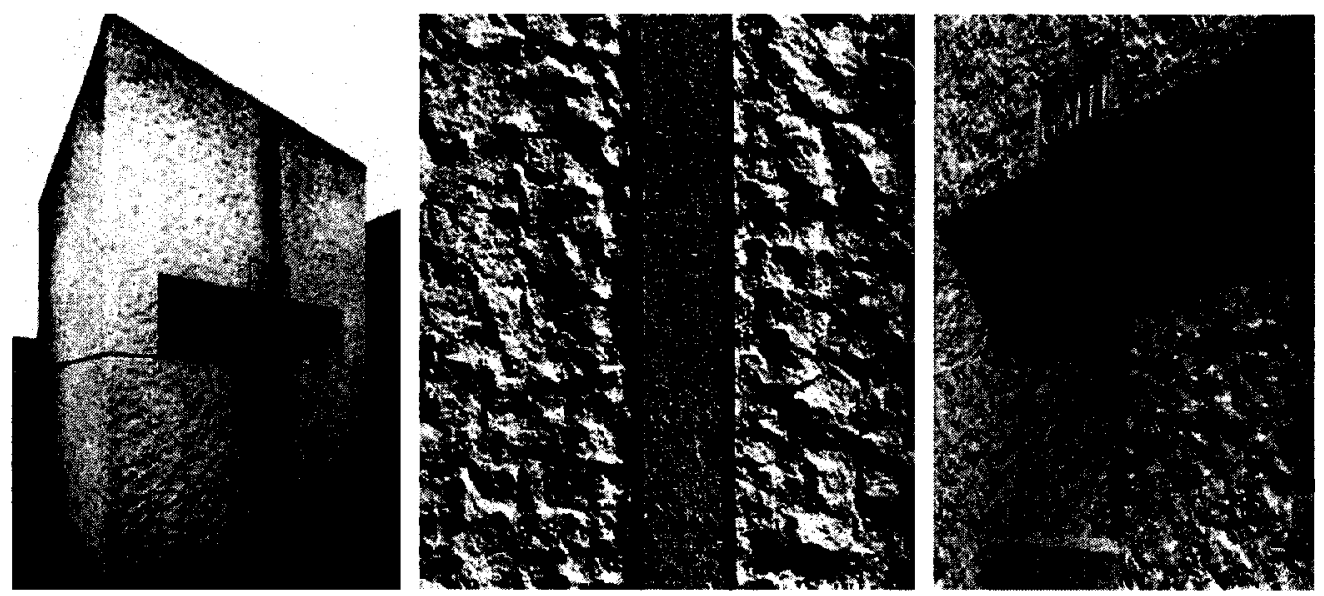

Figure 21: The Galli Tomb, Venice Italy 1978

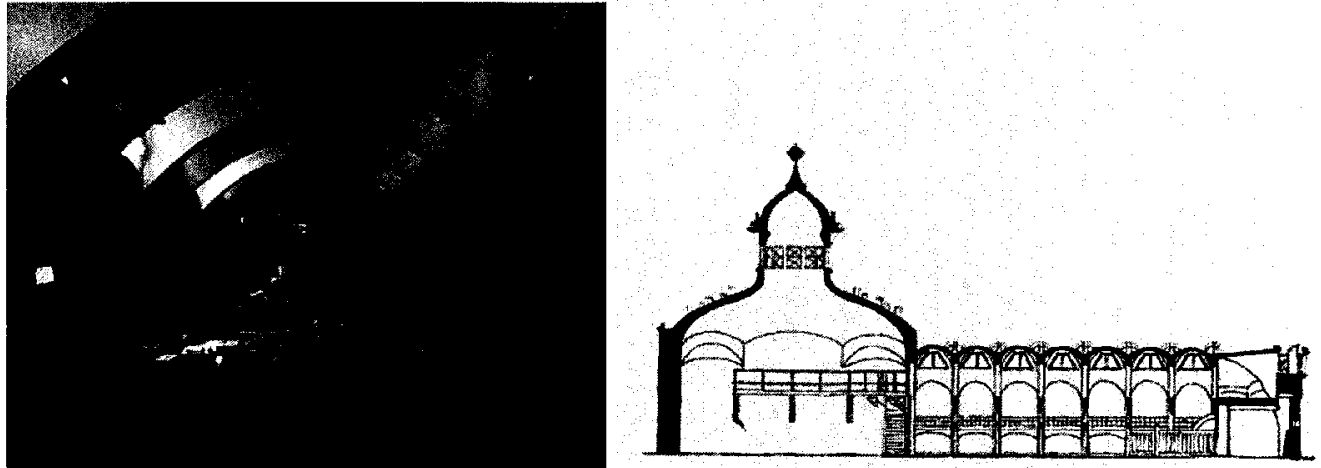

Figure 22: Finca Guell, interior \& sectional drawing showing the structural system, outside Barcelona 1887
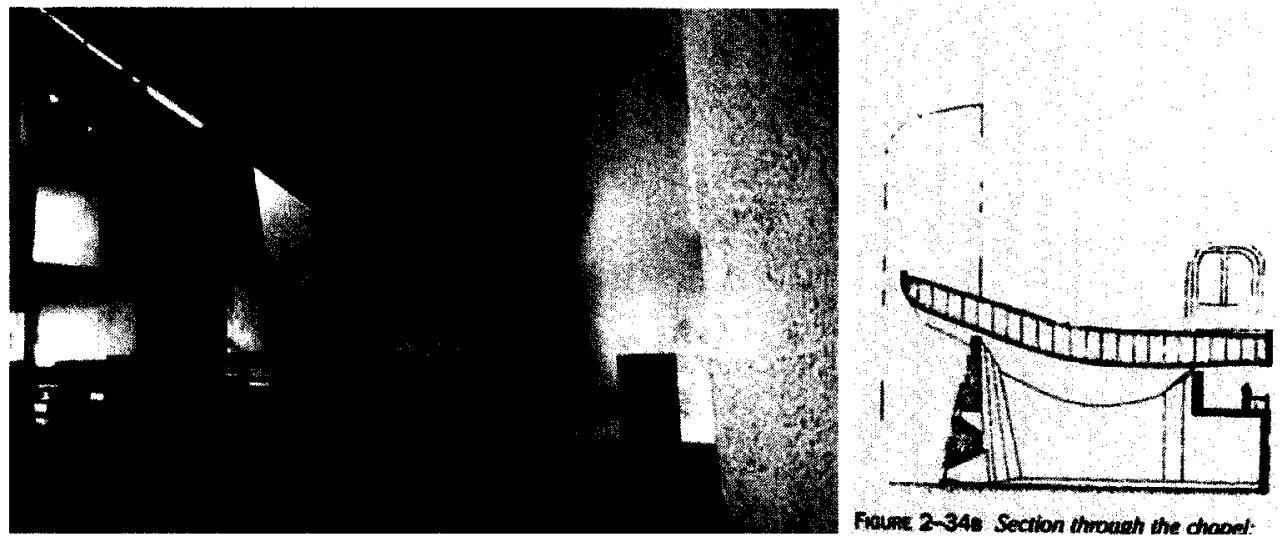

Figure 23: Notre Dame du Haut, Ronchamp France 1955 


\subsection{Boundary-less}

The greatest has no boundary.

The concept of Boundary-less implies a sense of a borderless and free environment for living. The attainment of such a situation depends upon the perception of the surrounding space. The human sense of space is dependent upon the ways that light reveals enclosure and form to us. One perceives different qualities of space when lighting conditions change; thus the perception of space is intertwined with light.

In the 1960s, James Turrell created a set of spatial installations (Figure 24) that explore the interaction between light and space. Turrell's light spaces have no referential character; they are places for perception where the experience of light and place is the work itself. The installations are seen at first to be flat planes of light on a wall, but in fact are three-dimensional spaces. Light seems to materialize into something that is beyond physical existence, and the interpretation does not always match the reality of the physical form. Turrell thus makes us aware of both the power of light and of human perceptual abilities.

Light in architectural space can emphasize both connection and separation. Visually, light defines the difference between inside and outside. It can be borrowed from a perimeter space and delivered or guided into an interior space, so that the perimeter space acts as both visual and perceptual access across a boundary. Light can either be a connector or a barrier that is incorporated into the design process.

Perimeter space as a connector can be made in many possible ways, such as the careful framing of views, the use of consistent patterns of light, the incorporation courtyards as

\footnotetext{
${ }^{49}$ Lao-tzu. Tao-Te-Ching. Vol. 307. (Shanghai: Commercial Press, 1929), Chapter 41.
} 
filters of light, and the expansion of perceptual space through reflection. The most important concern is to create a smooth transition between inside and outside.

Ando's "Church on the Water" (Figure 25) is set on a mountain plateau on the island of Hokkaido, Japan. In spring and summer, the area is covered with greenery, but in winter it is white and covered in snow. In his design Ando has carefully framed these views, bringing them into the space. He framed a massive opening on a main wall, which can slide open in a way that exposes the church to the pond and the wilderness beyond. This space allows viewers to see the distant view and create a sense of great distance; the space thus inspires the viewer's imagination. The idea of inside and outside becomes less defined as the interior and landscape merge into one space.

Light can also suggest movement if its patterns are consistent, creating rhythms and a sense of infinite space. In Ando's "Fabrica" (Figure 26) and "Komyo Temple" (Figure 27), the interior spaces seem to extend continuously into the exterior because the defining patterns of light are consistent and thus unify the space.

In urban settings, openings for daylight can be centered around courtyards. In Tadao Ando's “Kidosaki House" (Figure 28), plants are encouraged to grow over the openings of the courtyard, and they help filter light into the space. Over time, these plants change colour and form. In other words, this courtyard serves as a giant daylight fixture that filters and colours light between spaces and helps to connect interior and exterior space.

Another way of unifying spaces is to use a reflective medium such as water to work with the light. Tadao Ando's "The Annex of Naoshima Contemporary Art Museum" (Figure 29) demonstrates this concept through the pool of water that brings the sky's brightness onto the earth. He also created a roof opening, referred to earlier, 
above the reflecting pool, which gives the impression of extending the interior space into the sky; at the same time, the water reflection below the opening brings the sky within the space. This idea of extension and containment allows the space to grow outwards and suggests a unification with nature.

In addition to its role as unifier, light can also act as a separator of inside and outside. Separation can be used as a means to soften the harsh glare of light in certain climates, and it can also provide a metaphorical separation between inside and outside in order to enhance holy or meditative spaces. In Tadao Ando's "Church of the Light" (Figure 30), the wall and its opening emphasize separateness in such a way that people are prevented from obtaining an entire view of the outside, but nonetheless catch glimpses of the view; conversely daylight penetrates slowly and precisely into the dark space. This angled wall is also meant to keep people away but still allows access to the wonders and mysteries of the site.

In the "Unesco" building (Figure 31), Ando treated the concept of separation in a different way. He created only a slight opening in the roof around a reinforced concrete cylindrical structure allowing a slight, but powerful light to penetrate into the space. The light that penetrates through this slit appears incredibly strong due to the contrast with the dark interior space; the light seems to outline the shape of the roof and generates a strong geometrical form. Although the space is small, the intense lighting suggests there is another space or realm beyond the physical. On one level, the lighting separates the interior from the exterior space by giving no views of images; however, the light connects with the occupant's inner realm, encouraging serenity and peaceful meditation. 
Experiencing space through light in an architectural setting involves one's complete perceptual and sensorial system. The above architectural examples have shown the possible ways that light can be treated and can act as a visual and perceptual access route between boundaries, hence emphasizing the dweller's relationship to the surroundings.
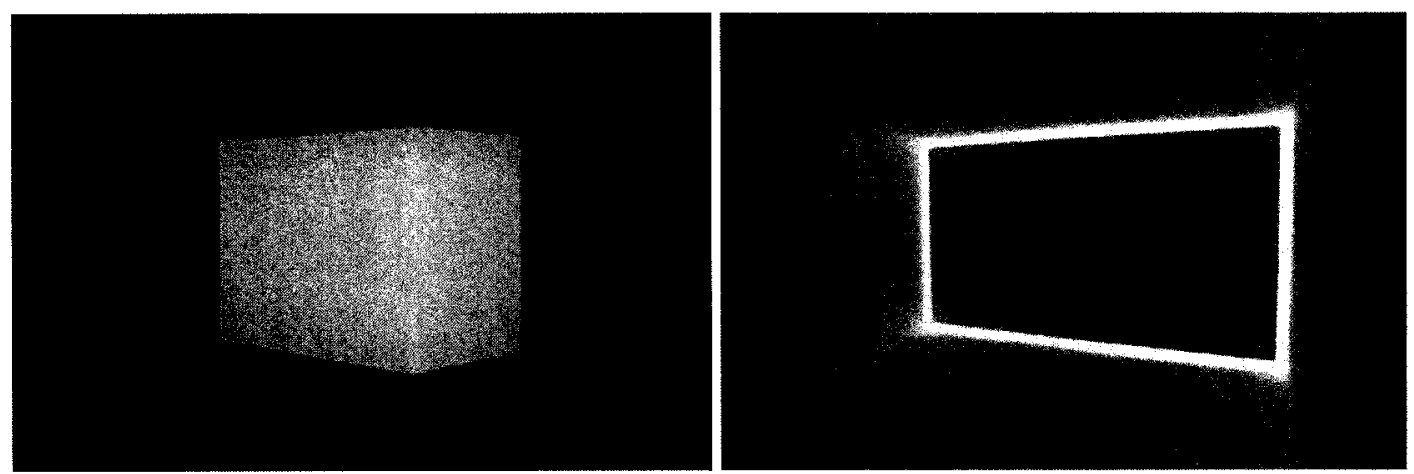

Figure 24: Afrum 1967, Installation Whitney Museum of American Art/ Raemar, 1969, Installation Whitney Museum of American Art
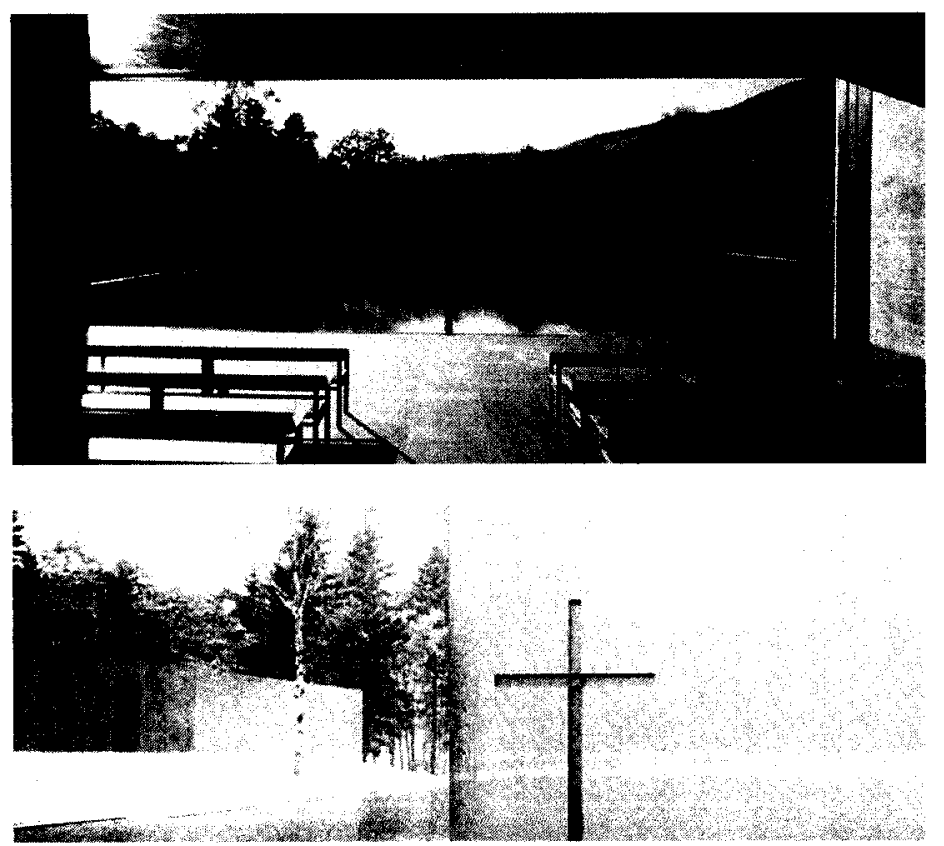

Figure 25: Church on the Water, Japan, 1988 


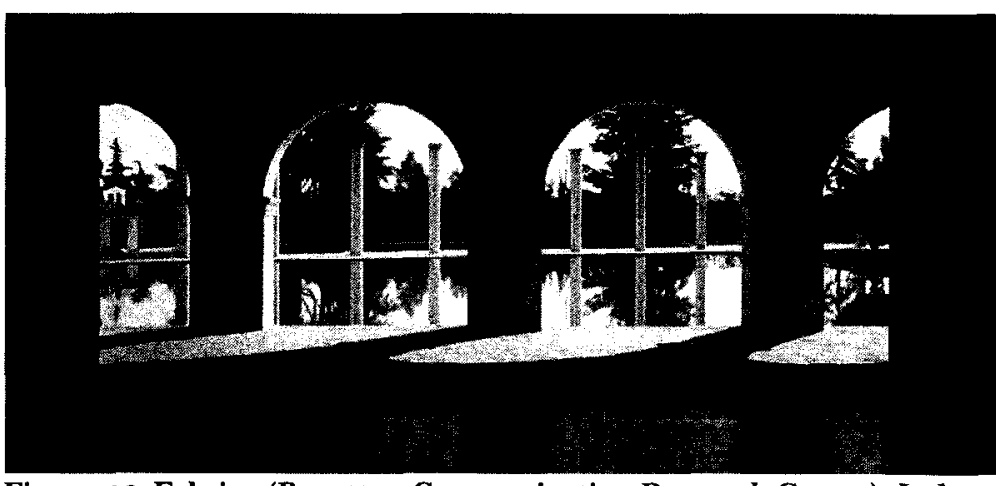

Figure 26: Fabrica (Benetton Communication Research Center), Italy 199
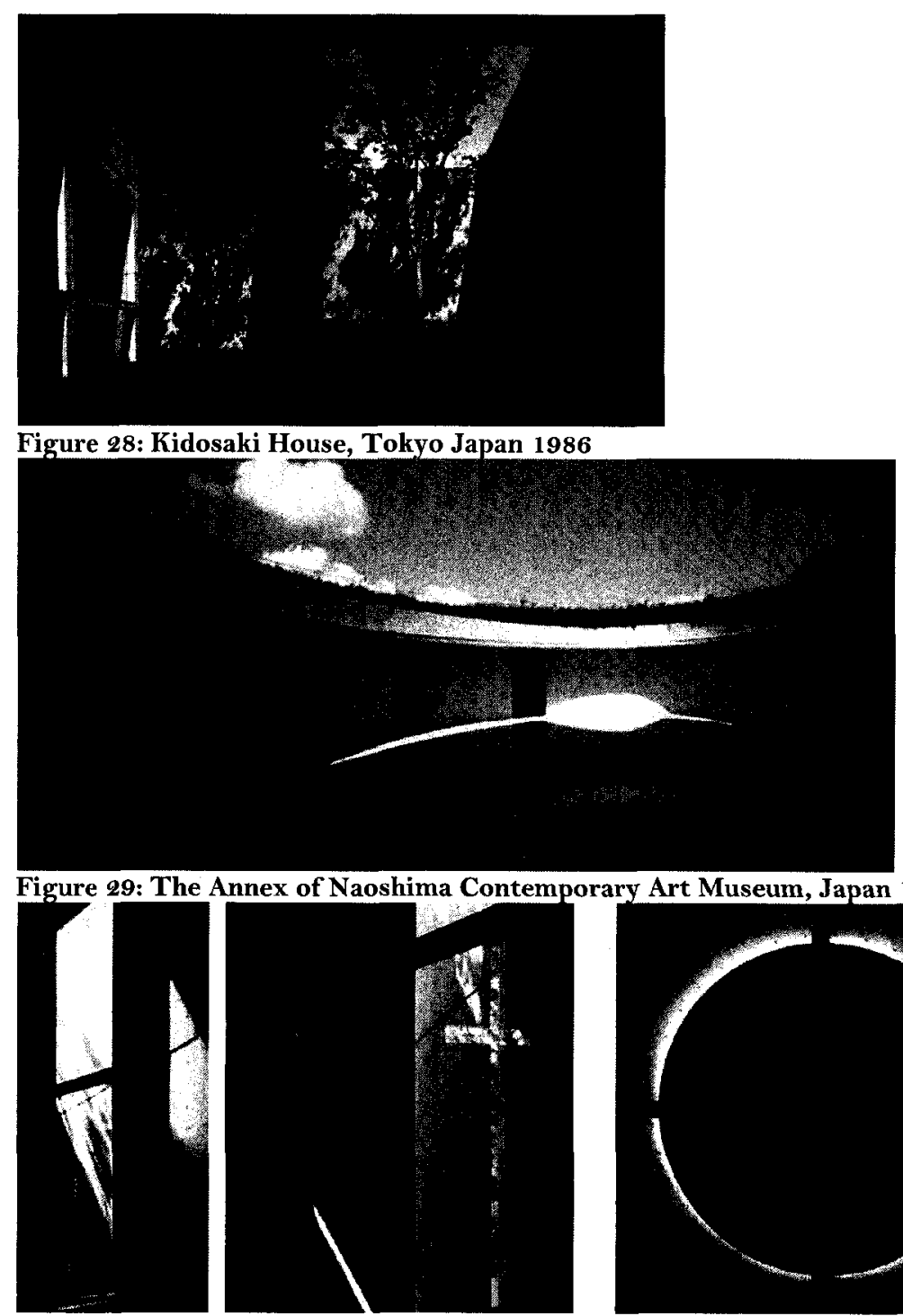

Figure 30: Church of the Light, Japan 1989

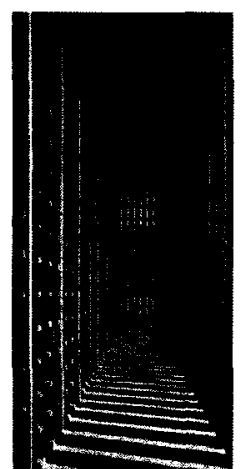

Figure 27: Komyo

Temple, Japan 2000 


\subsection{Scarcity}

\section{"Scarcity has the power to gain."}

The architectural concept of scarcity is to do less and let nature enrich a space.

Light, as an intangible commodity, is a powerful natural material with which to express this concept in architecture. For example, in Maya Lin's "Vietnam War Memorial" (Figure 32), light plays a major symbolic role in the design. The clouds, trees and puddles are all reflected in the polished face of the black granite surrounding the engraved names of the dead. The reflected image on the wall reminds one of the everchanging and ephemeral nature of the world, and, as visitors experience the work, thoughts about the meaning of life are likely aroused. The names of the dead are inscribed permanently in the granite while the people watching are reflected in it. The changing world is laid over the representation of the dead. As well, these symbolic meanings are strengthened by light as it interacts with the surface of the polished black granite.

Light symbolizes that which is beyond a person's normal comprehension and thus stimulates one's mind. One's awareness of space is enabled only through the presence of light, and this light can be interpreted in many different ways according to design features and personal interpretations. What is crucial is to allow the freedom for an individual to seek out their personal and emotional boundaries.

\footnotetext{
${ }^{50}$ Lao-tzu. Tao-Te-Ching. Vol. 307. (Shanghai: Commercial Press, 1929) Chapter 22.
} 


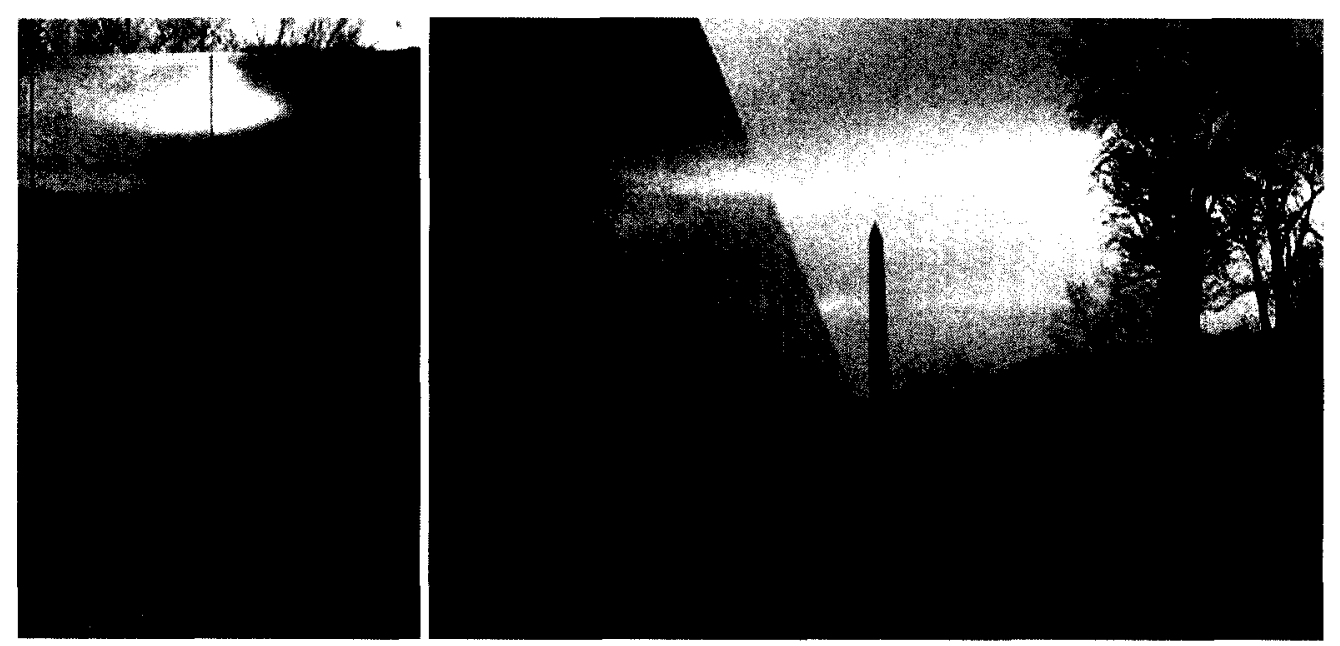

Figure 32: Vietnam memorial, Washington DC 1982

Light and the six concepts above are manifestation of the ways that buildings can reveal themselves both physically (practically) and experientially (artistically). Based on the above investigations, light can be often present unexpected effects and outcomes; it can treated in such a way that inspire creative thinking and reveals the essence of Taoist concepts through architecture.

\subsection{Case Study: The Silent Light of Louis Kahn}

A great building, in my opinion, must begin with the un-measurable, must go through measurable means when it is being designed, and in the end must be un-measurable. ${ }^{5 I}$ Louis Kahn

Through Louis Kahn's concepts of light and silence, we find many similarities to Lao-tzu's concept of the Tao. Kahn saw architecture as the meeting of the measurable and the un-measurable, describing the un-measurable as "Silence" and the measurable as 'Light'. Within this context, Kahn saw light as the means or tool of expression given by nature, and 'silence' as the desire for such expression from the unconsciousness. At the

\footnotetext{
${ }^{51}$ Lobell, John. Between Silence and Light: Spirit in the Architecture of Louis I. Kahn. (Boulder: Shambhala, 1979) 48.
} 
point of their meeting lies the inspiration that leads to the creation of a work of art. According to Kahn, nature, as objective reality, produces infinite variations but possesses no awareness of what it does. Therefore, Kahn believed that it is the role of architecture to discover and to bring realization into being in the circumstantial world: Realization is the sensing of a harmony of systems. It is the sense of order, or one may say that order is the name given to a harmony of system... Man makes rules which are of the lawes of nature and of the spirit. Physical nature is of law. The laws of nature work in harmony with each other. Order is this harmony. Without knowledge of the law, without a feeling for the law, nothing can be made..$^{s 2}$

According to Kahn, the laws of nature are eternally working in a harmonic interplay that he called order, which gives to everything both measurable and un-measurable qualities. Behind the idea of Silence (the un-measurable) is the desire to be and to express; this meets Light, the measurable, and giver of all presence. He believed that Silence was a process in motion rather than a fixed phenomenon, a great void beyond the confines of time and space. Yet, out of such emptiness came the galaxies, the planets and life. Thus, silence contains the potential for life.

Kahn's vision of the natural order shares some similarities with Lao-tzu's conception of the Tao. According to Taoism, the universe began with the invisible vital force that governs all things in nature, which contain both yin and yang qualities. In a similar way, Kahn saw nature as having two opposing qualities, the measurable and the un-measurable. Kahn saw silence as a process in motion rather than a fixed phenomenon, and this can be compared to the way that Lao-tzu described the Tao as

52 Tyng, Alexandra. Beginnings : Louis I. Kahn's Philosophy of Architecture. (New York: Wiley, 1984) 162. 
vital energy undergoing endless transformations. Both of their visions of the natural order describe the ever-changing nature of the world.

According to Taoism, to recognize Tao is to free oneself from previous experiences and knowledge, and allow unconscious intuition to take place. However, what is not entirely clear in this theory is how to manifest this. By exploring Kahn's experiments with light in his work, one can acquire a better understanding of how Taoism's essence and concepts can be manifested in the built environment.

To Kahn, natural light is the only true light, and he was intrigued by the nuances of mood created by the time of day, the weather and the seasons. He believed that the changeable quality of daylight gave life to architecture because one's relationship to a building changes according to the light surrounding and penetrating it. For this reason, he believed that no space was truly a space unless it received the lifegiving touch of natural light:

A space can never reach its place in architecture without natural light. Artificial light is the light of night expressed in positioned chandeliers not to be compared with the unpredictable play of natural light... The structure is the design in light. The vault, the dome, the arch, the column are structures related to the character of light. Natural light gives mood to space by the nuances of light in the time of the day and the seasons of the year as it enters and modifies the space. ${ }^{3 s}$

Kahn's understanding of light began on a practical level. He believed that to work with light means taming its fierceness while utilizing its changeability. This involves both practical considerations and a sense of light's symbolic meaning. In his early

${ }_{53}$ Tyng, Alexandra. Beginnings : Louis I. Kahn's Philosophy of Architecture. (New York: Wiley, 1984) 162. 
experiments with light, he considered openings and windows as the most significant parts of a room, which gave character and vitality to his spaces.

For example, Kahn's "Weiss House" (Figure 33-6) has a vertically sliding panel system in the windows of the living room which faces south. The window area on the outside is glazed over two stories and the wooden sliding panels on the inside can be shifted and arranged to optically connect or divide the interior from the exterior space. It can be entirely open during the day and close completely for protection at night. The interior façade therefore becomes a huge picture frame in which those picture selections can be arranged according to the occupant's need. Thus, the idea of the boundary of a space has been accomplished in a flexible way in which the boundary is defined based upon the desires of the occupants. More importantly, this window system offers more than a practical need, but as if it fastens the relationships between the interior and exterior space.

In the "Philadelphia Psychiatric Hospital" (Figure 37-8), Kahn designed a system of 'light filters' to protect a façade window from direct sunlight. The concrete floor slab of each floor is extended beyond the plane of the façade and is designed to support the hollow wooden cubes. These cubes work as the 'light filters' for the direct sunlight from the east and west. As the sunlight penetrates through these hollow cubes, there is only a fraction of sunlight will fall onto the façade resulting in an attractive geometric light pattern on the window surfaces. This creative way of filtering the sunlight has generated on the façade the dynamic forms of light and shadows. Since these forms are created by the changeable play of sunlight, the façade results in an unpredictable forms and patterns which bring surprises to the occupants. 
Kahn invented a window scheme called the 'keyhole window' (Figure 39), a free standing device used to screen the sun's glare. He decided that every window should face a wall that would take the sun's direct rays and reflect them into the interior space. The outer walls with their keyhole-shaped openings are intended to protect the inner recessed glass from the sun's full force. The outer panes are separated from the wall behind them and the gaping window frames reveal the emptiness behind. The un-built project, "Salk Institute's lecture halls" (Figure 40) further illustrates his idea of light by establishing an interdependency of light and structure. He thought that the structure of a room is defined by its light, and that conversely, the structure actually makes or molds light by taming it into a workable state. ${ }^{54}$ His design for this lecture hall is derived from Greek columns and the way they interact with light. He thought that the column could be hollowed out so that it becomes a filter for incoming light. He applied this hollowed column concept into his building design, treating the entire building as an enlarged and hollow column. The lecture hall is designed as a series of square shells wrapped around a circular building. The circular structural walls act as lightregulating devices that give definition and life to the space inside.

From these examples, we can see that Kahn saw architectural elements, such as columns, arches, domes and vaults in terms of the various ways that they can shape and influence light and shadow. He learned to control light in order to precisely define the nature and atmosphere of the space. Light is used to differentiate the faces of a threedimensional solid and fill interior spaces through openings. To Kahn, structure and light are inseparable. Kahn believed that light possessed an immense power which he saw as the ultimate inspiring force. He thought that light's ability to give life to

${ }^{54}$ Lobell, John. Between Silence and Light : Spirit in the Architecture of Louis I. Kahn. (Boulder: Shambhala: distributed in the U.S. by Random House, 1979) 
architecture is dependent on its own vital force and its changeability. He also felt that different aspects of light are usually perceived as colours, which are created by the changeable play of sunlight.

Let's go back to one of his most famous designs, the Salk Institute (Figure 4), and specifically the courtyard, to sum up Kahn's concepts of light and structure. Kahn designed an open courtyard which anticipates each special hue and intensity of light depending on such factors as the degree of enclosure, the openness to the sky, and the reflections of the sky on water and concrete. Kahn arranged the forms and materials of his building to capture light at every moment. This central courtyard is roofless with a simple band of water running through it towards the Pacific Ocean, leading one's eye toward the infinite frame of the sky and an ever-changing scene of colours. At each moment, the court has its own atmosphere and intimacy with colour. The courtyard becomes a place of silence and lets natural light manifest the properties of the surrounding building. To Kahn, this was a process of discovering the spirit of the space by capturing the unpredictability of sunlight.

Kahn taught us to understand what lies between idea and reality, and viewed light as a key link between the two, and as the source of life. His use of light in relation to silence gives life to architecture. The changeability of light in his building is in fact the experience of time and of the vital transformations of the natural order within the environment. 


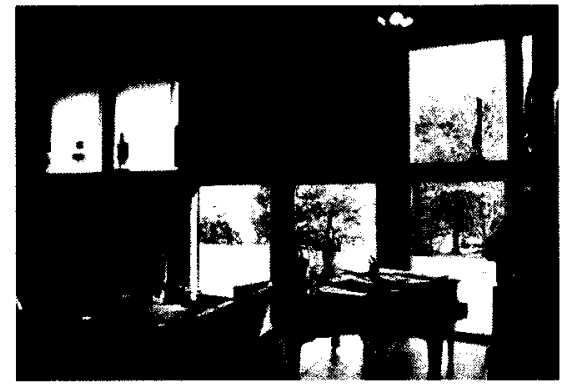

Figure 33: Interior view of the Living room, Weiss House, Philadelphia 1950

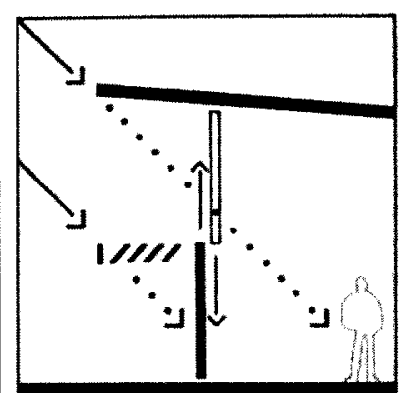

Figure 34: Conceptual sectional drawing

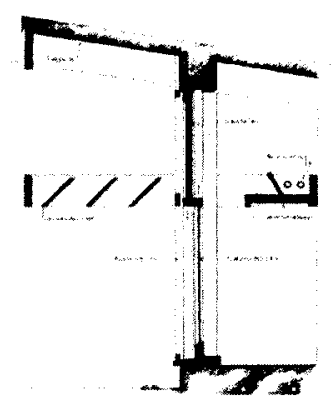

Figure 35: Detail sectional drawing
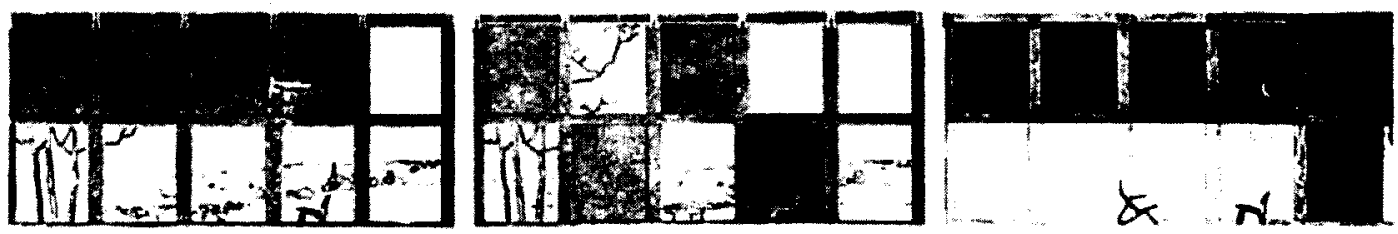

Figure 36: Explanatory drawing of possible arrangement of the sliding panels, south façade for the living room, Weiss House, Philadelphia 1950

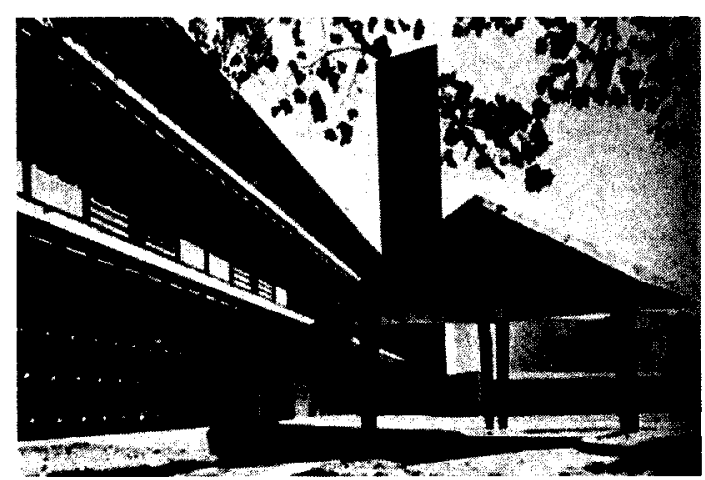

Figure 37: Northeast façade, Philadelphia Psychiatric Hospital, Philadelphia 1954

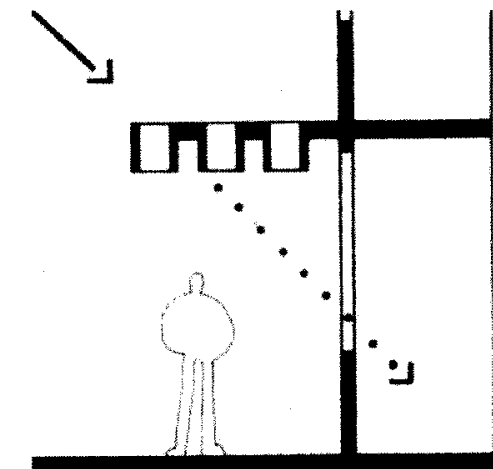

Figure 38: Sectional drawing of the Northeast façade, Philadelphia Psychiatric Hospital 1954

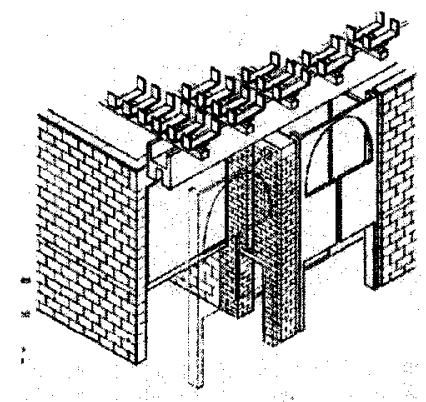

Figure 39: Keyhole Window: an Isometric diagram of the U.S.

Consulate and Residence (unbuilt), Angola 1962
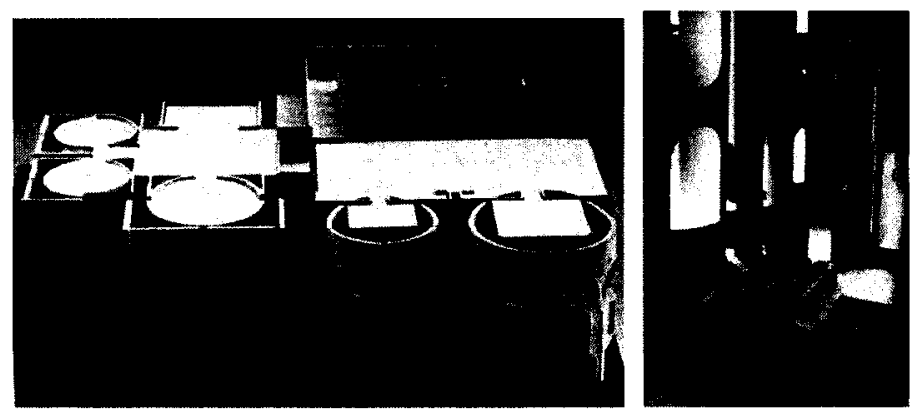

Figure 40: Salk Institute's lecture halls (unbuilt), La Jolla California 1965 


\section{Chapter Five: The Design Proposal}

\subsection{The Concept}

The main architectural program for this design proposal is a combination of a Retirement Home and a Daycare Center. The objective of this project is to allow the two most distinct but somehow correlated groups of dwellers, the elderly and the child, to dwell in a space in a harmonious and meaningful way. Such meaning and harmony will be informed by and manifested through Taoist philosophy and its philosophical concepts such as Vastness, Incompletion, Formlessness, Opposition and Scarcity, especially as revealed through light and architectural space. Light, as the source of life, ties both practical and theoretical issues together and contributes to the achievement of a balanced dwelling.

\subsection{Site Selection: Porter Island, Ottawa}

The proposed site for the project is Porter Island, in the city of Ottawa, Canada (Figure 41). Ottawa, the capital of Canada, is a city that is surrounded by and interspersed with parks, trees, farmlands, forests, canals and rivers; it is a city that is intimately in touch with nature. Porter Island is reached via Island Lodge Road, off of St. Patrick Street, which is near the popular Byward Market in Ottawa (Figure 42-3). It is a very distinctive natural place with much vegetation; trees grow around the island, and the water that surrounds the island generates a particular kind of atmosphere through the different lighting conditions and reflections. Indeed, the reflecting surface of the river has a dematerializing effect which counteracts the stable topographical structure of the buildings on the island. The reflections on the water also add a sense of mystery and change to the surrounding atmosphere. 
Aside from the attractive natural surroundings, what draws one's attention to this island is the six-storey Retirement Home located at the eastern end of the island. This retirement home (Figure 44) has accommodated about 180 seniors since 1964. Unfortunately, the location of this building on an isolated island shows that our society does not consider the elderly as part of the community. The building sits on an empty island, disconnected from any sense of neighborhood. The only physical connection is a bridge for cars and pedestrians, and the only people who access this island are the residents and staff of the building. Thus, the residents encounter a problem of having no social involvement; they are alienated from the general public and they have lost some of their social status and respect. However, the wonderful natural setting of this site has the potential to counteract this sense of isolation, if we can transform the site into accommodating and fostering a more holistic approach to living by more fully integrating nature. From this, an increased involvement with and awareness of the community should follow. 


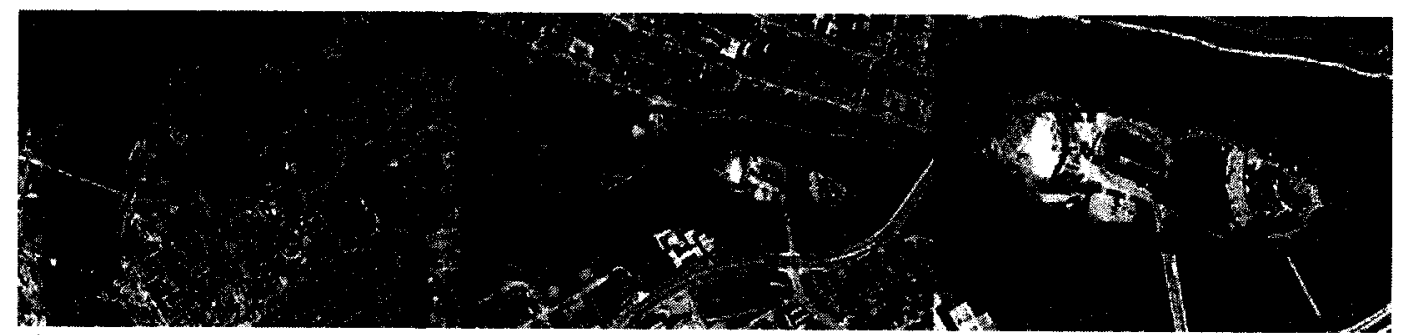

Figure 41: Aerial photo of Porter Island, Ottawa

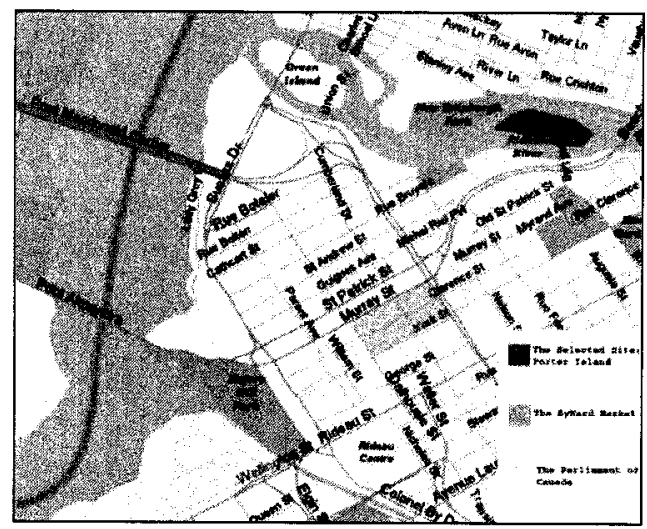

Figure 42: Site Map, in relation to important landmarks

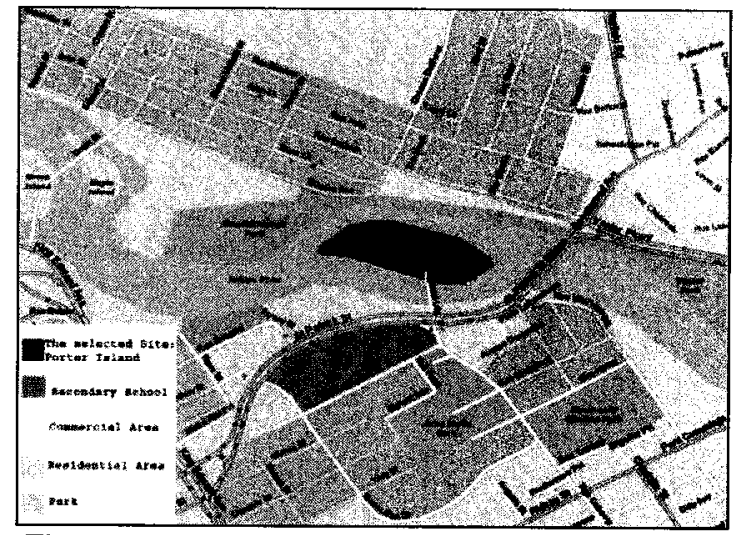

Figure 43: Site Map, Zoning of the neighborhood

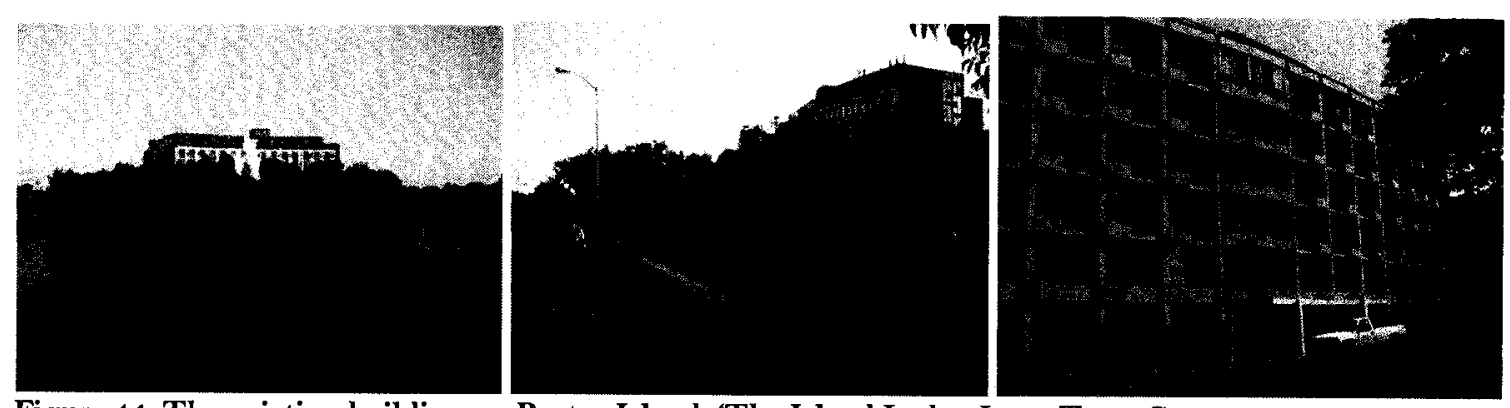

Figure 44: The existing building on Porter Island, 'The Island Lodge Long Term Care Home' 


\subsection{Program Selection: The combination of Retirement Home and Daycare Center}

The elderly face many problems associated with aging, as their roles in society gradually decrease. Their responsibilities decline and sharply reduce their social opportunities and ability to participate. The movement into the old age is often characterized as a sharp decline, as the elderly are considered weak, devalued and useless towards the end of life. Indeed, they often only represent the last stage in the sequence of a life span. Yet, Taoism teaches us that the life span should not be seen as a linear sequence; rather life should be seen as a sequence of meaningful stages that contribute to the cycle of life. Within our lifespan sequence, childhood is considered the beginning of life and old age as the end; this results in an inseparable relationship with each other because beginning follows the end in a continual endless cycle. As Lao-tzu suggested, "The way to acquire the positive is to contain the negative." 55 Thus, introducing a daycare center into a retirement home is an attempt to convey a closer relationship between the elderly and the community, to promote the positive aspects of all stages in life. The temporal activities of the daycare center will counteract the permanency of the retirement home, where a sense of isolation and alienation is common. With this meaningful and multi-use building, the elderly will be revitalized by the increased involvement with and awareness of the community.

\footnotetext{
${ }^{55}$ Lao-tzu. Tao-Te-Ching. Vol. 307. (Shanghai: Commercial Press, 1929) Chapter 28.
} 


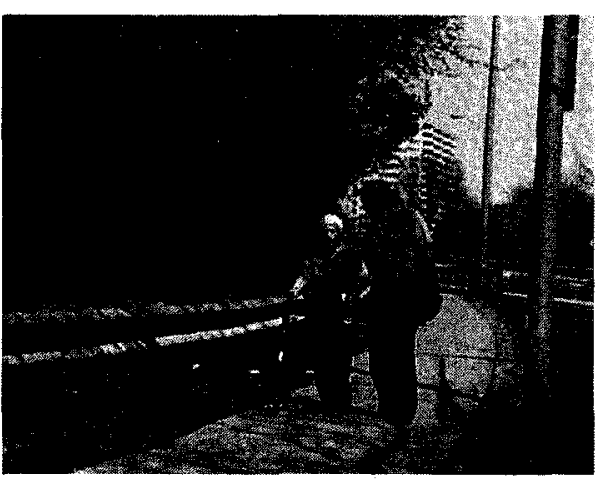

Figure 45: Senior exercise on Porter Island

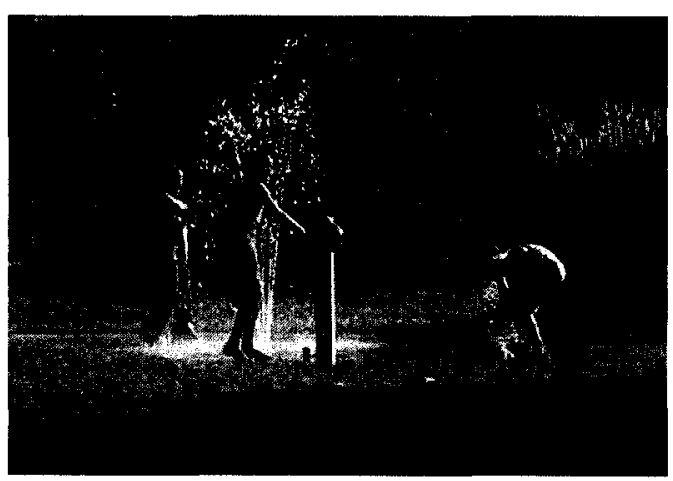

Figure 46: Kids playing at the park in the neighborhood

\subsection{Site Investigation: the six concepts as the exploratory tool in seeking the essence of the island}

This section is an attempt to explore the essence of the island by applying the six Taoist concepts as exploratory tools to reveal the intangible qualities of the site. Through the exploration, one may more fully understand the island from its transformations and its interactions with its greater surroundings. From this Taoist journey, one is able to experience the island without rushing past the immediate offerings of the site; it permits one to explore and understand the site through one's visions, sensations and the stimulation of one's imagination.
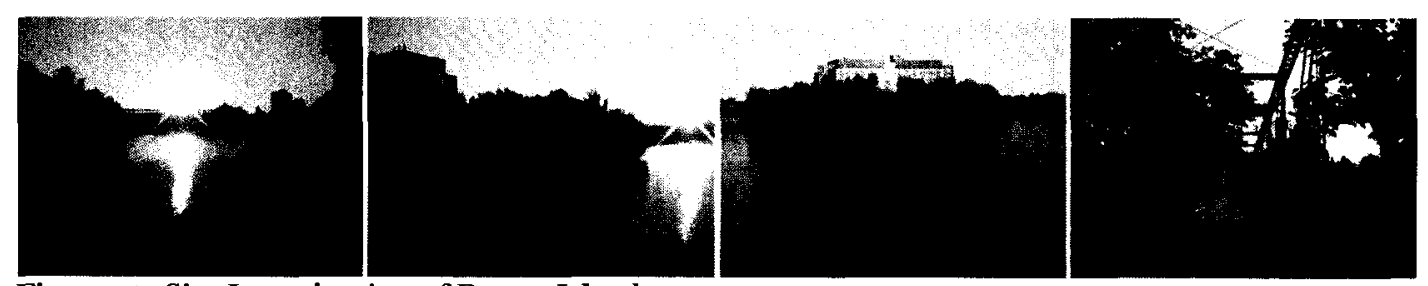

Figure 47: Site Investigation of Porter Island 


\section{Vastness: The Infinite Qualities of the Site}
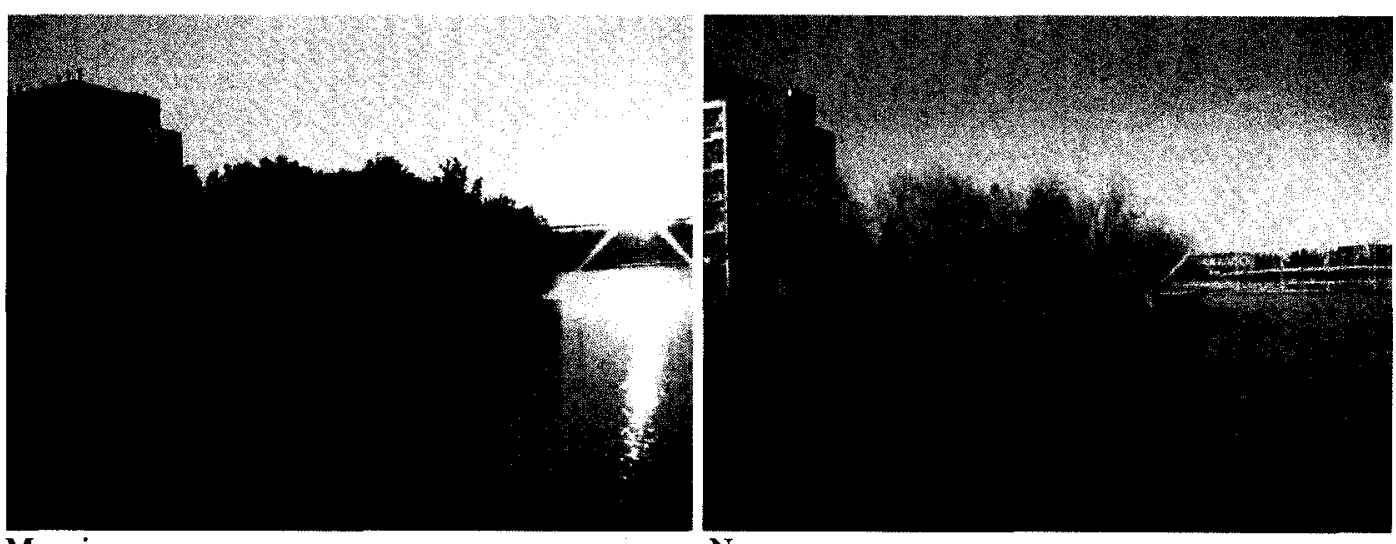

Morning

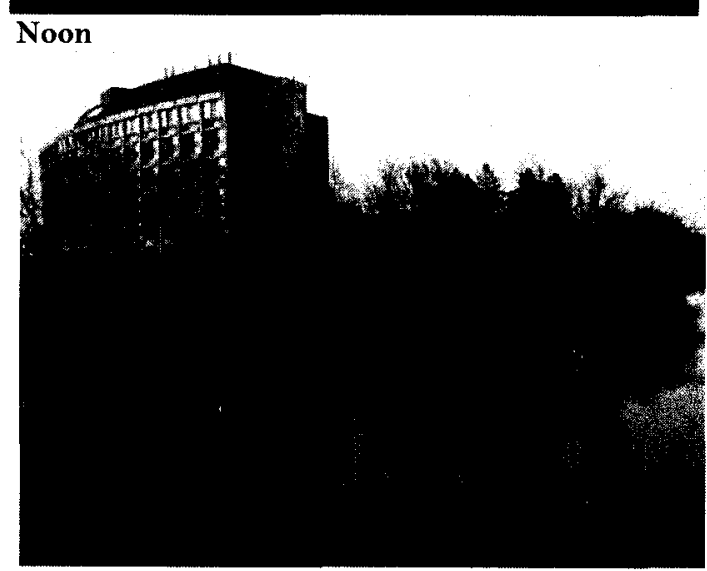

Afternoon

Evening

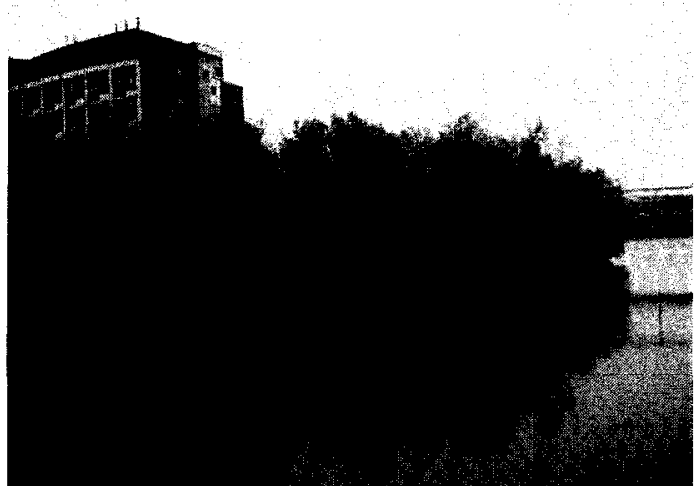

Figure 48: Observing the transformations of the site (viewing east towards the island)

\section{Perception:}

In the morning, the island still appears dark while the sunrise lights up the surroundings and reflects off the water from the river that surrounds the island. The strong and intense sunlight enters from the east onto the surface of the water, and the reflected light slowly reveals the shape of the island. This intense light generates a bright and lively setting in the mornings (Figure 48).

At noon, the sunlight is evenly distributed across the entire site, and the island and water appear to be the same colour; there is less contrast as compared with the 
morning. The sunlight hits the rapidly flowing water and reflects in many directions, which gives an exciting and energizing atmosphere to the site.

In the afternoon, the intensity of the sunlight appears weaker compared with midday. The flow of the water slows down and provides a calm and relaxed atmosphere through the blurry reflections of the island.

In the evening, the sunset provides gentle lighting for the site. The water that surrounds the island is almost immobilized and is able to reflect almost perfectly the exact image of the building and the trees on the island. Here, the island appears motionless, silent and peaceful.

\section{Interpretation:}

The daily rhythms of sunlight generate ever-changing qualities for the site, from bright and lively, to active and excited, from clam and blurry to motionless and peaceful. From the beginning to the end of the day, the interactions between the sunlight, the island and the water offer a seemingly infinite number of relational effects, as changes in lighting conditions take place. Every moment, the qualities of the site are transformed, and dwellers perceive the site along with these transformations as if they are living in a vast, borderless and ever-changing setting. Through an awareness of these infinite qualities, dwellers are able to intuit the grandeur and vastness of space within their own surroundings through the consistent rhythms of sunlight. 
Incompletion: Growth and Changing Visions

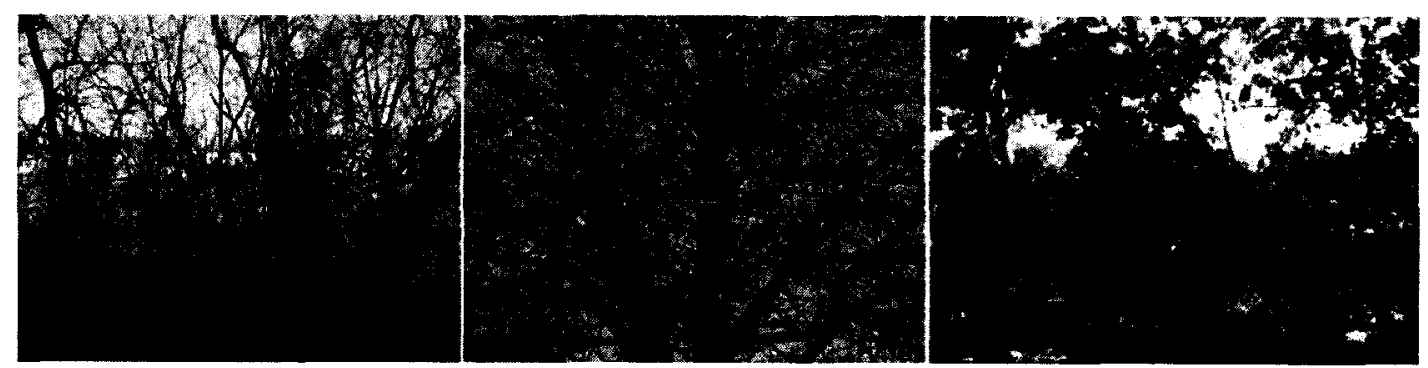

Figure 49: View out from Porter Island, January to August
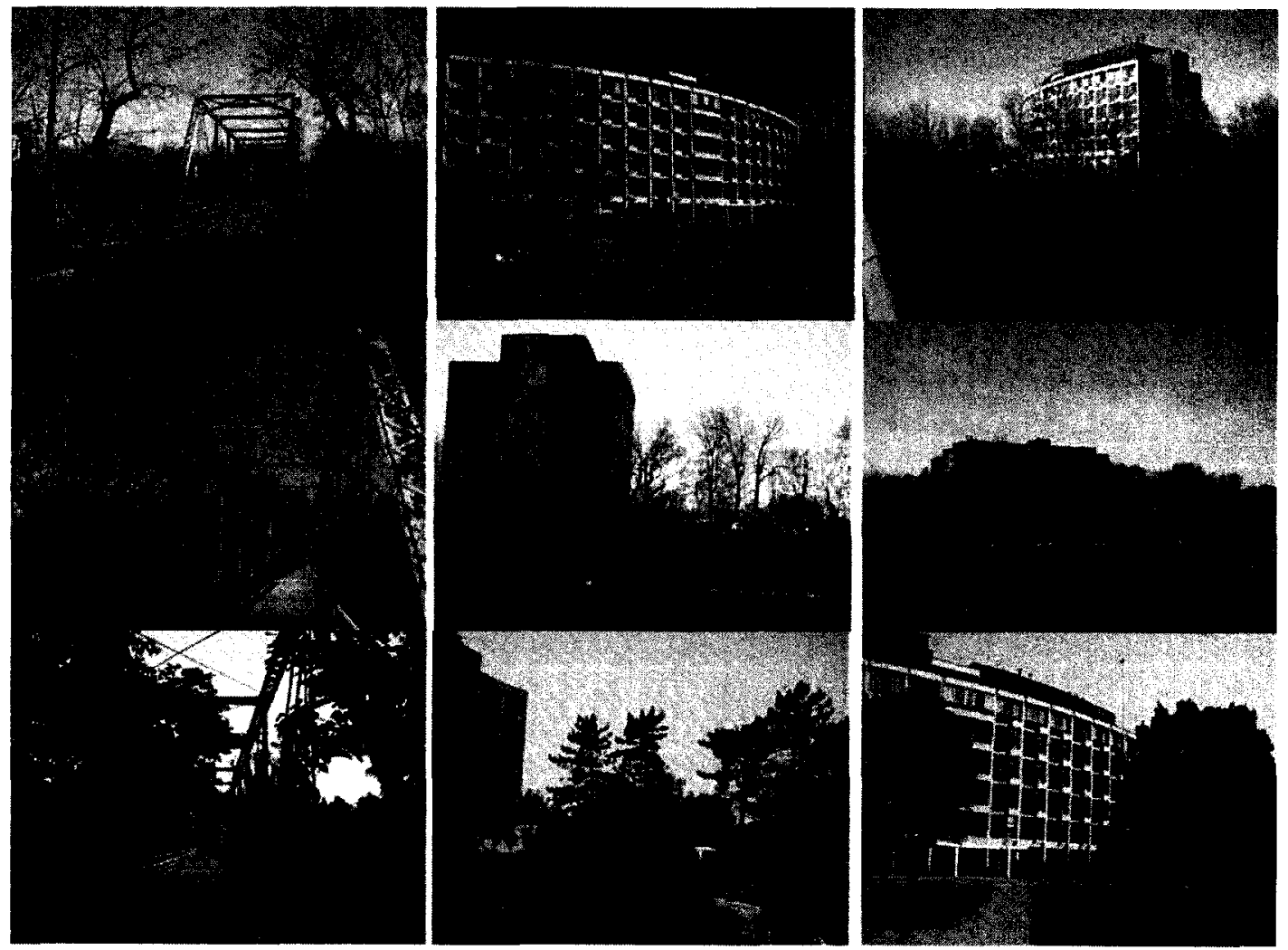

Figure 50: Changes of Porter Island from January - August

\section{Perception:}

In the fall and winter, the trees that grow around the island release all their leaves, and the branches form a chaotic frame when one looks out from the island

(Figure 49). The sunlight penetrates through the branches into the island and casts strong and clear shadows on the ground. During the spring time, the small green buds 
start growing out of the branches adding to the feelings of fuzziness and chaos in the branches. These features add another semi-transparent filter for the sunlight. In the summer, the leaves grow out and cover the branches, in some places entirely blocking the view when one looks out from the island. Sunlight is filtered through the little gaps between the leaves and subsequently becomes softer (Figure 50).

\section{Interpretation:}

Through the changes of the seasons, the site is constantly transformed; this change generates many different colour tones, lighting conditions, and thus affect one's feelings towards the site. The tones of the site change from brownish to yellowish to greenish due to the growth of the trees and the changing position and intensity of the sun. These colours significantly influence feelings and perceptions of the site. The brownish setting gives a cold and harsh feeling due to the absence of the leaves allowing more sunlight to enter and giving a wider and clearer view of the expanse beyond the trees. The yellowish tones give a sense of rebirth and new beginnings as the small green leaves grow out and contrast with the brownish branches. The verdant greenish tones promote warm and pleasurable feelings. The leaves almost cancel out the views of the island and vision is thus turned inward as the area becomes more secluded and sheltered. The conditions of the site transform endlessly and consistently; the idea of incompletion encourages us to be ever-aware of these transformations and consistency that would allow change to be part of the design considerations. 

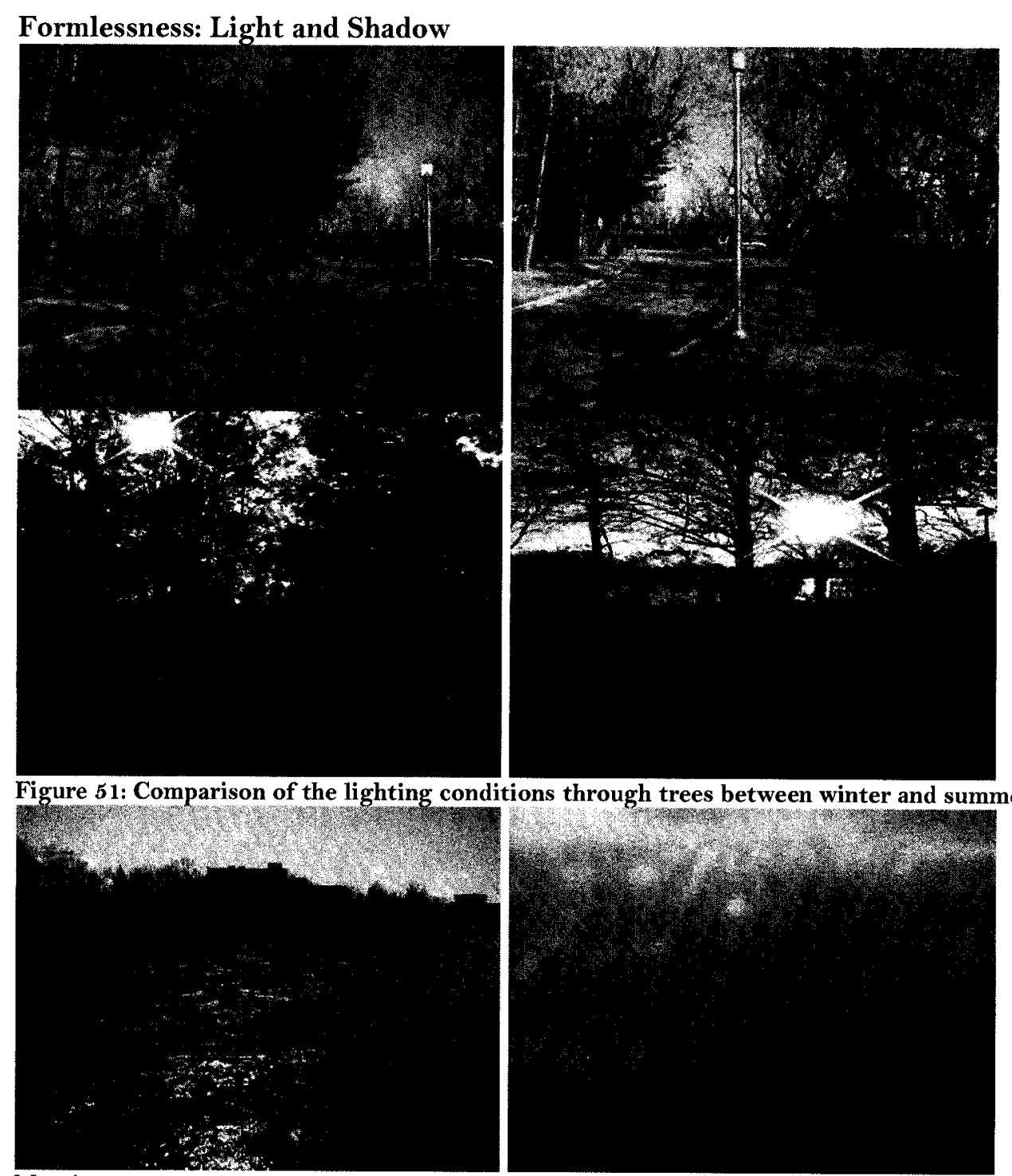

Morning

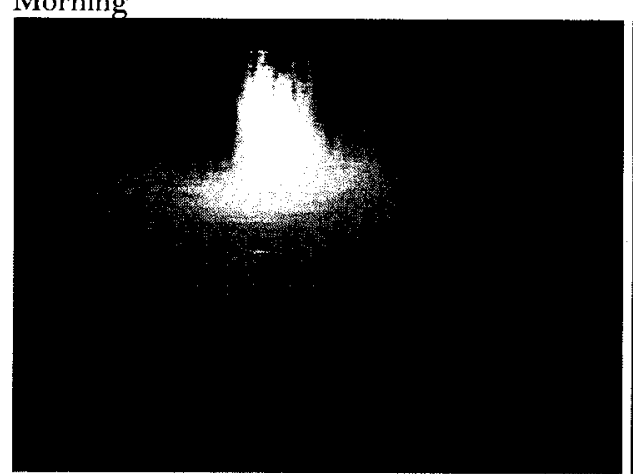

Afternoon
Noon

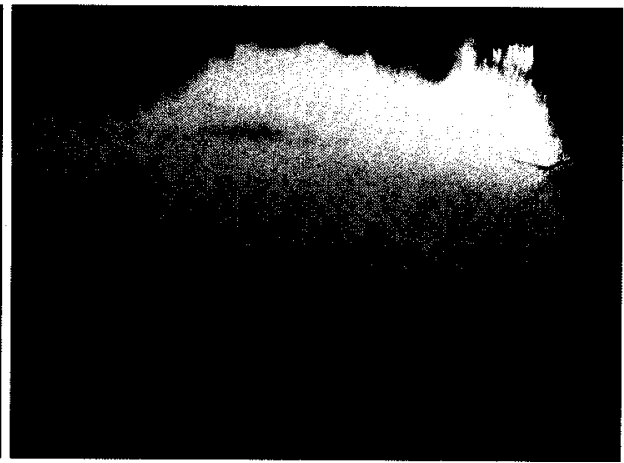

itions of a day through water (view out from the island) 


\section{Perception:}

In the winter time, the shadows cast by the tree branches form clear and strong shapes. As the intensity and the angles of the sunlight change, the shadows reshape themselves and are cast upon the ground as if they are animated. In the summer time, the shadows become more diffused and scatter unevenly on the ground (Figure 51). The island's lighting conditions are also significantly affected by the water that surrounds it (Figure 52). Smooth surfaces reflect clear images; rippled surfaces produced blurry images and fast moving water bounces light away producing shimmering images on the surface.

\section{Interpretation:}

One of the most distinct characteristics of this island is that it is surrounded by trees and water. The forms of the trees and the patterns of the water thus significantly affect the way that the island receives sunlight. The branches of the trees in the winter time allow the sunlight to enrich their forms by casting clear and strong shadows on the ground. The dwellers on the island thus perceive the bright sunlight strongly contrasting with the dark and clear shadows. In the summer time, the leaves of the trees filter the incoming sunlight and slightly blur the shadows on the ground. The sunlight thus strengthens the forms of objects in winter, while it decomposes those forms during the summer months. Aside from the gradual seasonal changes, the daily changes of water movement affect the incoming light to the island. Morning water tends to be fast and erratically reflects sunlight and gives a shimmering effect. The island thus receives morning light that is bouncy and in motion, giving an energetic and 
a lively setting for the morning. In the evening, water movement slows down, and its smooth surface reflects the clear image of the sky, which is then reflected onto the island. This provides a sense of calm and peace for the evening. Thus, the playfulness of light enriches the forms of the objects on the island and consequently leads to an enrichment of the quality of the life on the island as well.

\section{Oppositional Balance: The Duplicated Image}

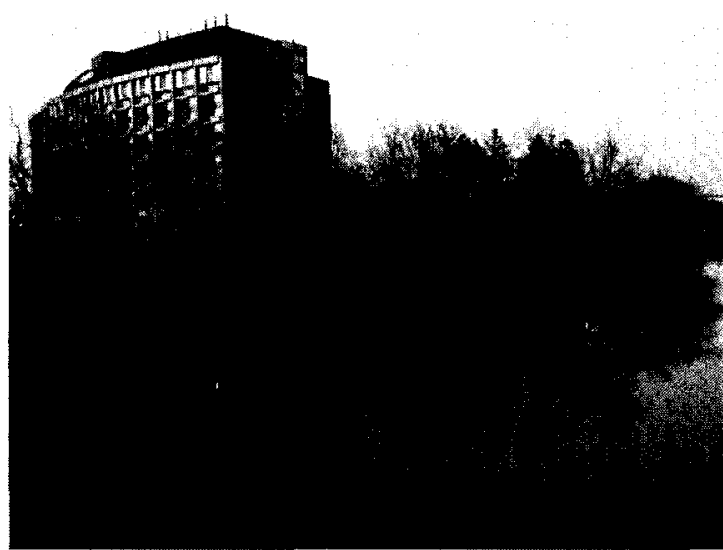

Reflection on water (viewing east towards the island) Figure 53: Light and the reflection, the reciprocal image

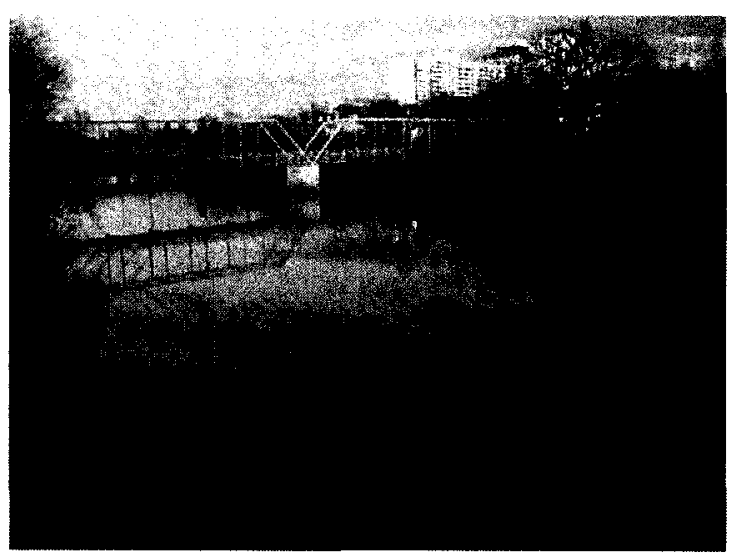

Reflection on water (viewing south from the island)

\section{Perception:}

The island appears as double when light hits the smooth surface of the water.

The reflections in the water seemingly bring the vastness and brightness of the sky and the images of the building and the trees into the earth's dark surface. This illusion seems to place the objects on the island and the sky at one's feet. The interaction of light and water also adds a luminous quality to the island and the surroundings (Figure 53). 


\section{Interpretation:}

The soft and gentle topography counteracts the stable structure of the building on the island. Light and water project an illusion of the building and its surrounding greenery as being placed at our feet. The reciprocal image suggests a sense beyond the physical, as if the island also exists in an imaginary realm. The overall setting stirs one's imagination and it expresses a sense of balance and harmony between existence and the imaginary when one perceives the island.

\section{Boundary-less: The Borderless Vision}
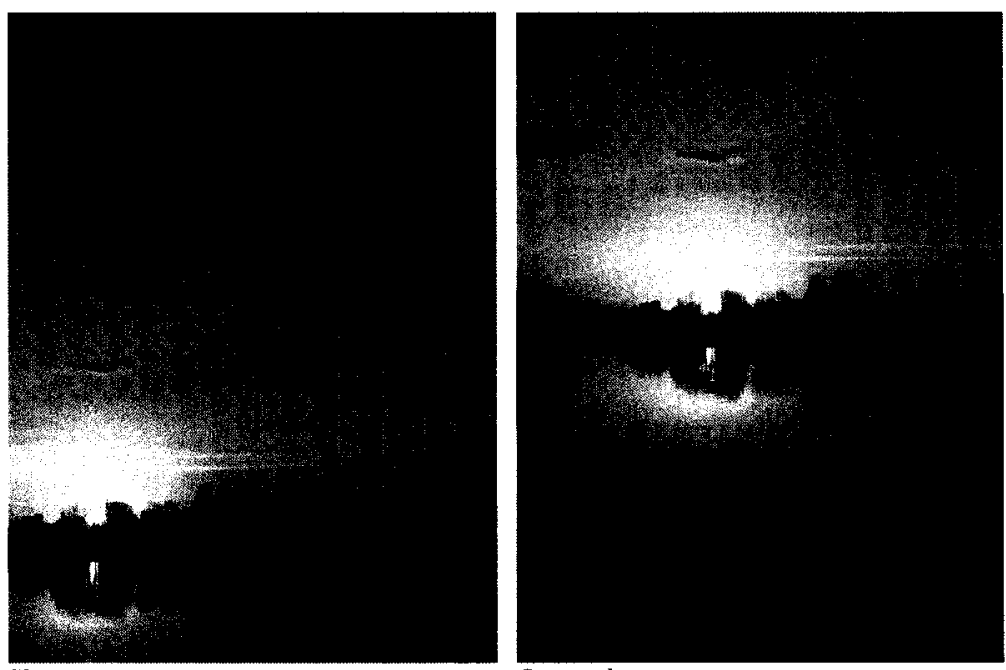

Ground

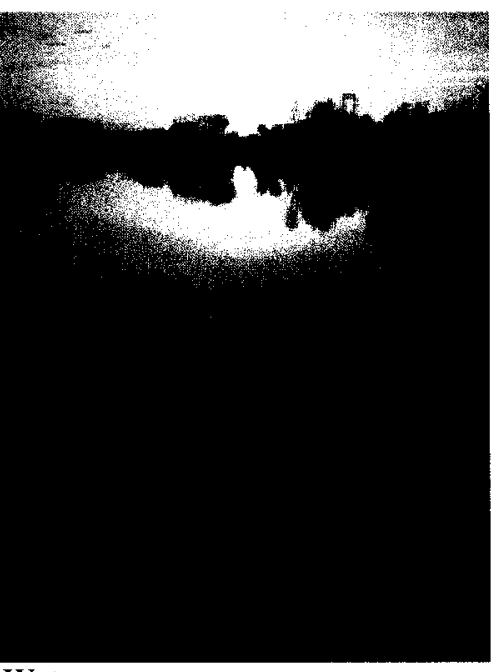

Sky

Figure 54: Framing the vision (viewing west from the island)

Water

\section{Perception:}

When one looks up from the island, one sees the sky; looking out, one sees the horizon of the ground at a distance; looking down, one sees the water with the reflected image of the sky (Figure 54). 


\section{Interpretation:}

One of the characteristics of this island is that it offers wide and clear views for dwellers as if they are situated in a boundary-less setting. These views can be framed with three parts: the sky, the ground and the water. When one looks up to the sky, the horizon is placed at one's feet; when one looks out to the horizon, it is placed at eye level; when one looks down to the water, the horizon shifts to the sky. These views offer many possible choices for dwellers to perceive their surroundings and permit perceptual access to their own designated boundaries.

\section{Scarcity: Letting Colours Enrich One's Mind}

\section{Perception:}

As light interacts with the diversity of things on the island at different times, the colours and hues change as if the island is subject to an ever-changing palette. The colours change from grey to blue, yellow to pink, revealing the unique character of the site at every moment of transformation (Figure 54).

\section{Interpretation:}

The dynamic colours that light offers to this site rouse one's mind and permit one's imagination to engage with the experience of light. For example, yellow brings feelings of relaxation while blue can carry refreshing connotations. The site offers plentiful colours, which convey many different sensations according to personal interpretations. What is crucial is to provide the freedom for individuals to seek their own sensations and permit the light and its colours to liberate one's mind. 


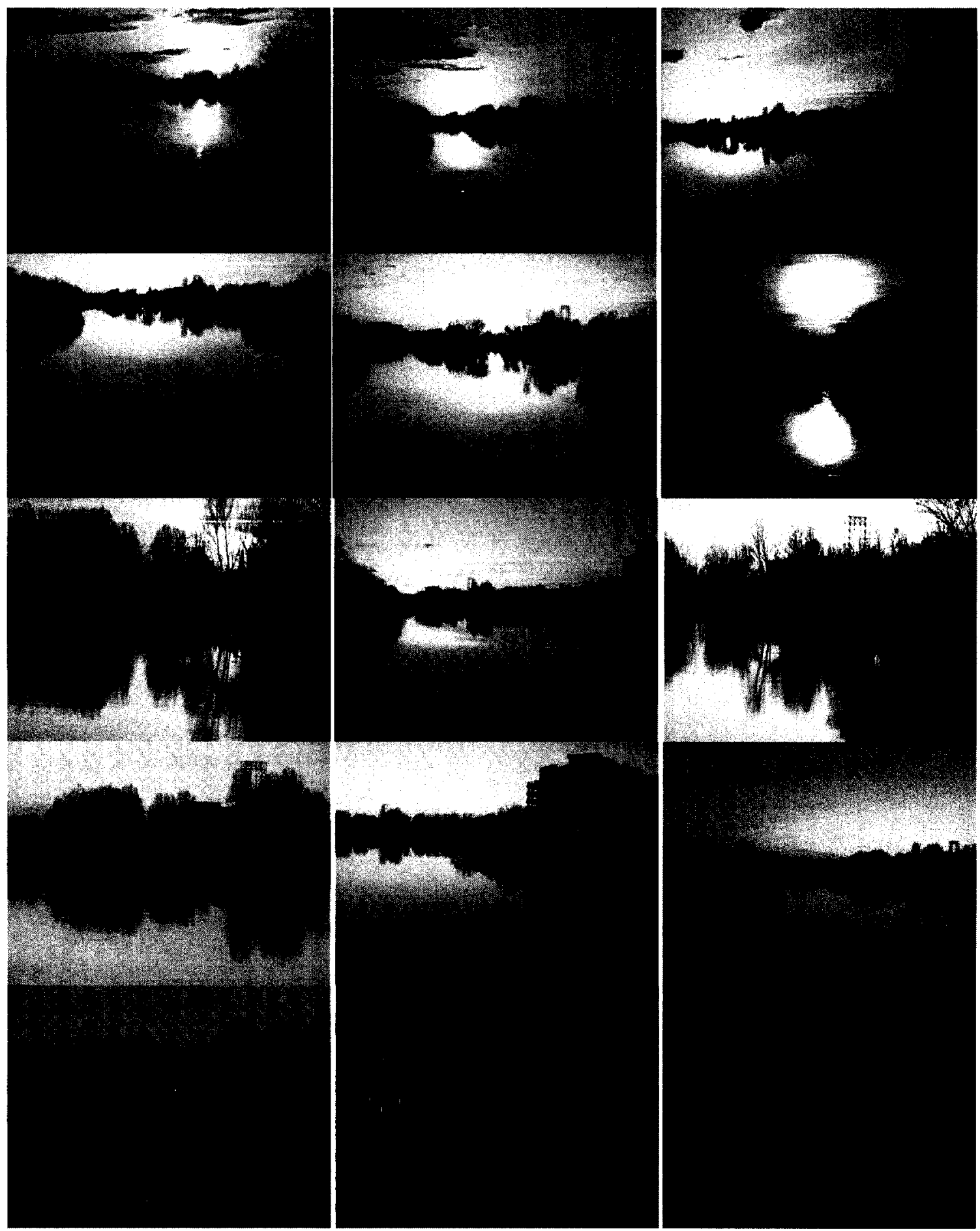

Figure 55: Sunset of Porter Island, Ottawa (viewing west from the island) 


\subsection{Design Issue: Various Perceptions of the Elderly and the Children}

The elderly and children have different physical abilities, so they experience their physical environments in very different ways. Young children have limited personal history, and are thus less concerned with time as they are with daily phenomena. They have less of an appreciation for things that are old because of their limited personal history. On the other hand, the elderly are experienced, and they perceive things with knowledge based on their historical background. They are more aware of the passage of time and concerned with moments of reflection and repose. The elderly are more sedentary, whereas children are more active and energetic. Due to their different physical abilities and experiences, the way they perceive space is different.

Children may perceive space and be aware of the qualities of their space if these qualities are visually brought to their attention. Because children are energetic and anxious, the design approach will need to catch their attention by offering something to evoke their consciousness through their curiosity. On the other hand, the elderly are more sedentary and more often perceive spatial qualities through the passage of time and respond according to their body and personal experiences. The design approach will thus need to offer flexible and self-adjustable features. 


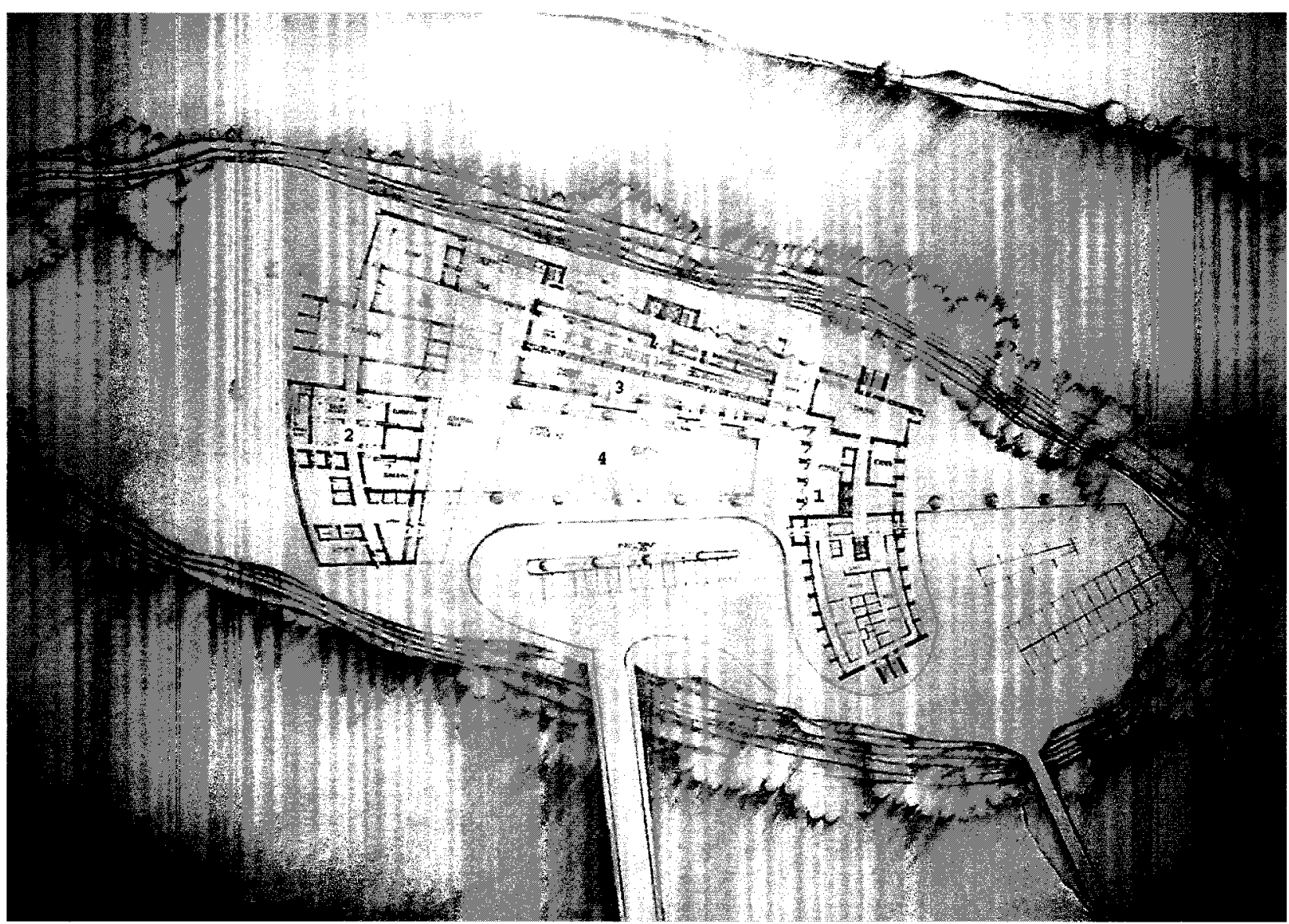

The existing building of the Retirement Home island

The new proposed Daycare Center on the The new extension building in-between: planting garden, a space and the new living units

4. Landscape Planning: the leflecting pool/wate
playground

Figure 56: The Site Plan drawing (1: 500) 


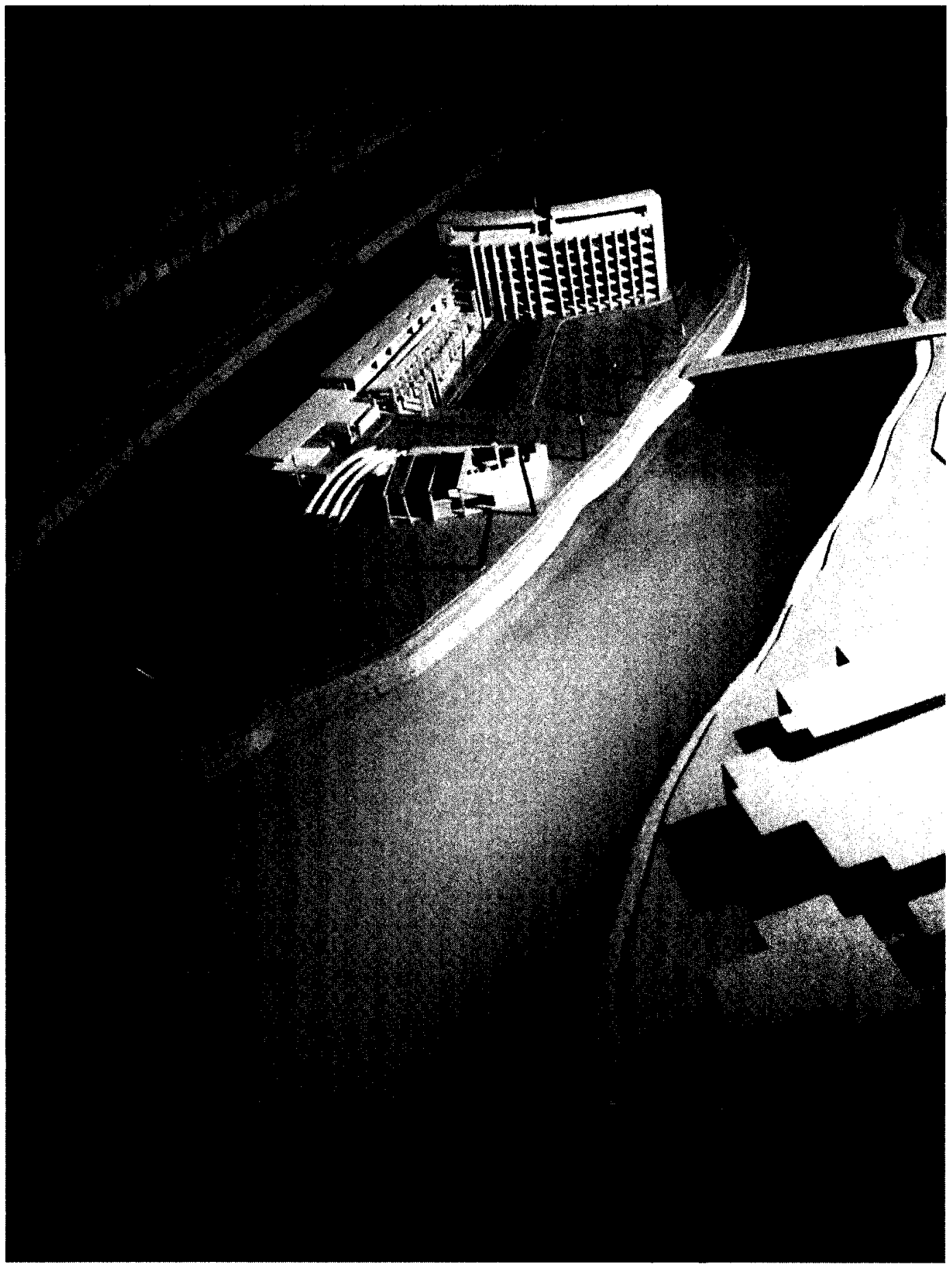

Figure 57: Site Model (1:500) 


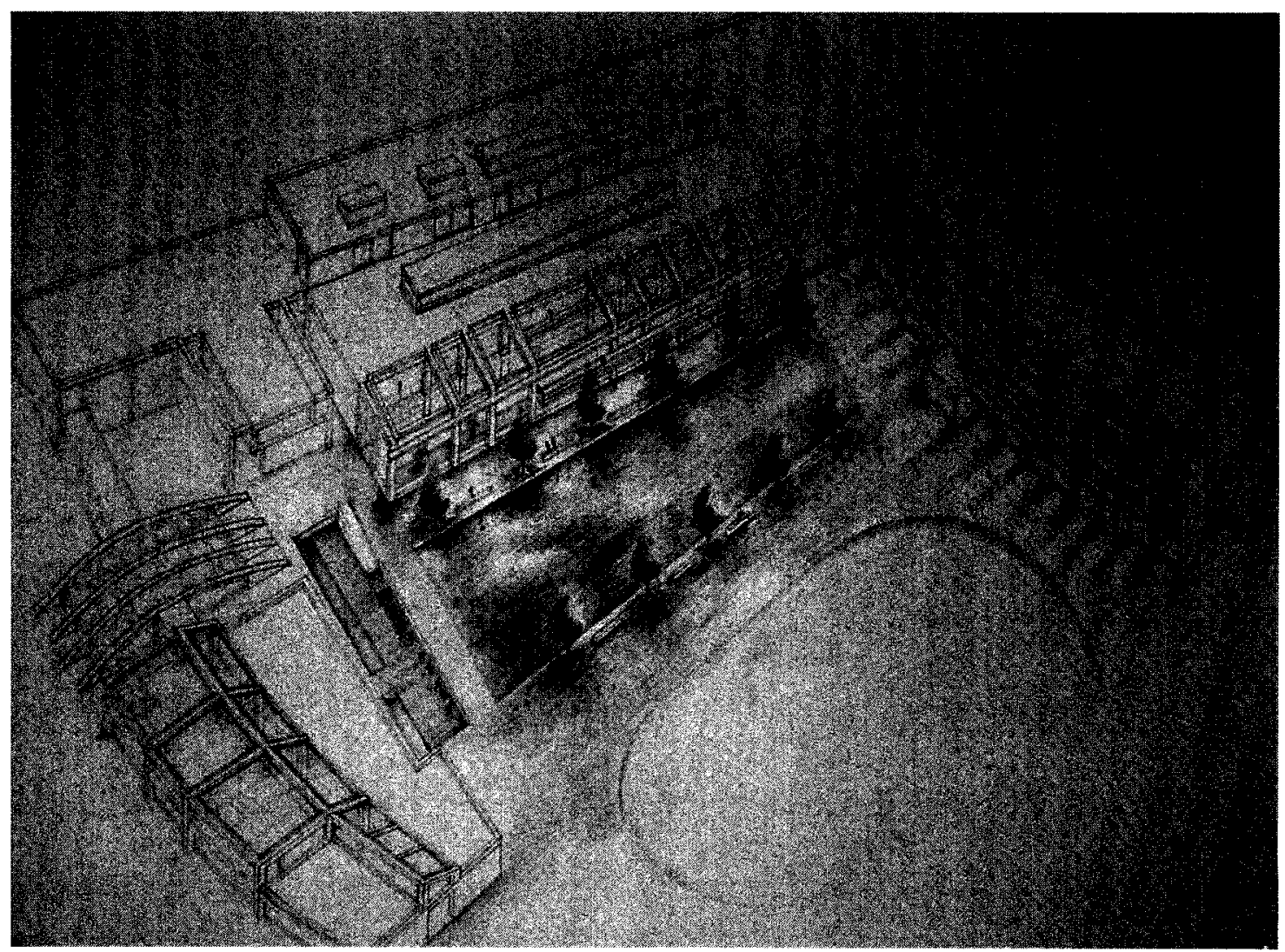

Figure 58: The axonometric drawing (1:250)

\section{The Organization:}

It is proposed that the daycare center be situated at the west end of the island, which is the opposite end of the existing retirement home. The two separate buildings will be connected by a new extension building which holds a south facing indoor planting garden, a library, a meditation space and the new living units. A reflecting pool/water playground with a surrounding exercising path is proposed for the center of the island to act as an anchor that visually holds the buildings together through light and reflection. This setting allows the two groups of dwellers to inhabit the space together not physically but visually (Figure $56 \& 58$ ). 


\section{The Juxtaposition:}

\section{Permanence vs. Change:}

The lobby of the daycare center is placed across the lobby and the living lounge of the retirement home. (Figure 63, 1a \& 2a) The elderly are thus able to observe the daily and temporal activities of the daycare center from their communal living space. The elderly may sit and chat in their living room while observing, for example, parents dropping off their kids in the morning and picking them up in the evening; they can also observe and be aware of incoming visitors to the island. By juxtaposing the senior living lounge and the daycare lobby, the senior's routine and living rituals would be enriched by the ability to observe the temporal activities of the daycare center.

\section{Restfulness vs. Playfulness:}

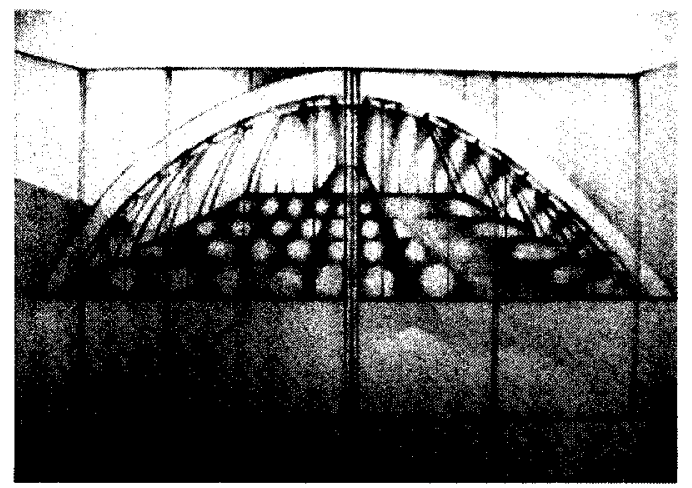

Figure 59: Vignette, from the lounge of the senior home viewing across the playground of the day care center
The children's playground is placed next to the senior's lounge and planting garden that is situated in the new extension building. (Figure 63, $3 \mathrm{e}$ \& 2f) This was done in order to give the garden a clear view of the children, allowing the elderly to observe the children at play. The residents can

thus sit in a serene and peaceful environment while their eyes and minds are visually stimulated by the playful atmosphere. This juxtaposition creates a chance for the elderly to perceive a space through sensations and visual appearance that evokes their imaginations (Figure 59). 
Observed vs. Observing:

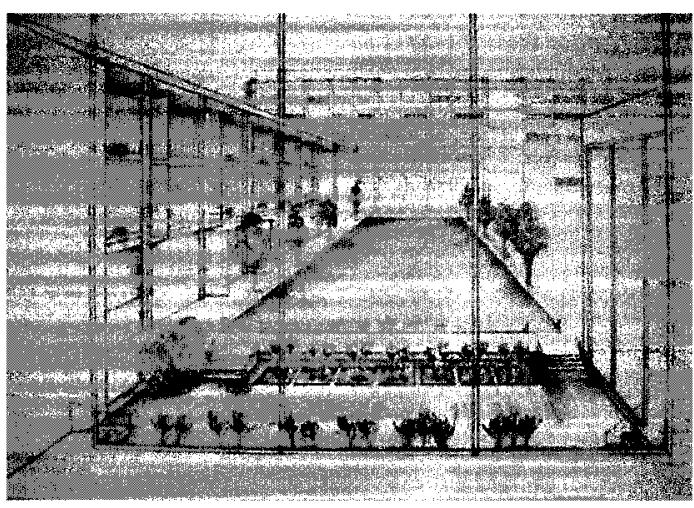

Figure 60: Vignette, Children Classroom viewing out to the water Playground/ Reflecting Pool

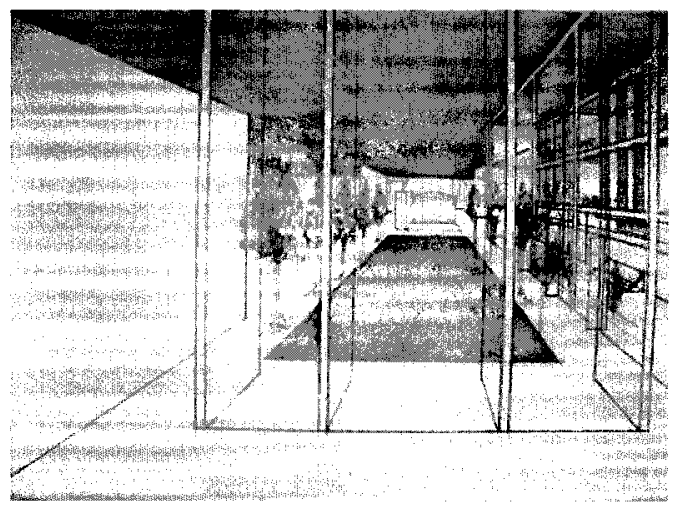

Figure 61: Vignette, Senior Assembly hall viewing out to the Reflecting Pool

The children's classroom is placed across from the senior assembly hall and separated by a reflecting pool/water playground that is placed between the two. (Figure $63,1 b \& 2 d)$ The children are able to view the reflecting pool from their classroom while they are learning, giving them a chance to observe a variety of natural transformations: the water reflecting the different colours of the sky, weather patterns and seasons. In the summer, part of the reflecting pool will serve as a water playground for the children, while the path that surrounds the reflecting pool becomes an exercise path for the elderly. And, of course, the activities in or around the pool are all reflected on the surface of the water, which will serve to enhance the visual space for people who are in or around the building. The setting thus creates interesting moments during which one may observe and at the same time be observed. (Figure $60 \& 61$ ) 
Life vs. Death:

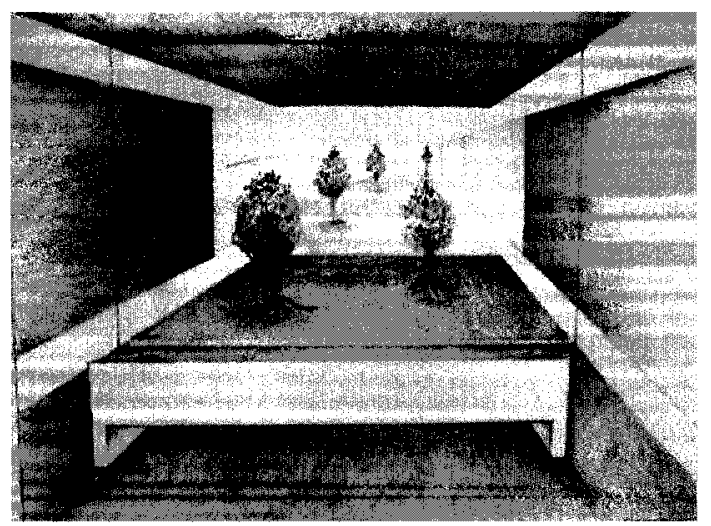

Figure 62: Vignette, The planting garden
The planting garden is a space that allows for some direct contact between the children and the elderly, as some residents may work as volunteers to instruct the children on planting flowers and plants.

Metaphorically, the planting process allows them to experience time together: a seed grows from the soil by careful watering along with the help of the sunlight; this process is repeated over many days, nights, months and years. The agricultural cycle represents birth and death, the life cycle; as the elderly and the children participate in the planting activity, they can experience the passing of time and an enhanced feeling of transience. (Figure 62) 


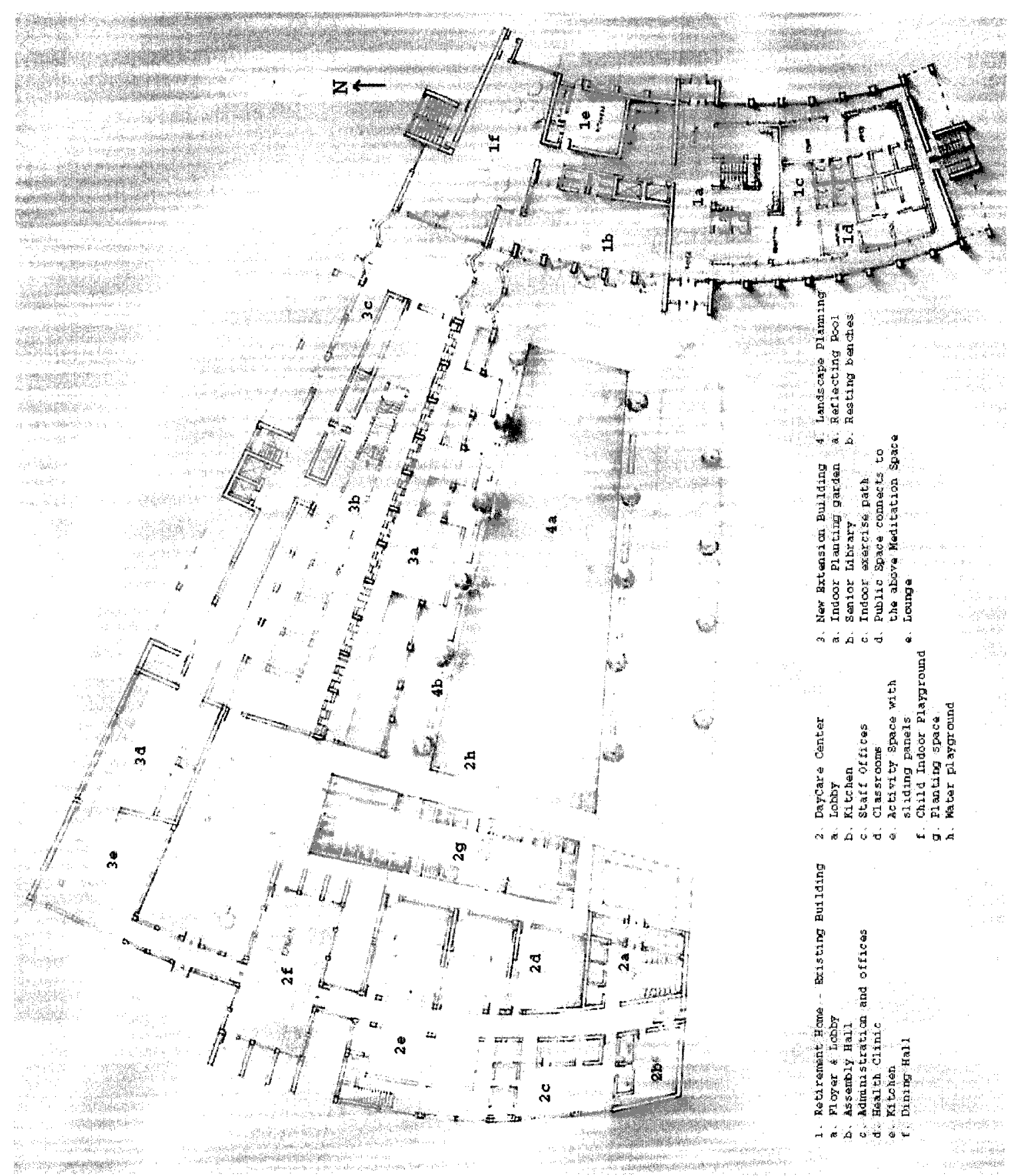

Figure 63: The Ground Floor Plan (1: 250) 


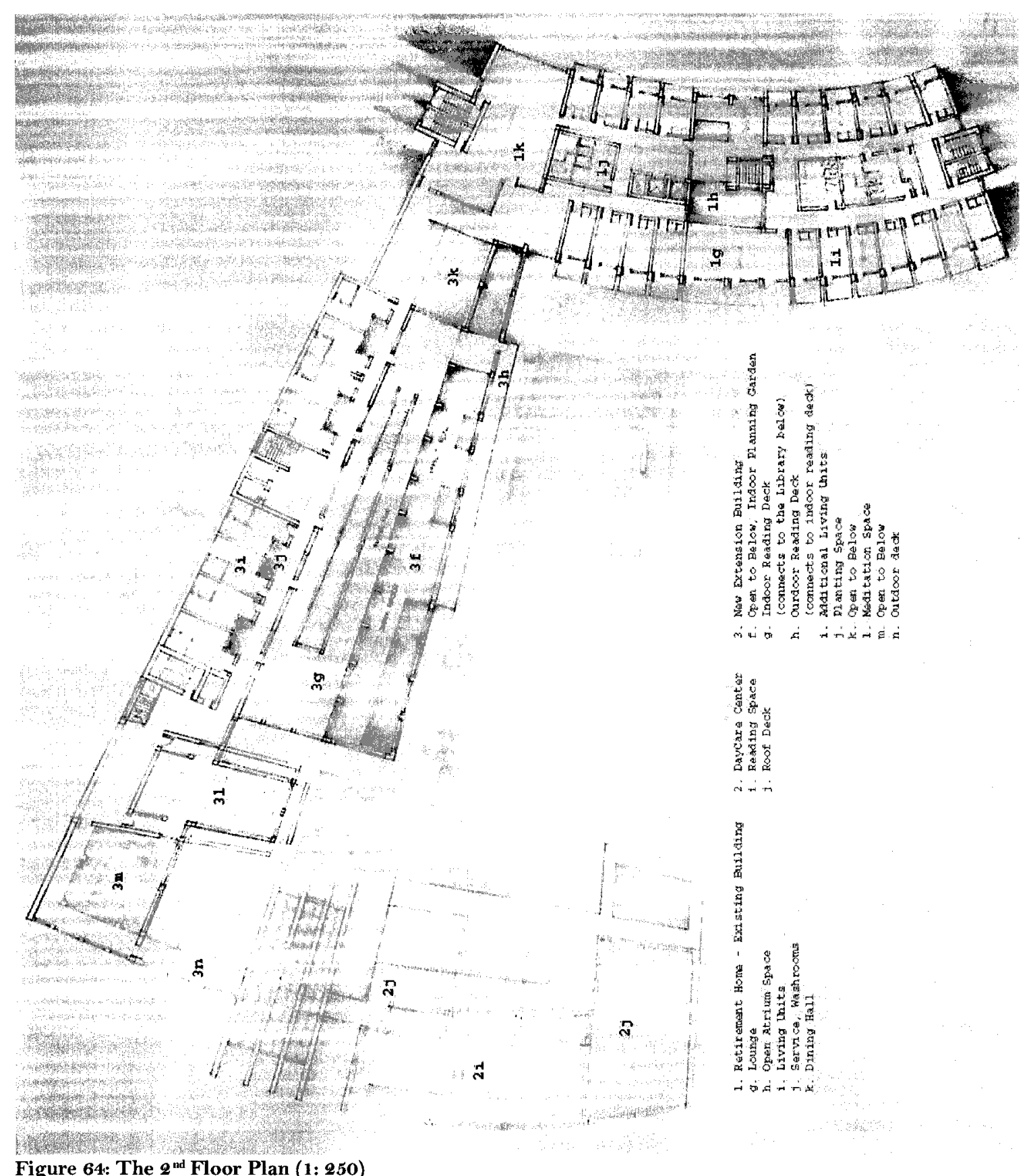


5.7 The Retirement Home: The Reconstruction of the Façade of the Existing Building
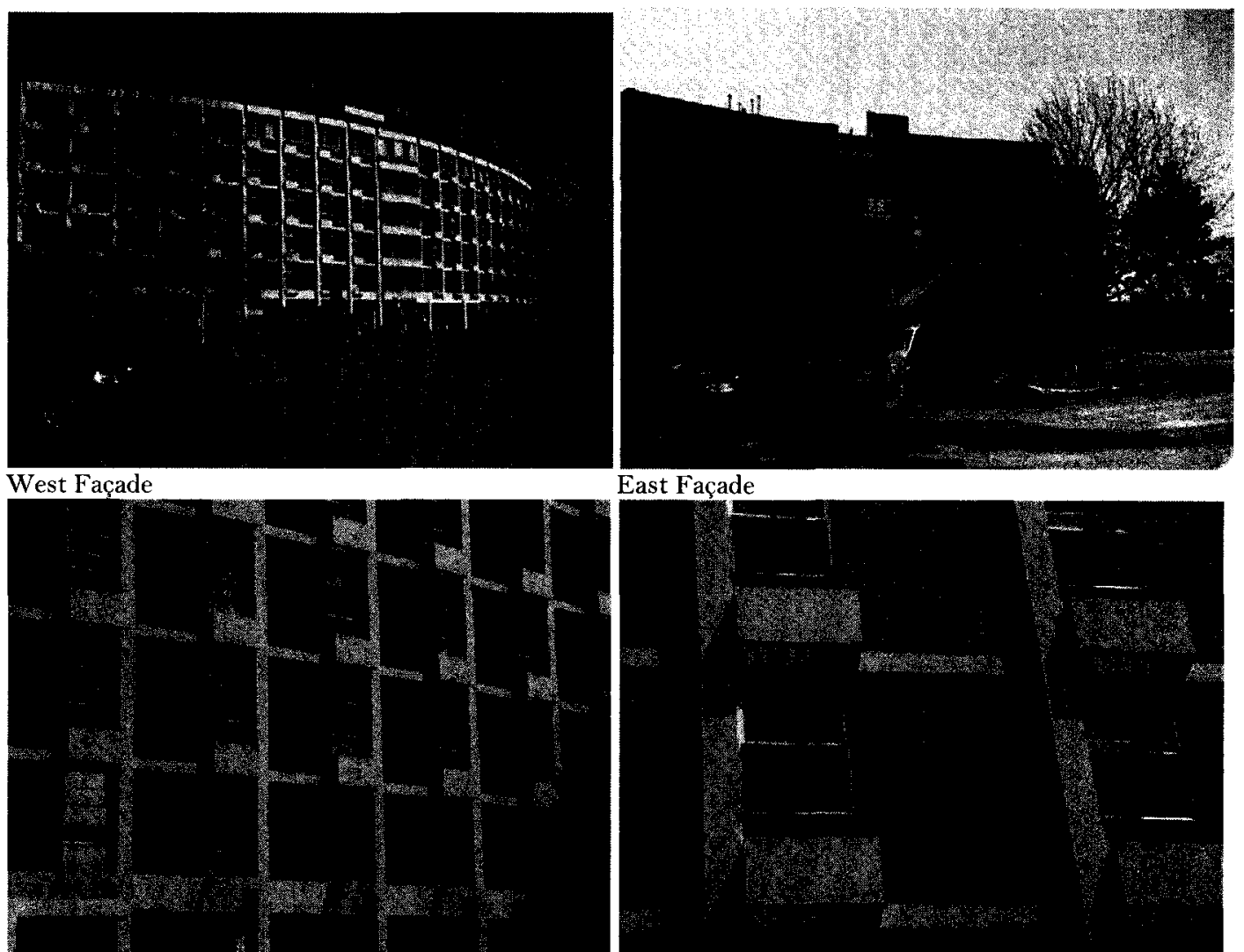
East Façade

West Façade, closer view

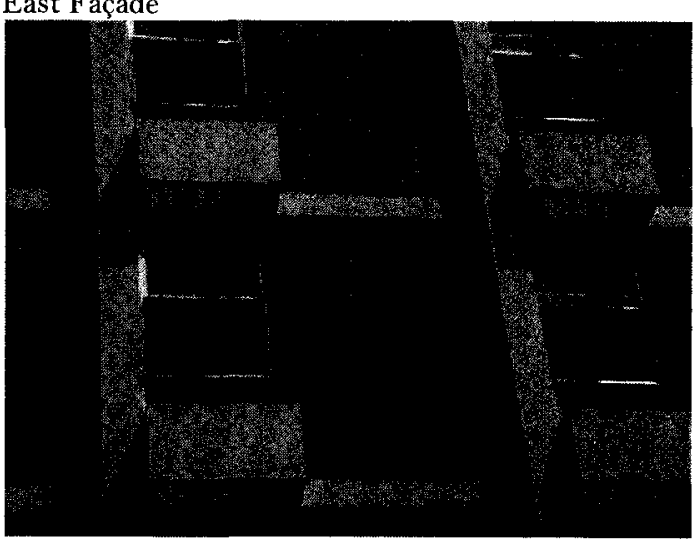

Figure 65: The Existing Building Condition

\section{Existing Building Conditions:}

All the living units (bedrooms) are organized along the west and east sides of the existing building, and all the services are organized in the center of the building, including washrooms, storage, staircases, elevators and hallways accessing the units (Appendix A). The western and eastern façade of the building are the two most important building skins that will directly affect the lighting condition of the units and the rest of the building. However, the existing façades (Figure 65) offer limited openings into each living unit, which constrains both the view and the amount of 
sunlight allowed into the unit. From the above site investigation, we see that the lighting conditions of the site transforms dramatically from the beginning to the end of a day, and throughout the year. The façades thus need to incorporate changes in order to encourage stronger relationships between the dwellers and their space.

\section{Living Unit: Louver Façade}

As the senses are part of one's body and part of the world, the way to know about a dwelling space is to perceive it through one's body. The concept of designing these façades is to provide flexible ways for the residents to react and respond to changes in the external lighting condition. The façade is thus designed with two adjustable louvers that can be controlled by the residents.

The original façade is to be replaced by a window façade which would give a wider view from the unit and the floor slab is to be extended out, becoming a balcony space where the adjustable louvers are placed. The louvers extend out from the window façade to the balcony space. (Figure 66-7)

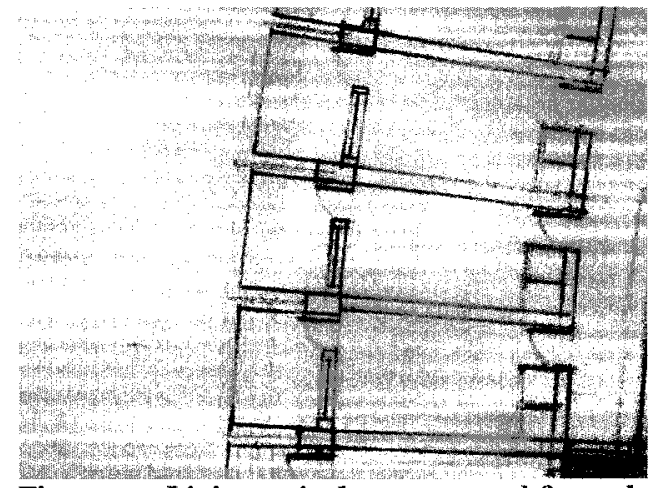

Figure 66: Living unit, louver extend from the unit out to the balcony, floor plan drawing

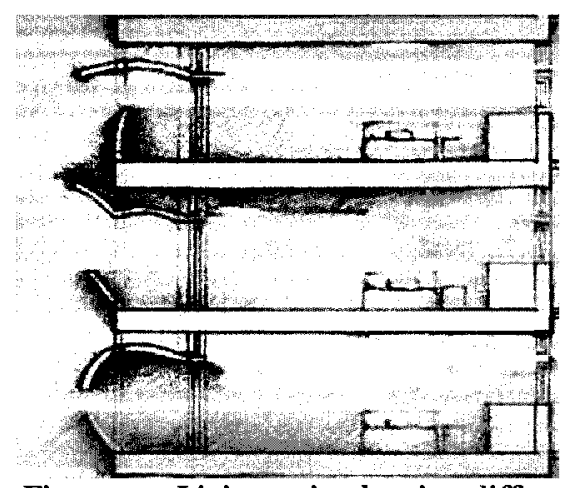

Figure 67: Living unit, showing different ways of adjusting the louver and shading different parts of the room, section drawing 

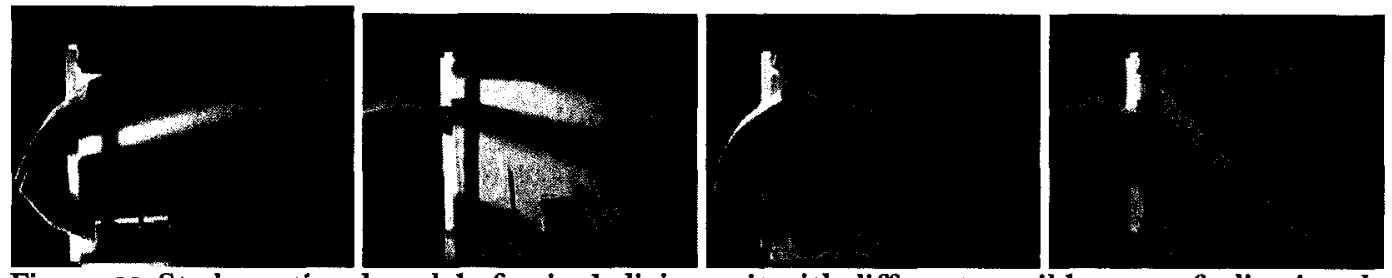

Figure 68: Study sectional model of a single living unit with different possible ways of adjusting the louver when light penetrate into the space
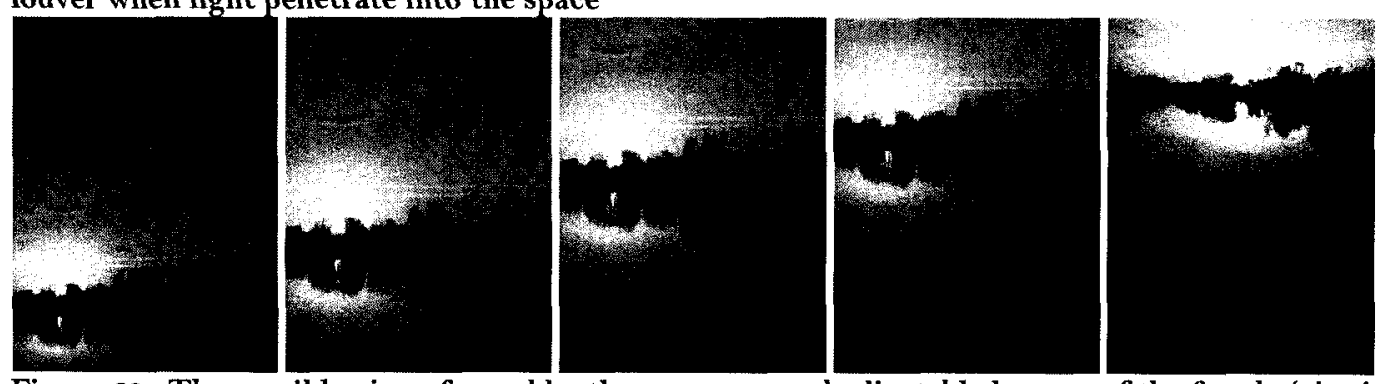

Figure 69: The possible views framed by the new proposed adjustable louvers of the façade (viewing out from the unit)
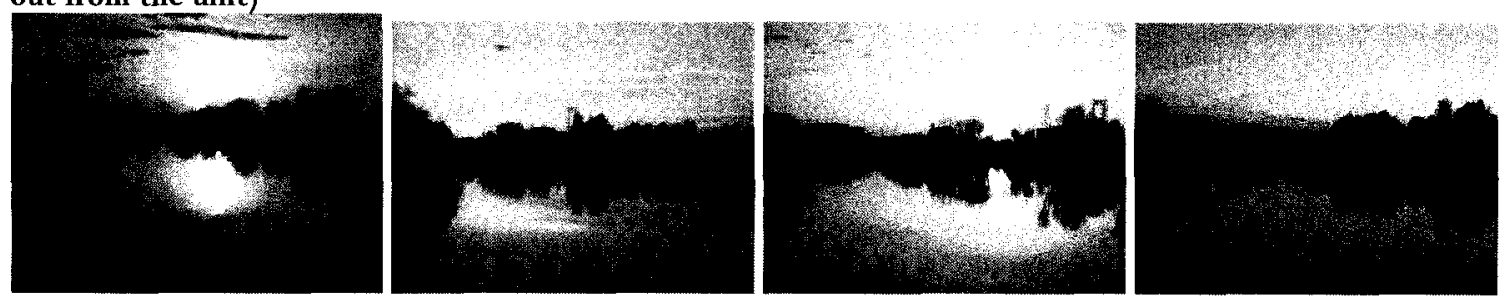

Figure 70: The selected view, transform in different time of a day

The study model (Figure 68) shows the possible ways that the proposed

adjustable louvers can be opened and the amount of sunlight that can be allowed into each living unit in accordance to the dwellers' need. The upper louver is designed to control the intense sunlight during the day when the sunlight comes from high in the sky. The lower louver can be controlled to address the morning and evening light when the sunlight penetrates from a lower angle. The upper and lower louvers can also be adjusted to frame a designated view towards the sky, the horizon or the water (Figure 69). These views offer many possible choices for dwellers to perceive their surroundings and permit the individual to access their own personally designated views. The wide and clear vision that this island offers gives a sense that they are situated in a boundary-less setting. The framed view promotes a sense of vastness in the space, 
especially as the colours of light change over time (Figure 70). The chosen views and the transforming qualities brought into the unit would enrich daily living.

\section{Units: Louver relationships}
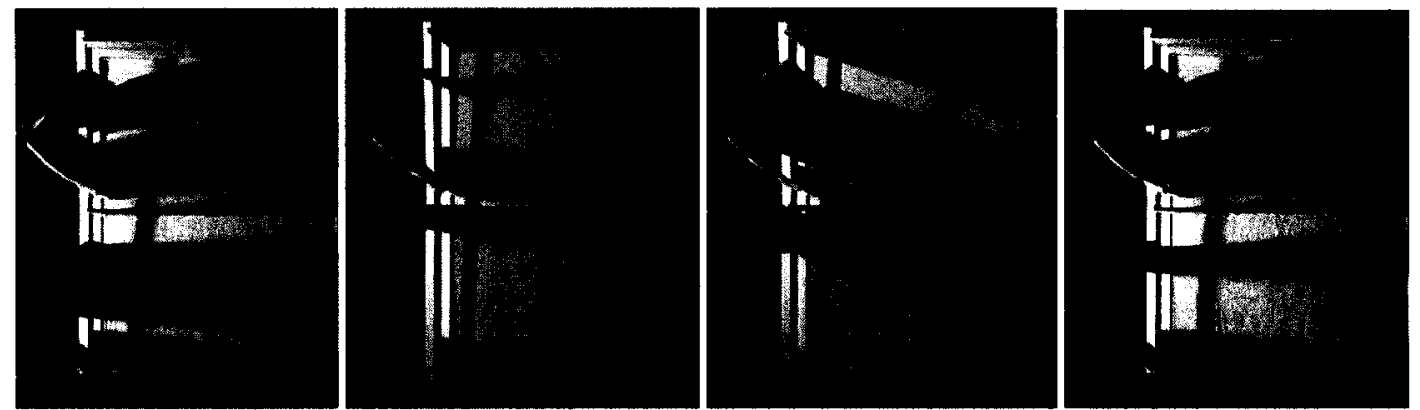

Figure 71: Study sectional model of two units showing the relative relationship between the upper and lower units

The study model (Figure 71) shows the relative relationship between the upper and lower units when the louvers are adjusted differently. The action that dwellers make will slightly affect the lighting conditions of the lower unit. However, it is intended that the light that bounces between the upper and lower louvers would not affect the spatial quality but bring about an awareness of light to other dwellers and hence encourage stronger relationships between the dwellers and the surrounding spaces. 


\section{Corridor: Louvered Ceiling}
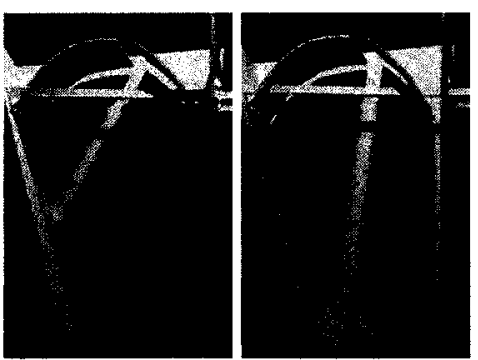

Figure 72: Study model, louver ceiling for the summer with non-reflective material
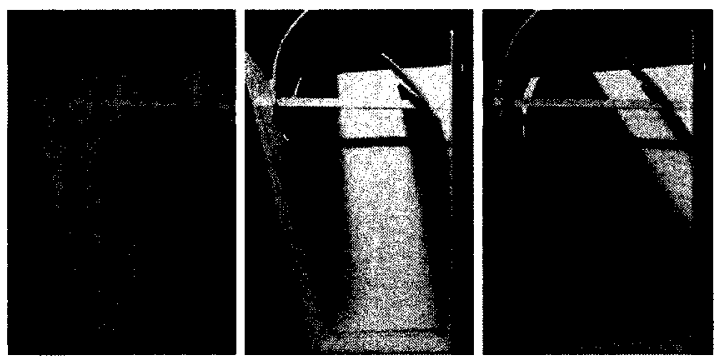

Figure 74: Study model, louver adjusted with different angle for the winter, with non-reflective material
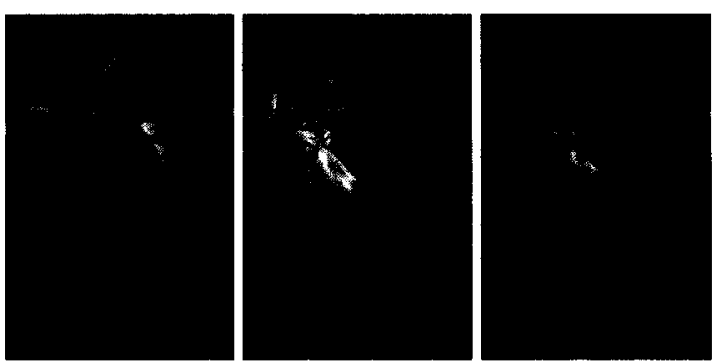

Figure 73: Study model louver ceiling for the summer with reflective material
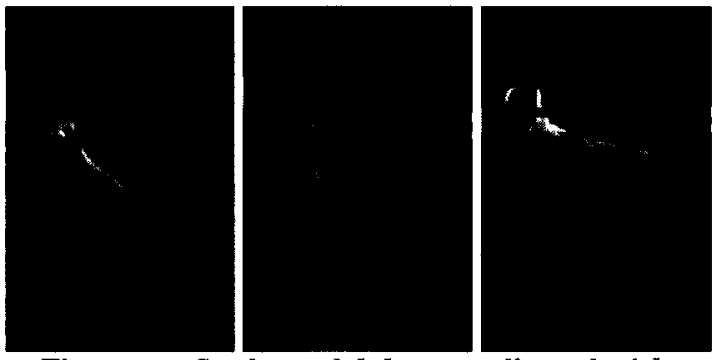

Figure 75: Study model, louver adjusted with different angle for the winter, with reflective material

The concept of the louver in the units runs along to the ceiling of the corridor of the building. The models show different lighting conditions during morning, noon and evening for both summer and the winter. The first set of models (Figure 72) shows the quality of light when the louver is made of non-reflective material and it is closed against the intense summer sunlight. The second set (Figure 74) shows the louvers opened to maximize the meager sunlight in the winter. The light that appears in both of these models clarifies the form of the space through the creation of strong contrasts between light and dark. The light that contrasts the dark suggests a sense of movement that direct one's vision along the light paths. On the other hand, the louvers are made of a reflective material (Figure 73) that bounces light randomly, a soft and dynamic gesture that gives the space a fuzzy and mysterious feeling. In contrast to the nonreflective material, this lighting condition doesn't give any directions, only a sense of 
pulse and wonder as the light diffuses randomly. The design of the corridor ceiling for this building incorporates both ideas together: the corridor composes light rhythmically between motions and pulses. The pulses allow dwellers to have a moment to decide and think before accessing other spaces. The interplay between these two rhythms of light ultimately turns the corridor space into a lively and welcoming space. In order to let the corridor on each floor have this light experience, a small portion of the floor slab will be glazed for light to penetrate down below. (Figure 76)

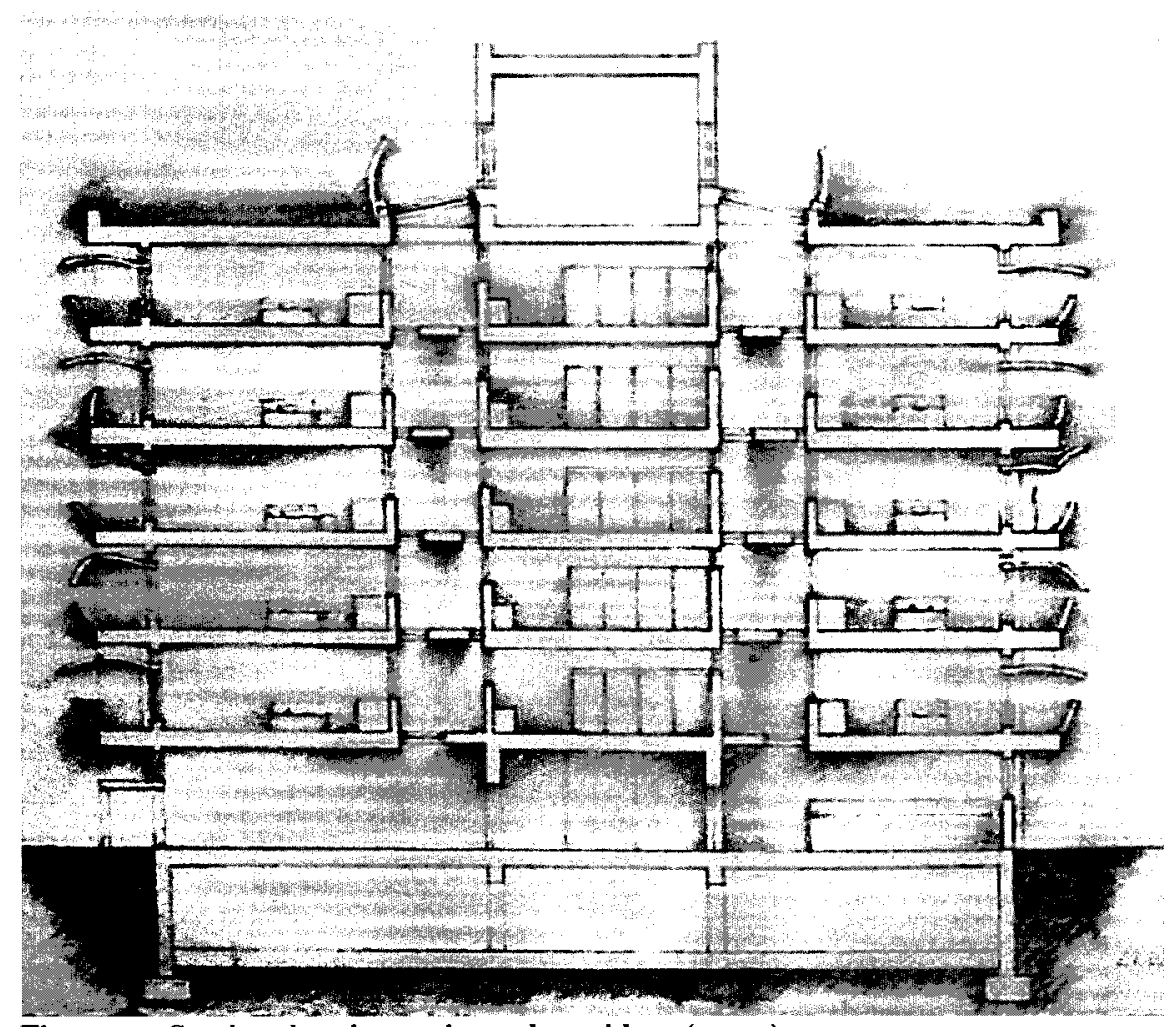

Figure 76: Section drawing, units and corridors (1:100) 


\section{Communal Lounge: Atrium Space}

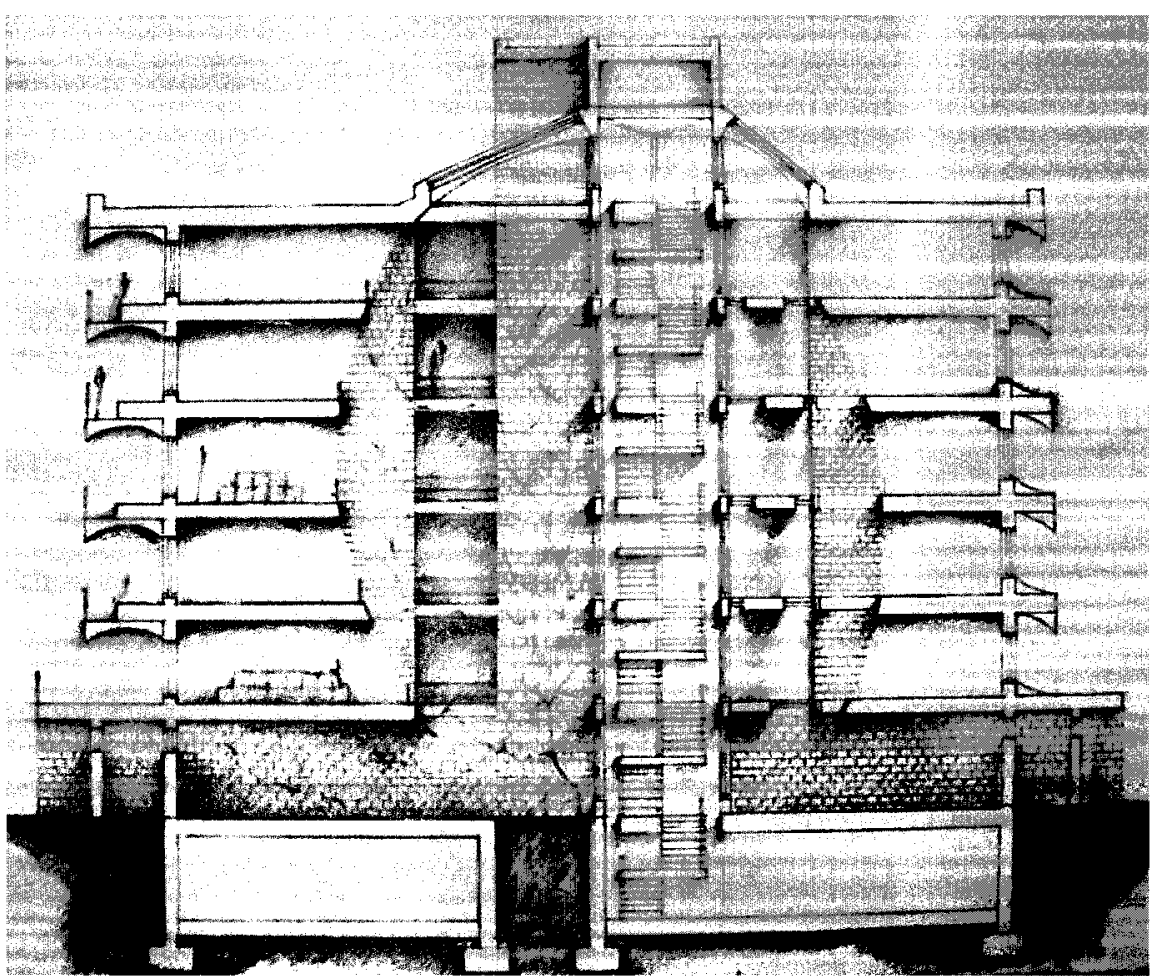

Figure 77: Section drawing, communal lounge with the atrium space $(1: 100)$

An atrium space is proposed in the center of the building. (Figure $78,1 \mathrm{~h}$ ) The curved form of the corridor ceiling is further developed into the form of the atrium space. The curve shape is intended to maximize the sunlight for the west side of the lounges in the morning and vice versa for the east side of the spaces to capture maximum sunlight in the evening. (Figure 77) The wall of the existing staircase is proposed to be turned into glass which permits the light through casting shadows of the occupants as they walk on the stairs. The movements of the walk and their shadows give the occupants a feeling of dynamic and exciting as if the light is a celebration of the spaces. 


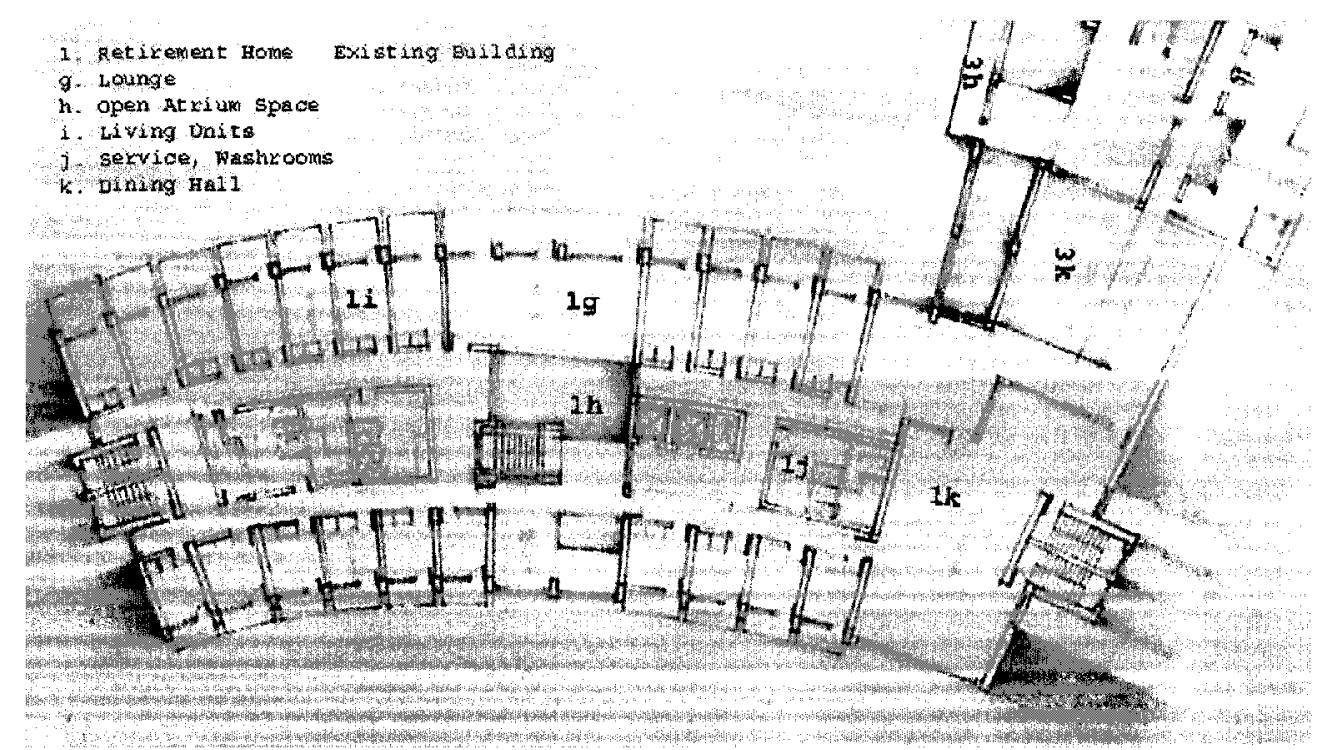

Figure 78: The renovated floor plan of the retirement home: $2^{\text {nd }}$ floor with living units

\section{Design Conclusion:}

The proposed changes to the building skins will change the spatial qualities of the entire existing building. The new living unit façade will provide choices for the individual dweller to adjust and respond to external lighting conditions according to their own sensations and feelings. The design allows them to frame their designated perspective of the world and bring temporal qualities into their living spaces. The designs for the corridor ceiling and the communal atrium space are aimed at directing the rhythms of the sunlight into the space and generate spaces with rhythmical and dynamic qualities. It is important to bring such awareness and attention into spaces for the dwellers because, as discussed earlier, Taoists believed that lives on earth are in temporal flux and the way for ideal living is to permit one to experience the temporal and dynamic orders of nature. Thus, the changes that have been made to the existing building would enhance a closer relationship for the dwellers and their living spaces with the temporal experiences of sunlight and time passage. 


\subsection{The Daycare Center}

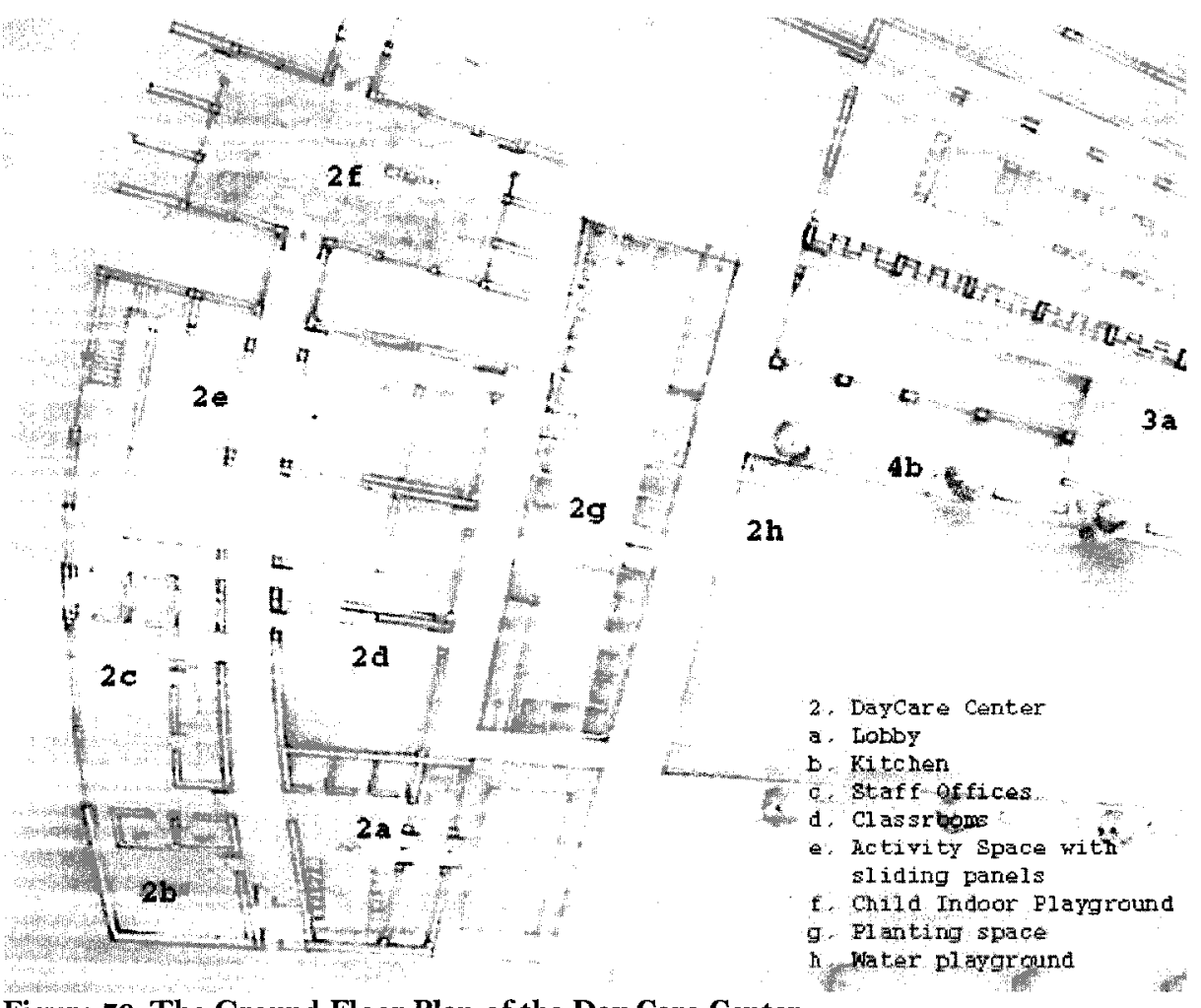

Figure 79: The Ground Floor Plan of the Day Care Center

The Children's Playground:

The intention behind the Daycare Center is to spark the curiosity of the children through learning and playing and hence increase their awareness of their surrounding space. This concept is primarily expressed in the design through an arched roof that covers the entire playground (Figure 79, 2f). The roof stretches from east to west and contains small circular openings that allow the sunlight through, projecting light and shadow onto the ground. (Figure $80 \& 81$ ) The ground serves as a canvas that captures the light and shadow of the structure above and also the shadows of the children themselves. As they play on the ground, their own body shapes are cast among the other shadows and their bodies interact with the structural form. The lighting 
condition within the space transforms at different times of day in accordance with the angle of the sunlight. Thus, the appearance of the physical forms, the intensity of the sunlight and the direction of the light source change constantly through the day and year. The consistent transformations of the space would structure the essence of this playground. 


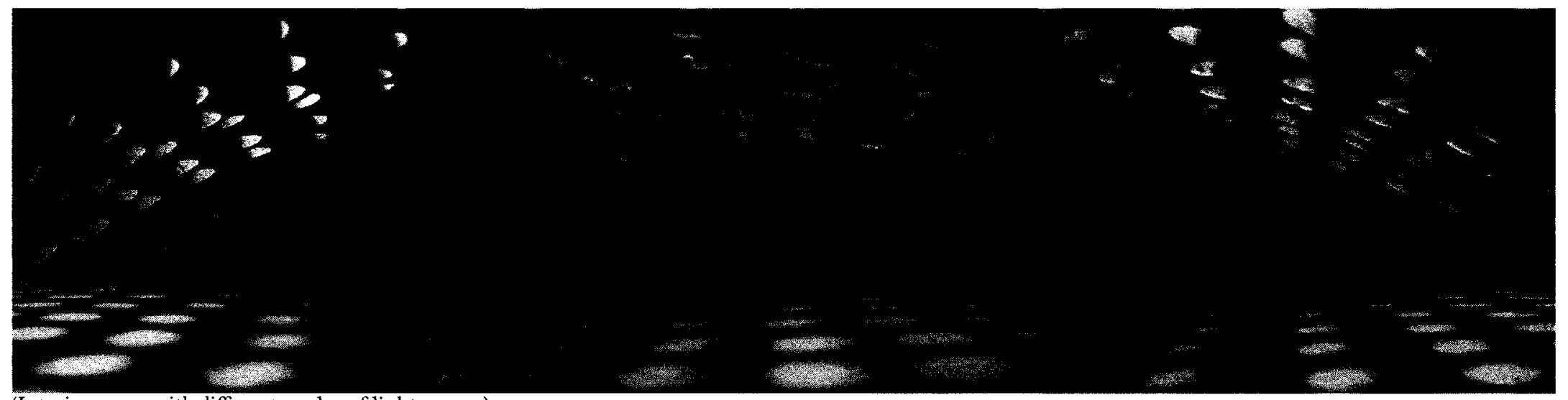

(Interior space with different angles of light source)

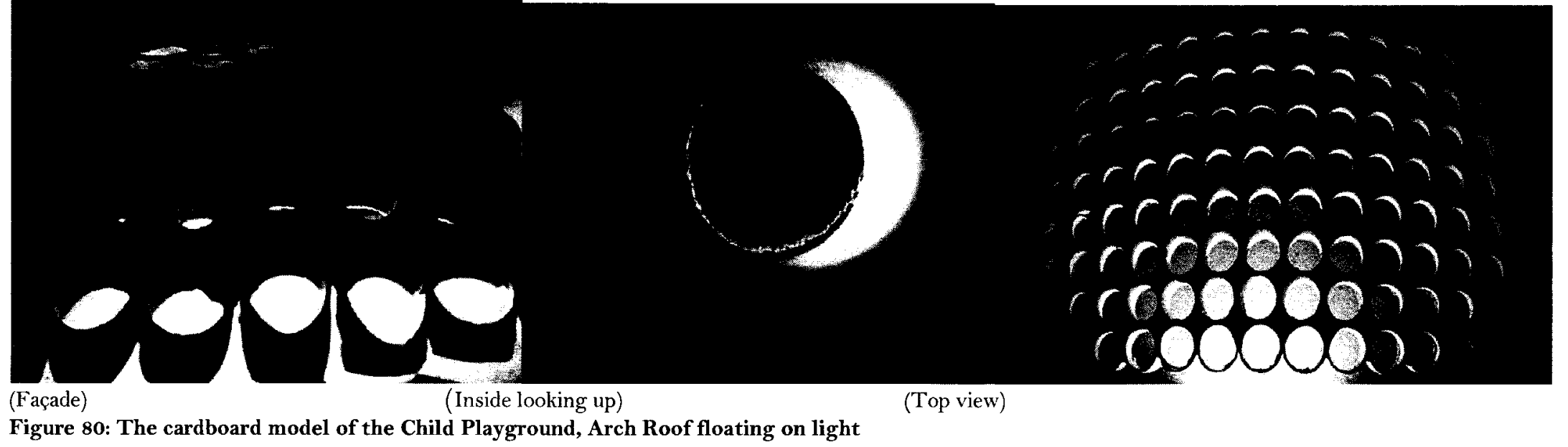




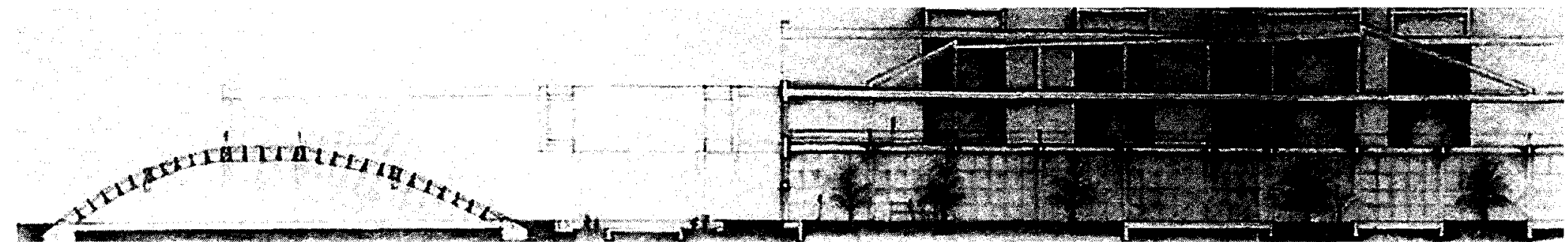

Figure 81: Arch roof of playground viewing the planting garden, section drawing (1:100)

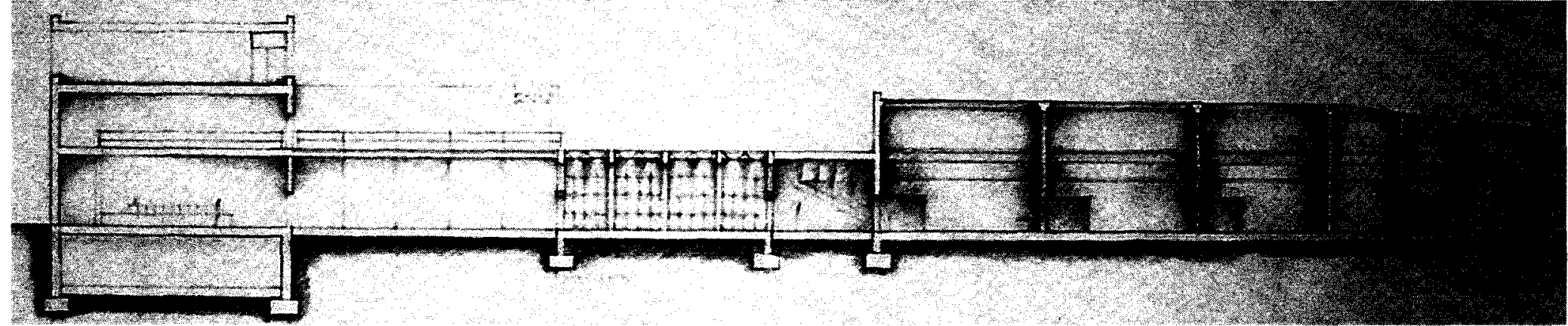

Figure 82: Corridor space connects to retirement home, section drawing (1:100)

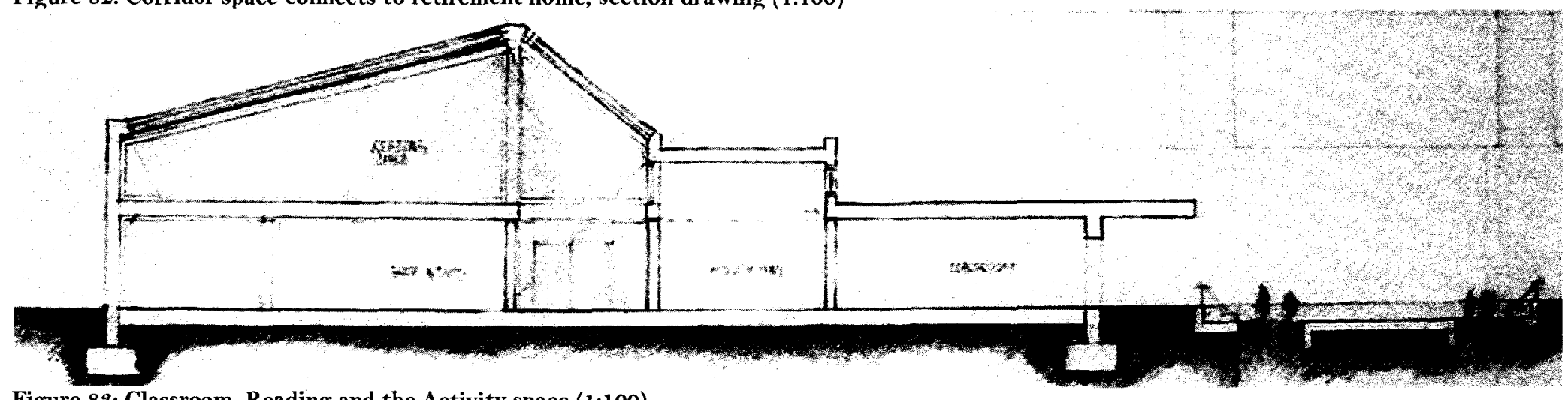

Figure 83: Classroom, Reading and the Activity space (1:100) 
The Classroom, Reading and Activity Space:

The walls that divide the three classrooms are designed as sliding panels which can be adjusted and combined from three classrooms into one space. (Figure 79, 2d) The same idea also applies to the activity space adjacent to the classroom, so the activity space can merge into the classrooms for group activities. The reading space is placed on the $2^{\text {nd }}$ floor and serves as a skylight for the spaces below. (Figure 83) The glasses of this skylight are tinted in blue, yellow and red. When sunlight penetrates through these three primary coloured glasses, the reflected sunlight would transform into various colours into the space. Thus, the space below the skylight would receive all different colours as sunlight penetrates from different angles. (Figure 82)

As young children have limited personal history and life experience, the way they perceive space is more concerned with daily phenomena. The design of the playground, classrooms, activity and reading room bring the natural light into a playful and vigorous space that permits children to learn and understand the place that they are situated in.

\subsection{The New Extension Building}

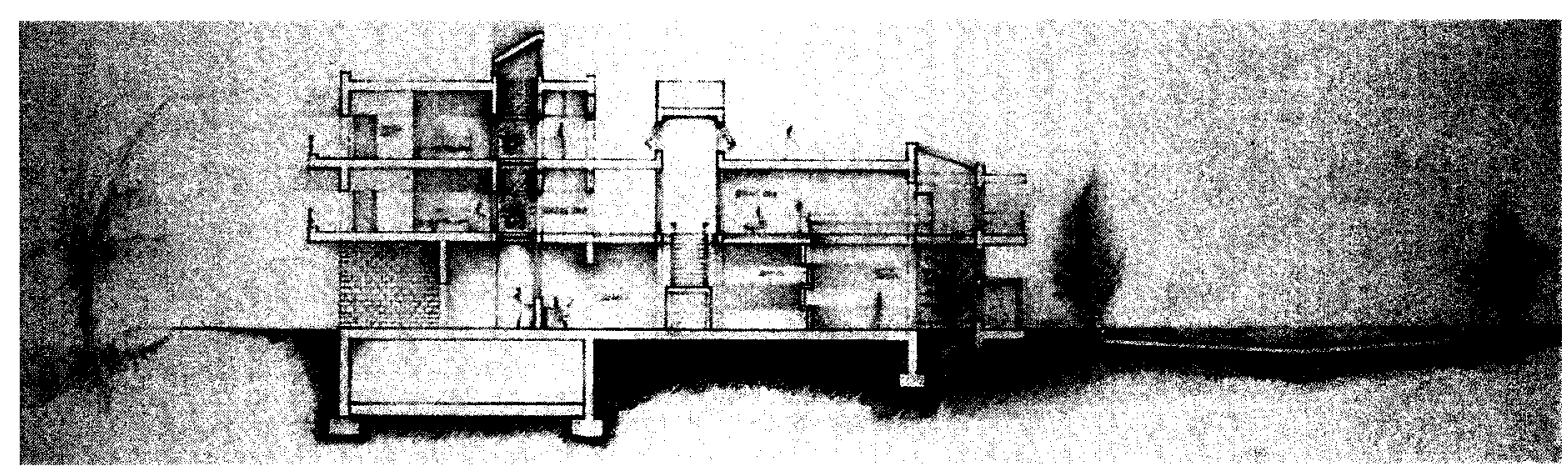

Figure 84: Section drawing, relationship between units, library and the indoor garden (1:100) 
The new extension building is three stories high with: an indoor planting garden, a library, 16 new living units, and a meditation space. (Figure 64 \& 84)

\section{Planting Garden/Flower Market:}

The south facing indoor planting garden is two stories high. The garden facade consists of movable glass doors that can be opened and closed. (Figure 85) When it is open, the garden expands out into the reflecting pool area and brings the garden outside and turns it into a public space

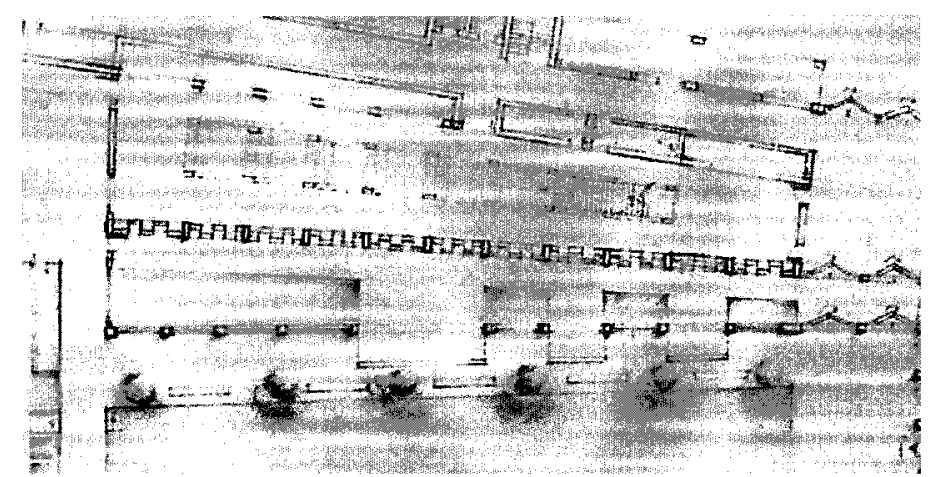

Figure 85: Indoor planting garden, floor plan (1:250)

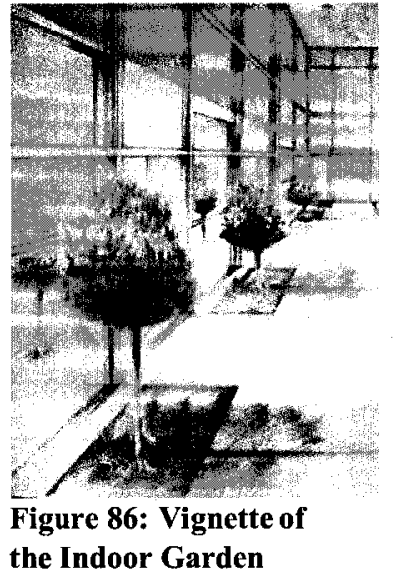

The garden allows contact between the elderly, the children and the community. Through the planting activity, the elderly may instruct the young children on a variety of garden skills; their products may be sold to neighbours and the garden can even turn into a flower market during weekends. The program would enhance social participation among all factions of the community. 


\section{The Library:}

The new proposed library is placed behind the planting garden that is separated by a south facing wall. (Figure 87) The library has two levels: the ground floor is mainly used to store books and the second floor is a reading deck which is connected back to the indoor planting garden. On the ground floor, a southern wall is designed to filter the intense southern sunlight into the library and protects the books from a direct exposure to the sunlight. (Figure 88) The wall is made of concrete panels and organized in a grid pattern. The panels are set at an angle which leaves gaps inbetween the panels and allow light to enter through these gaps at an angle. This avoids direct glare from the sunlight and offers a more comfortable space especially in the afternoon. The concrete panels would absorb the sunlight during the day, releasing their heat and warming up the space at night. During the day, the sunlight softens the rigid grid structure and renders the wall into different lighting patterns at different times of the day (Figure 89). Readers in the library would be aware of the time passage through these patterns. At night, the wall also becomes a lighting fixture for the indoor garden when the library is occupied. 


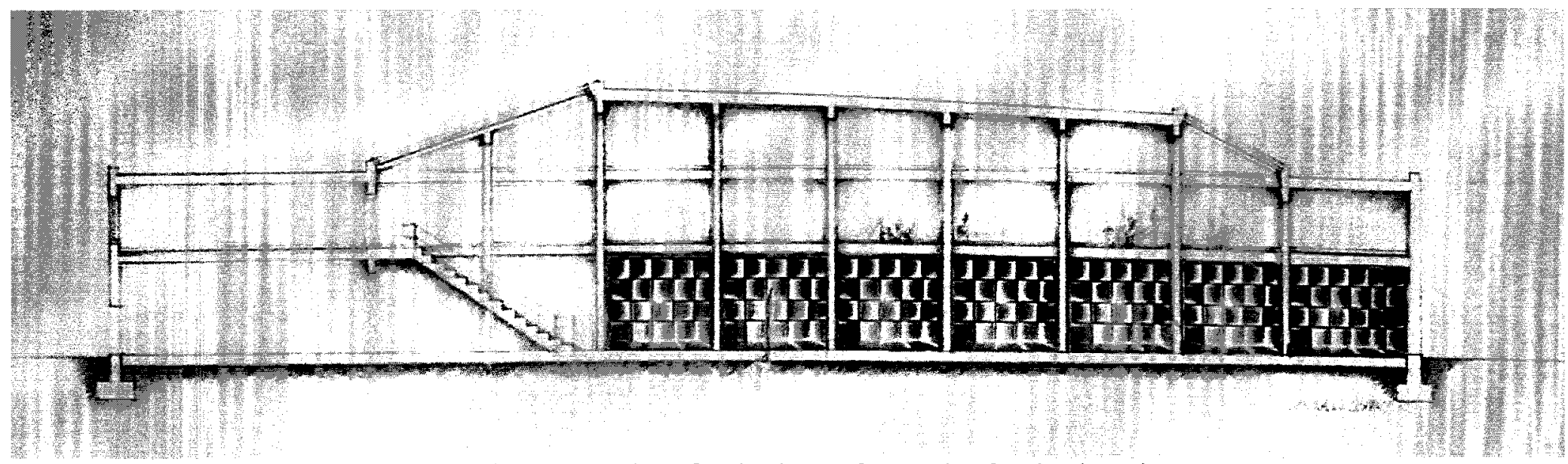

Figure 87: Library viewing the southern wall that separate from the planting garden, section drawing (1:100)

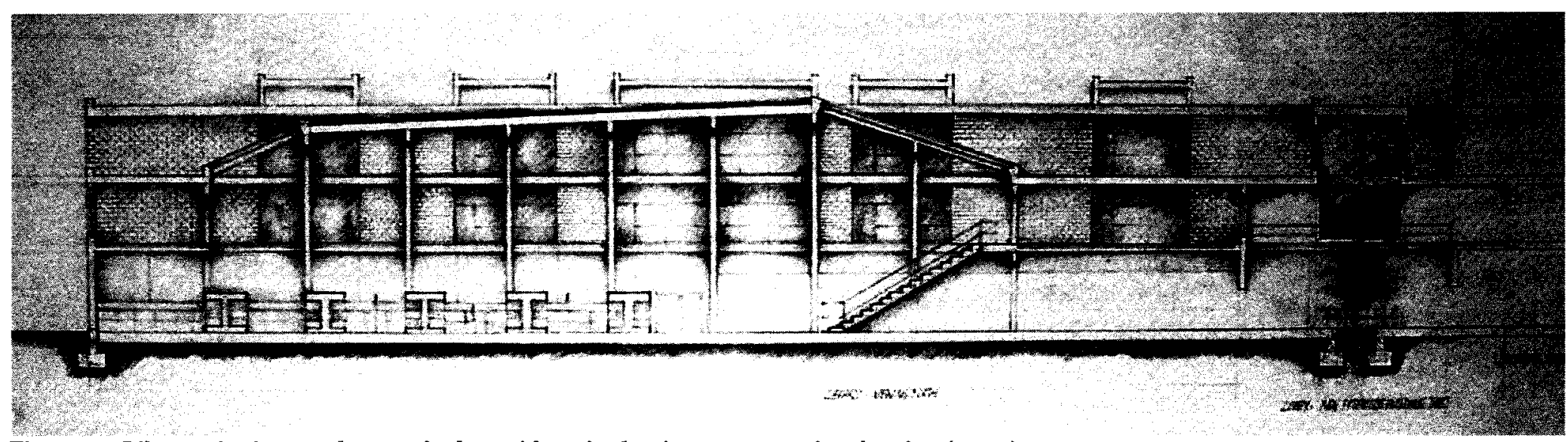

Figure 88: Library viewing north towards the residence's planting space, section drawing (1:100) 


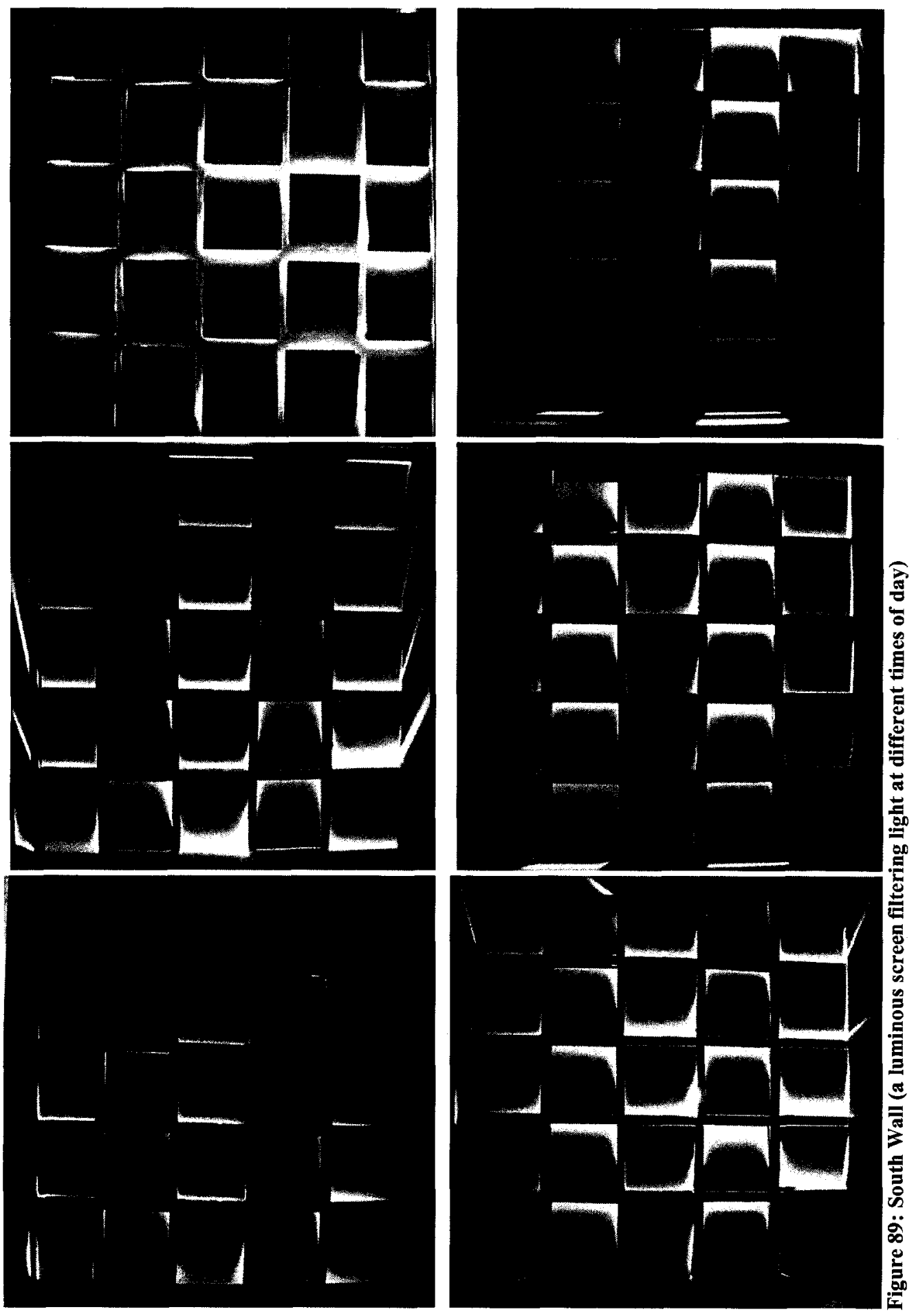




\section{The new Living Units:}

Since some of the units in the existing building have been removed, the new living units are proposed to be relocated on the second and third floors of the new extension building. In front of each unit, there is a planting space for the dwellers to plant and decorate the south entrance. This planting space is also a light shaft where the sunlight may penetrate down from the skylight into the units or it may also penetrate straight from the south into the units. (Figure $90 \& 91$ ) Dwellers are able to be aware of the passage of time through experiencing the different lighting conditions of the living space.

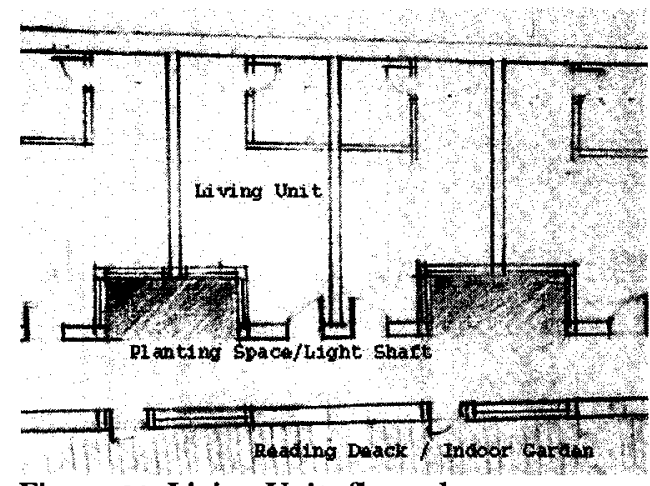

Figure 90: Living Unit, floor plan

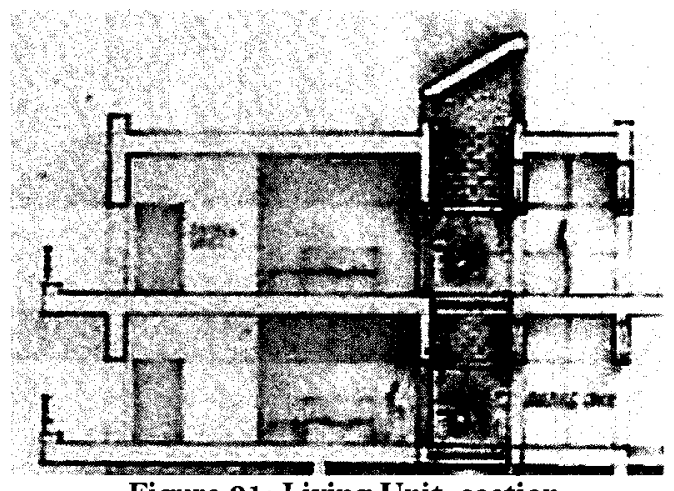

Figure 91: Living Unit, section

\section{Meditation Space:}

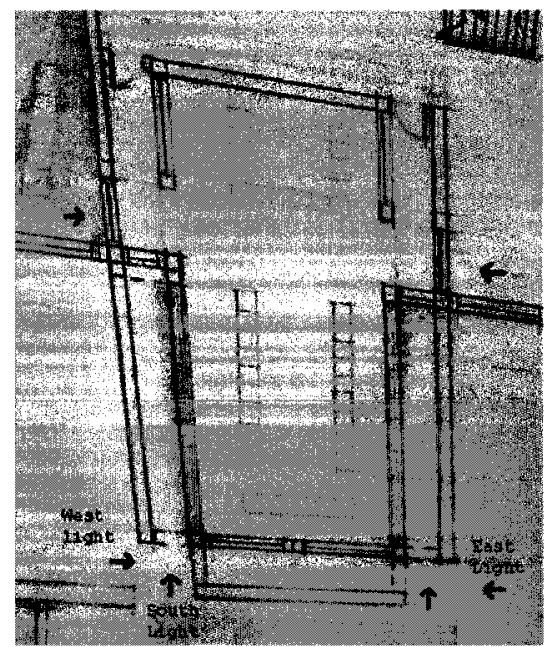

Figure 92: Meditation Space, floor plan
This program is designed for

residents to meditate and rest while experiencing the passage of time through light. The space is designed in a rectangular shape and is glazed on four sides; around this glazed box, there are four opaque walls surrounding the space but left with a gap in- 
between the glazing and the opaque walls. When sunlight penetrates through the space in the morning from the east, the sunlight would enter through the gaps from the east direction and lights up the south and north side of the space. As sunlight penetrates from the south at noon, the light would light up the east and west side of the space. (Figure 92) The space provides the residents with access to experience the passage of time through light. Such experience would inspire their imagination and encourages peaceful meditation.

\subsection{Landscape Planning: The Reflecting Pool}

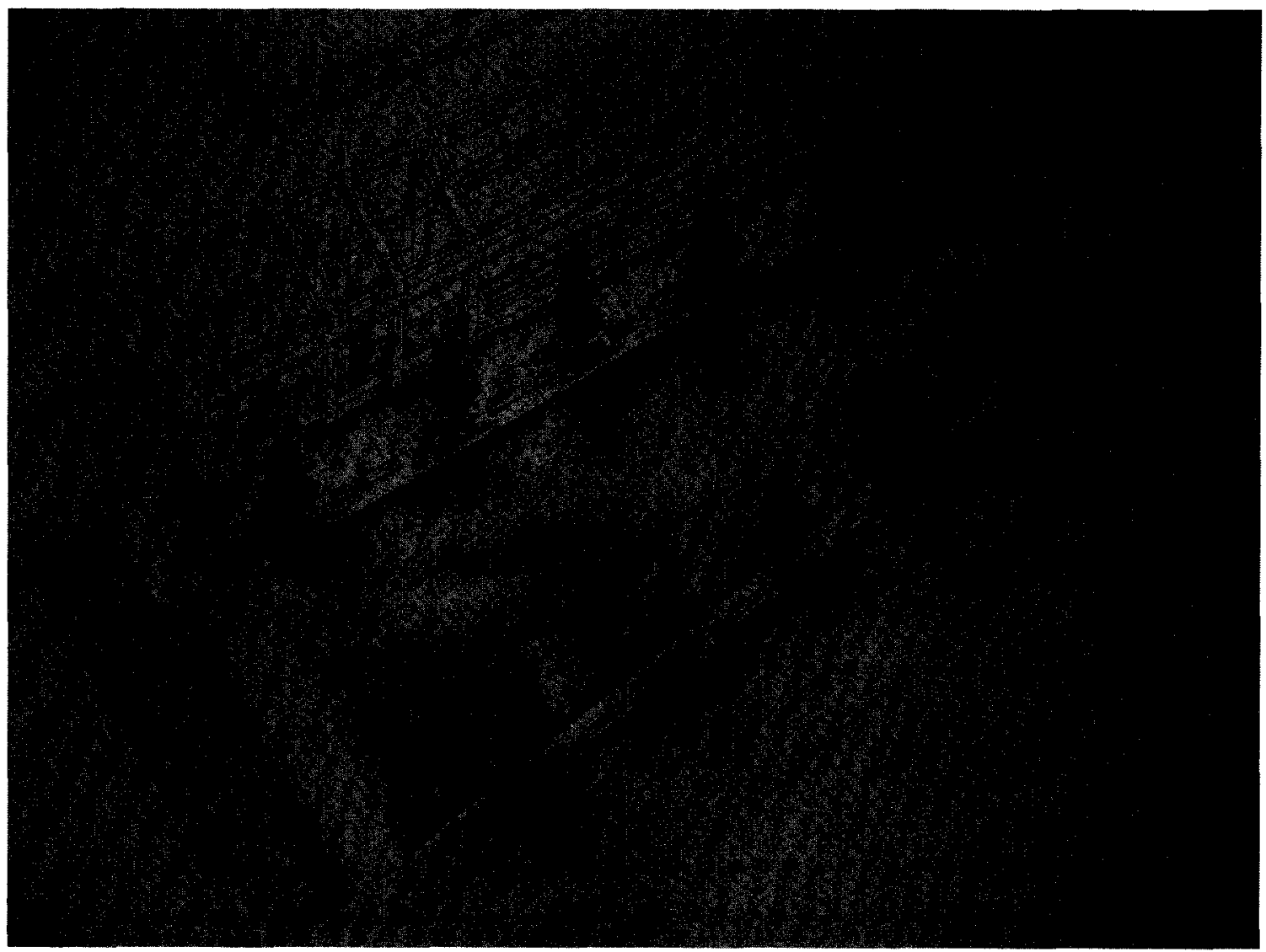

Figure 93: The Reflecting Pool, Axonometric drawing (1:250)

The reflecting pool/water playground is located at the center of the island.

Trees will be planted and benches placed around the pool. Next to the trees and 
benches, there is a peripheral exercise path surrounding the pool. During the days in the summer, part of the pool will serve as an aquatic playground for the children, and this playful activity would add a lively and energetic atmosphere to this outdoor space. The residents may observe the children playing while they are in the garden next to the pool. At night time, the children leave the island, and it becomes quiet and peaceful. The stillness of the water in the pool will then acts like a mirror and reflect the light from the moon and stars. During the winter, the water will be transformed into snow and ice, and the playground will turn into an area for ice sculpting and skating, while the elderly residents may again observe from the garden. (Figure 93)

In terms of Taoist philosophy, the void is always present and it is important to let the intangibles appear within what is present in the natural environment. This outdoor planning creates a void and public space in between the retirement home and the daycare center. This void serves as an anchor that visually holds the dwellers and the buildings together through light and reflection. The reflections from the pool emphasize both the natural phenomena and the daily activities on the island. Through them, dwellers may observe the changing lighting conditions of the sky, and the changes of the weather and seasons by observing the transformations from water to snow and ice. The pool thus serves as a container that lets nature manifest its properties and allows dwellers to participate in and observe the changes in nature. Metaphorically, water on the ground contains the image of the sky, but at the same time the reflected images extend one's vision towards the sky. This oppositional setting, contained and extended, ties the ground and the sky together into one single entity; dwellers are encouraged to sit calmly and observe as nature is brought inside oneself. All of these proposed programs are meant to emphasize the relationships 
between inhabitants and their space. When a space is meaningful, people feel at home, they begin to dwell. One's understanding of living space goes beyond its mere function as a shelter; it articulates experiences which give meaning to the relationships between people and the natural environment. 


\section{Conclusion}

The sun brightens our world with its light, but what gives us 'vision' is the light of our mind. In other words, light gains meaning only when we translate the external sensations into meaningful perceptions. One may see the sunrise, but may never notice its transformations and its impact on the surroundings if one rushes past the immediate offerings of the senses. As we have learned from Taoist philosophy, the ideal life allows natural wonders into our lives and progress gradually in a calm and tranquil way. Thus, it is critically important to understand our living environment through careful observation and a sensitive awareness of natural transformations; then we would be able to dwell along with our own senses and insights. The living experience that is intertwined with and dependent on the experience of light is an interactive process between sight and mind. Thus the way to seek the essence of dwelling is to live through this process, based on a sensory understanding of our surrounding space.

Through the above research and design, I have noticed that the process of experiencing a place involves a strong relationship among three importance factors: human, appearance and essence. One perceives the appearance of things through the presence of light. Then, one may be able to explore and identify the characteristics of appearances using the mind, and hence begin to understand essence. Between man and appearance, different perceptions and interpretations are involved because each person has his or her own perception. For example, the elderly may generally appreciate softer and gentler lighting conditions in their living spaces since they are more sedentary. By contrast, young children appreciate bright and playful lighting conditions in their spaces since they are active and energetic. Of course, all people have different perceptions and interpretations based on their personal histories. As everyone has his 
or her unique characteristics and perceptions, the value or essence changes from place to place and from time to time. As each place has its own characteristics, it is important to explore the structures behind the appearances of a place in order to permit individuals to express their own values and perceive essences within the same structure.

The above design project offers clear and wide views for dwellers to observe the world around them; the quality and variety of these views turn the island into a unique place. Based on the play of light and the Taoist concepts of Vastness, Incompletion, Formlessness, Oppositional Balance, Boundary-less and Scarcity, a structure will take shape behind the appearances of the site. The spatial design behind this structure provides a common ground for dwellers to observe and experience at a personal level, within the same structure.

As light reveals the appearance of a place, it also conceals the essence of a place. The process of experiencing and understanding a place through light permits the individual to see the invisible (essence) through the visible (appearance). This idea is parallel to Lao-tzu's thoughts on living: "Seeing into darkness is clarity. Knowing how to yield is strength. Use your own light and return to the source of light. This is called practicing eternity." ${ }^{56}$ To Lao-tzu, the ideal way to live is to be able to incorporate intangibles into one's life since the infinite growth of nature is inherent in the realm of intangibility. One is asked to be aware of such growth and comprehend habitual experience because such growth is what makes up one's living environment. Only if one responds to natural growth with insight can one recognize the true nature and be able to liberate one's mind, and hence achieve eternity. Taoism's ultimate goal for living is to achieve the eternity that gives freedom to human thought.

\footnotetext{
${ }^{56}$ Lao-tzu, Tao Te Ching, trans. Stephen Mitchell (New York: Harper \& Row, 1998), p.52.
} 
What makes us individual is the uniqueness of our minds. Our understanding of a place involves individual thought and imagination, which establishes a place as a safe and creative realm; indeed, this relates to the notion of dwelling, which is a state that lets acts of imagination take place. Thus, the value of architecture is to encourage one to dwell and hence, to dream, allowing for the freedom of one's mind and sight to collide, and the cultivation of inner perfection and a greater connection with nature. Thus, architecture should reveal the natural order and establish a harmonious dialogue with the world around us. In this way, one is able to maintain a balance between inner and outer worlds.

Through my research into Taoist philosophy, I've learned that a real sense of living comes when one is capable of communicating with the outer environment, and the understanding of this communication becomes crucial in the process of this research. Through the six concepts that I derived from Taoist philosophy, I've established a way to establish a communication between Porter Island and the architectural spaces that I have designed. With these six concepts as guides, I perceived the island from a number of different perspectives, which permits me to more fully understand the island with respect to its transformations and thus enabled me to reveal the intangible qualities of the site and incorporate them into the design. I've learned from Taoism that every place has its own character and uniqueness, and as an architect, it is crucial to reveal the intangible elements and bring people into contact with them. Architecture thus becomes a mediator that helps to communicate and bring people in contact with the vitality of intangible elements. 
Design is, therefore, more than a process of solving functional and technical problems; it is inherently a phenomenological and ontological process. In other words, it is a process that involves an understanding of the context of a place and reveals its essence through form. From this understanding, I've learned that the design of a wall, a roof, a skylight and a spatial composition are crucial elements in this process because they create the thresholds between dwellers and nature. The function of a wall then becomes less of a separator between spaces, but instead it serves as a site that permits dwellers to enter into dialogue and discourse with the world. For example, the south facing courtyard wall in the proposed design permits sunlight to enter in such a way that dwellers are more aware of the passage of time. Similarly, the design of the arched roof of the playground and the coloured skylight of the reading space transform natural light into playful and vigorous forms, which better permits children to learn about and understand the place that they are situated in. The spatial composition here is anchored by the reflecting pool, which serves as a void space that holds dwellers and the surrounding environment together visually through light and reflection. All of these design features attempt to bring dwellers into contact with natural phenomena; and at the same time these designs teach us that the architectural framework is more than a functional construction, but a framework that reveals the natural order and make this order part of the dweller's own. Thus, a skylight is more than an opening to let sunlight enter; it becomes a communicating device to bring dwellers into contact with the sky. Thus, the design process must incorporate the idea of dwelling, a process of exploration that enables us to experience the intangibles of the world, with our sensibility and imagination. 
Throughout this research, I've attempted to incorporate Taoist philosophical concepts into real everyday experiences through architecture. I hope to infuse architecture with a sense of living and promote inspiration in daily life by bringing nature into contact with the deepest aspects of human nature. 
Appendix A: The Existing Bunding (122 -

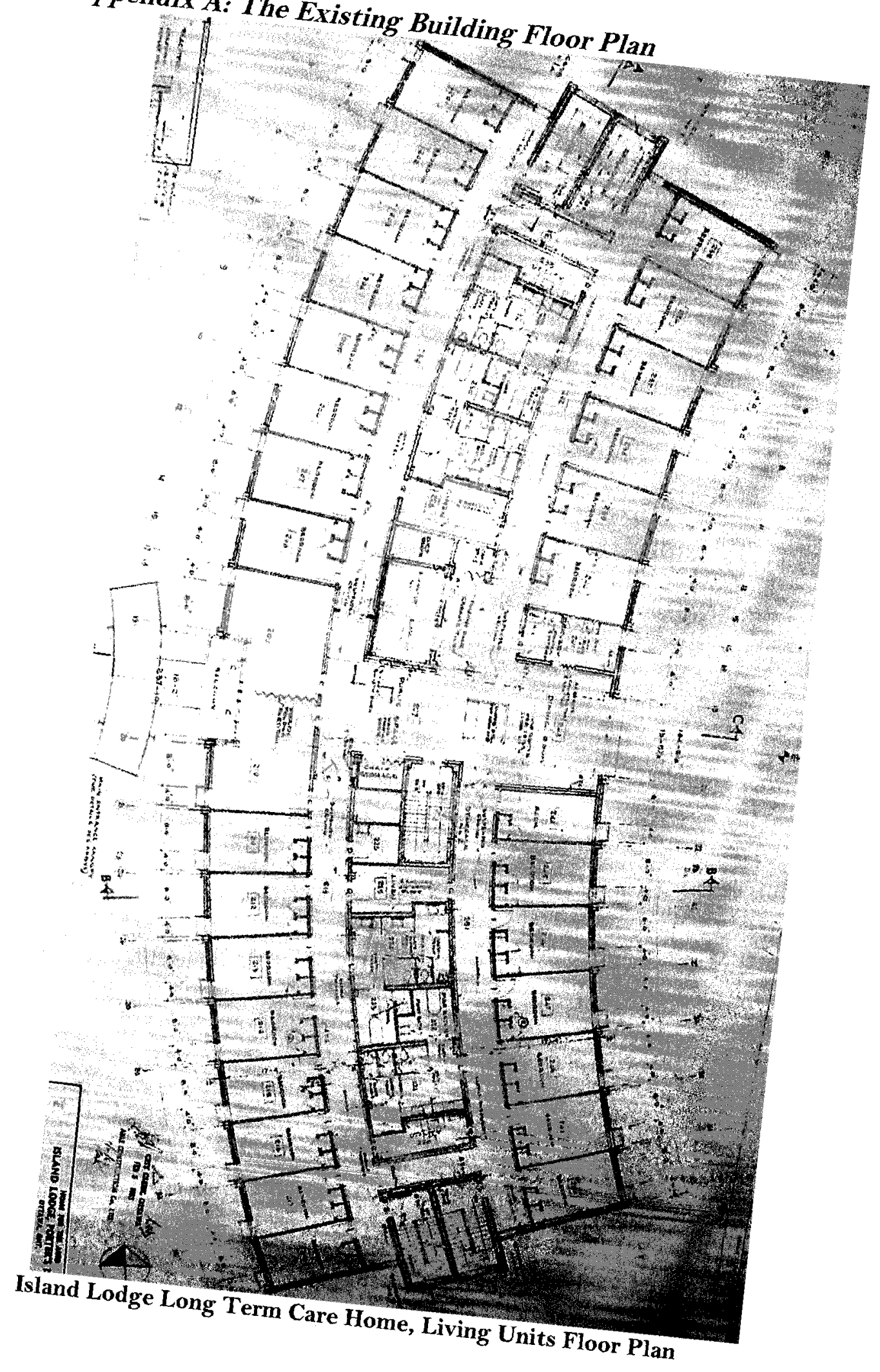

Reproduced with permission of thr 


\section{Works Cited}

Ando, Tadao. Architecture and Spirit. Barcelona: Editorial Gustavo Gili, 1998.

-. Tadao Ande: Light and Water. Trans. Kenneth Frampton. New York: Monacelli Press, 2003.

Auping, Michael. Seven Interviews with Tadao Ando. London: Third Millennium Information Limited, 2002.

Buttiker, Urs. Lowis L. Kahn: Light and Space. New York: Whitney Library of Design, 1994.

Chang, Amos Ih Tiao. The Tao of Architecture. New Jersey: Princeton University Press, 1956.

Chang, Amos Ih-Tiao. "A Scientific Approach to Experimental Aesthetics: Mindful Media/Form and Heartfelt Message/Function." Dichotomy Vol. 9. Spring (1990): 48-53.

Chuang-tzu. Autumn Flood. Vol. 536. Shanghai: Commercial Press, 1929.

Crowe, Norman. Nature and the Idea of a Man-made World: An Investigation into the Evolutionary Roots of Form and Order in the Built Environment. Massachusetts: The MIT Press, 1997.

Fletcher, Valerie J. Isamu Noguchi: Master Sculptor. New York: Whitney Museum of American Art, 2005.

Frampton, Kenneth. Le Corbusier. London: Thames \& Hudson Ltd., 2001.

Francesco Dal Co, ed. Tadao Ando: Complete Works. London: Phaidon Press Limited, 1995.

Heidegger, Martin. "Building, Dwelling, Thinking." Rethinking Architecture: A Reader in Cultural Theory. Ed. Neil Leach. New York: Routledge, 1971. 100.

---. The Question Concerning Technology: And Other Essays. Trans. William Lovitt. New York: Harper \& Row, Publishers, Inc., 1977.

--. On the Way to Language. New York: 1971.

Helfenstein, Josef, and Christoph Schenker, eds. James Turrell; First Light. New York: Kunstmuseum Bern, 1991.

Kaufmann, Edgar. Fallingwater, A Frank Lloyd Wright Country House. New York: Abbeville Press, 1986. 
Kohn, Livia. Early Chinese Mysticism: Philosophy and Soteriology in the Taoist Tradition. New Jersey: Princeton University Press, 1992.

--. The Taoist Experience: An Anthology. New York: State University of New York Press, 1993.

Lao Tzu. Tao Te Ching: A New Translation by Gia-Fu Feng and Jane English. Trans. Gia-fu Feng and Jane English. New York: Random House, Inc., 1972.

Lao-tzu. Tao-Te-Ching. Vol. 307. Shanghai: Commercial Press, 1929.

Le Corbusier. Towards a New Architecture. Trans. Frederick Etchells. New York: Dover Publications, Inc., 1986.

Lin, Maya Ying, ed. Maya Lin. Electa: American Academy in Rome, 1998.

Lobell, John. Between Silence and Light: Spirit in the Architecture of Louis I. Kahn. Boulder: Shambhala, 1979.

Maspero, Henri. Taoism and Chinese Religion. Trans. Frank A. Kierman, Jr. Amherst: The University of Massachusetts Press, 1981.

Menin, Sarah, and Flora Samuel. Nature and Space: Aalto and Le Corbusier. London: Routledge Tylor \& Francis Group, 2003.

Millet, Marietta S. Light Revealing Architecture. New York: Van Nostrand Reinhold, 1996.

Norberb-Schulz, Christian. Genius Loci: Towards a Phenomenology of Architecture. New York: Rizzoli international publications, Inc., 1980.

Parkes, Graham, ed. Heidegger and Asian Thought. Honolulu: University of Hawaii Press, 1987.

Scarpa, Carlo. Carlo Scarpa: The Complete Works. New York: Rizzoli, 1984.

Tyng, Alexandra. Beginnings: Louis L. Kahn's Philosophy of Architecture. New York: Wiley, 1984. 